\title{
Paraben Compounds-Part II: An Overview of Advanced Oxidation Processes for Their Degradation
}

\author{
João Lincho, João Gomes (D) and Rui C. Martins *(D) \\ CIEPQPF-Chemical Engineering Processes and Forest Products Research Center, \\ Department of Chemical Engineering, Faculty of Sciences and Technology, University of Coimbra, \\ Rua Sílvio Lima, Polo II, 3030-790 Coimbra, Portugal; jlincho@eq.uc.pt (J.L.); jgomes@eq.uc.pt (J.G.) \\ * Correspondence: martins@eq.uc.pt; Tel.: +35-1-23979-8723; Fax: +35-12-3979-8703
}

Citation: Lincho, J.; Gomes, J.;

Martins, R.C. Paraben

Compounds-Part II: An Overview

of Advanced Oxidation Processes for Their Degradation. Appl. Sci. 2021, 11, 3556. https://doi.org/10.3390/ app11083556

Academic Editor: Bart Van der Bruggen

Received: 6 March 2021

Accepted: 12 April 2021

Published: 15 April 2021

Publisher's Note: MDPI stays neutral with regard to jurisdictional claims in published maps and institutional affiliations.

Copyright: (C) 2021 by the authors. Licensee MDPI, Basel, Switzerland. This article is an open access article distributed under the terms and conditions of the Creative Commons Attribution (CC BY) license (https:// creativecommons.org/licenses/by/ $4.0 /)$.
Abstract: Water scarcity represents a problem for billions of people and is expected to get worse in the future. To guarantee people's water needs, the use of "first-hand water" or the reuse of wastewater must be done. Wastewater treatment and reuse are favorable for this purpose, since first-hand water is scarce and the economic needs for the exploration of this type of water are increasing. In wastewater treatment, it is important to remove contaminants of emerging concern, as well as pathogenic agents. Parabens are used in daily products as preservatives and are detected in different water sources. These compounds are related to different human health problems due to their endocrine-disrupting behavior, as well as several problems in animals. Thus, their removal from water streams is essential to achieve safe reusable water. Advanced Oxidation Processes (AOPs) are considered very promising technologies for wastewater treatment and can be used as alternatives or as complements of the conventional wastewater treatments that are inefficient in the removal of such contaminants. Different AOP technologies such as ozonation, catalytic ozonation, photocatalytic ozonation, Fenton's, and photocatalysis, among others, have already been used for parabens abatement. This manuscript critically overviews several AOP technologies used in parabens abatement. These treatments were evaluated in terms of ecotoxicological assessment since the resulting by-products of parabens abatement can be more toxic than the parent compounds. The economic aspect was also analyzed to evaluate and compare the considered technologies.

Keywords: parabens; CEC; environmental pollution; AOP; wastewater treatment

\section{Introduction}

Water scarcity is experienced by 1.1 billion people and about 2.7 billion people suffer from lack of water at least once a year [1]. It is expected that in 2025 , about 1.8 billion people will be living in areas suffering from this problem [2].

To guarantee sustainability and all the needs for all forms of life, particularly in the areas affected by water scarcity, it is mandatory to ensure correct treatment and reuse of wastewater [3]. Effective wastewater treatment is not easy to obtain with the traditional treatments installed in the municipal wastewater treatment plants (WWTP) [4]. The exploitation of "first-hand water" could be a solution to overcome water scarcity, but this is expensive and such water is also scarce. In addition, the recovery of wastewater can be more economically viable than the exploration of "first-hand water"; even considering the economic aspects, the treatment of wastewater can present advantages [3].

Treated wastewater is mostly used in agricultural applications [2], since this activity requires high water consumption [3]. Additionally, the irrigation systems that are used in agriculture could lead to environmental, soil, and water pollution problems and can even present health risks due to the existence of contaminants and pathogenic microorganisms in treated water $[2,3]$. 
With this, claimed water from wastewater must have adequate quality to be reused, which sometimes is only possible when the wastewater is depurated with additional or complementary treatments to the traditional approaches [3].

Compounds that are continuously detected in water sources at low concentrations ( $\mu \mathrm{g} / \mathrm{L}$ or $\mathrm{ng} / \mathrm{L}$ ) are called contaminants of emerging concern (CEC). This category includes several compounds such as endocrine disruptors (ED), pharmaceutical and personal care products (PPCP) [4], pesticides [3], illicit drugs, synthetic and natural hormones [2], and heavy metals [5], among others.

These pollutants enter and accumulate in water resources due to continuous effluents discharges [6,7] and the fact that existent WWTPs are not designed to remove these types of contaminants, mainly due to their recalcitrant character [8].

One group of compounds that are detected in different water sources are parabens [9]. They have already been detected in rivers [10], tap water [11], pool water [12], drinking water [13], and effluents [14].

Parabens are used in industries (cosmetic, food, and pharmaceutical) mainly due to their good preservative and anti-microbial properties but also due to their chemical stability, low toxicity, and low production costs $[7,15,16]$. These compounds are endocrine disruptors [17,18], which can present estrogenic [19] and antiandrogenic activity [20]. Furthermore, they are related to male infertility [17] and tumors [21], so parabens can negatively affect human health [17]. In animals, the use of parabens can have negative impacts, since endocrine disruptors compounds can cause feminization, imposex, abnormalities, and a decrease in fecundity of species [22].

Due to their continuous detection and negative impacts on different organisms, special measures must be taken to control and remove parabens from ecosystems. The use of advanced technologies in wastewater treatment can help to decrease the discharge of parabens and other CECs present in treated wastewater into rivers and other water resources. With this, advanced oxidation processes (AOPs) can present the most suitable solution since these technologies can efficiently promote the CECs abatement.

AOP technologies such as ozonation [23-25]; catalytic ozonation [26]; photocatalytic ozonation [27,28]; Fenton's process [29,30]; photo-Fenton [31]; photocatalysis with UV radiation [7,32], visible radiation [6,33], and solar radiation [34]; photolysis using UV radiation [35]; photoelectrocatalysis [36]; photo-sonochemical degradation [37]; or sonochemical oxidation $[38,39]$ were already used for parabens abatement.

This paper overviews the application of AOPs in the removal of parabens from water mixtures. The effect on treated water ecotoxicology is considered, as well as the costs associated with the treatment.

\section{Advanced Oxidation Processes}

Advanced Oxidation Processes are technologies that can generate hydroxyl radicals that interact with the organic molecules and oxidize them into simpler substances [40]. This oxidation converts the pollutants into intermediate compounds or $\mathrm{CO}_{2}$ and $\mathrm{H}_{2} \mathrm{O}$ when mineralization occurs [40].

The degradation mechanisms of AOPs can be hydrogen abstraction, electron transfer, or radical addition, and these technologies can eliminate complex compounds that cannot be removed by conventional approaches [40,41]. In WWTPs, AOPs can be used as preliminary processes in order to transform persistent and recalcitrant compounds into compounds that biological treatments can remove, or they can be applied as a final depuration step before the discharge of the effluent into water sources [42].

AOPs present several advantages, such as elimination of complex and persistent compounds [41], treatment of different effluents [42], toxicity reduction [43], increasing the effluent biodegradability [43], elimination of pathogenic agents, or achieve pollutants complete oxidation into $\mathrm{CO}_{2}$ and $\mathrm{H}_{2} \mathrm{O}$ [44]. In addition, some AOP treatments can be important to decrease COD (chemical oxygen demand), BOD (biochemical oxygen demand), coloration, and turbidity, which are important parameters regarding effluent discharge 
regulations. The main disadvantage of the use of these technologies is their expensive costs since they demand a significant amount of energy or reagents [41]. Moreover, in general, when real wastewater is considered, the AOP treatments can present efficiency problems, since the presence of carbonate or bicarbonate ions (or other scavenging compounds) can act as scavengers of hydroxyl radicals, which can negatively affect their reaction mechanism and decrease the pollutants removal $[42,45]$.

Hydroxyl radical is the most common radical produced by AOPs and presents a high oxidative power and non-selective behavior. Furthermore, the generation of other oxidant species can occur during the use of AOPs, due to the existence of specific operational conditions. Examples of oxidizing radicals can be seen in Table $1[42,46]$.

Table 1. Oxidant potential of different oxidizing species.

\begin{tabular}{cc}
\hline Oxidant Species & Oxidation Potential/[V] \\
\hline Hydroxyl $(\mathrm{OH})$ & 2.80 \\
Fluorine $(\mathrm{F})$ & 3.03 \\
Ozone $\left(\mathrm{O}_{3}\right)$ & 2.07 \\
Sulfate $\left(\mathrm{SO}_{4}{ }^{2-}\right)$ & 2.01 \\
Hydrogen Peroxide $\left(\mathrm{H}_{2} \mathrm{O}_{2}\right)$ & 1.77 \\
Permanganate $\left(\mathrm{MnO}_{4}{ }^{2-}\right)$ & 1.77 \\
Chlorine dioxide $\left(\mathrm{ClO}_{2}\right)$ & 1.57 \\
Chlorine $\left(\mathrm{Cl}_{2}\right)$ & 1.36 \\
Dichromate $\left(\mathrm{Cr}_{2} \mathrm{O}_{7}{ }^{2-}\right)$ & 1.23 \\
Oxygen $\left(\mathrm{O}_{2}\right)$ & 1.23 \\
\hline
\end{tabular}

Other radicals such as ozonide $\left(\mathrm{O}^{3-}\right)$, superoxide $\left(\mathrm{O}^{2-}\right)$, or hydroperoxyl radical $\left(\mathrm{HO}^{2-}\right)$ can also appear $[40,47]$. The radical's generation occurs in situ and can occur due to the existence of reagents, catalysts, or radiation [41].

The group of AOPs is composed of several technologies, such as ozonation, photocatalysis, Fenton, wet air oxidation, radiation, oxidation by reagents, electrochemical oxidation, anodic oxidation, sonochemical methods, and others $[41,46]$. The combination and integration of several single techniques is also part of AOP, like photo-Fenton, photocatalytic ozonation, sono-Fenton, electro-Fenton, sono-photocatalysis, photo-ozonation, catalytic ozonation, and peroxone, among others [41-43]. Figure 1 presents a scheme summarizing some of the AOPs technologies reported in the literature.

Several studies are being carried out with the objective of lowering the operational costs, using new reactors [41], catalysts, reagents, and even radiation, particularly the use of solar radiation for being free, infinite, and considered as a "green-energy" [44].

\subsection{Photolysis and Photocatalysis}

Photolysis and photocatalysis are two technologies that use radiation for radicals generation, and they differ since photocatalysis also has a catalyst present, to increase the radical's formation rate.

Photolysis can be classified as direct or indirect photolysis, and it usually uses UV radiation from $200-400 \mathrm{~nm}$. Direct photolysis allows the degradation of pollutants due to the photons generated by the irradiation source, and indirect photolysis (known also as photochemical degradation) causes the conversion of pollutants by the presence of radiation and different reagents that enhance the hydroxyl radicals' production [48]. Nowadays, UV radiation is already used for disinfection (inactivation of pathogenic organisms) purposes [49]. 


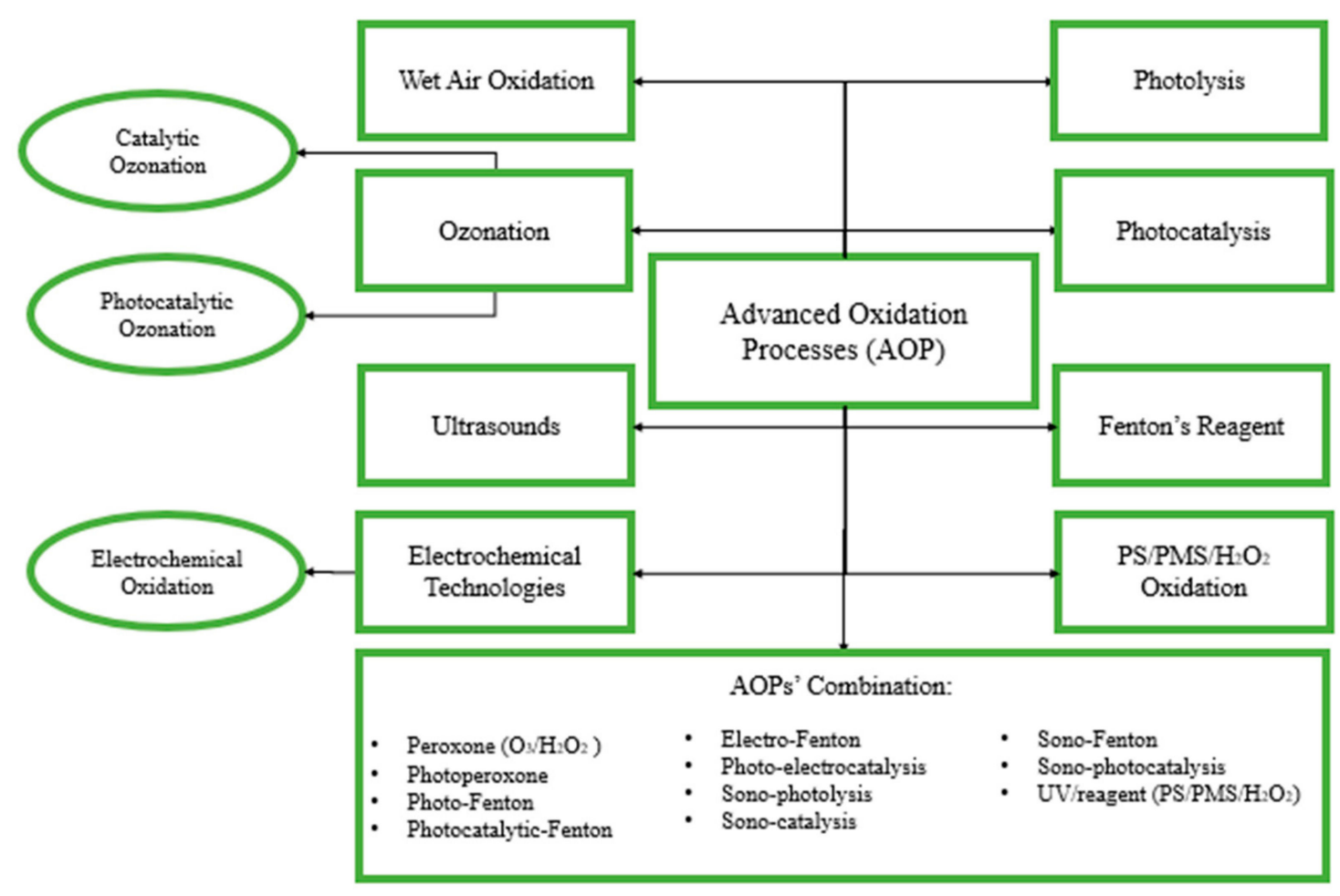

Figure 1. Scheme of examples of Advanced Oxidation Process (AOP) technologies.

Photocatalysis requires radiation to activate a catalyst, generally a heterogeneous semiconductor, and only this activation allows the radical's generation and the pollutants elimination [50]. To activate the catalyst, the radiation source must emit photons with equal or higher energy than the catalyst's bandgap, which are absorbed into the catalyst and cause the excitation and migration of electrons from the valence band (VB) to the conduction band (CB). This electron migration generates electron-hole pairs $\left(\mathrm{e}^{-} / \mathrm{h}^{+}\right)$, which will interact with the pollutants present in the reactional medium or in the catalyst surface $[44,47,51]$. This interaction causes the generation of radicals, which react with the pollutants and promote their oxidation.

In photocatalysis, several catalysts, like $\mathrm{TiO}_{2}, \mathrm{ZnO}, \mathrm{ZnS}$, or $\mathrm{CdS}$, among others, have already been used $[44,50]$. Titanium dioxide $\left(\mathrm{TiO}_{2}\right)$ is one of the most common catalysts, due to its low cost, high photo-activity, and chemical stability [52,53]. This catalyst can present three different crystallite phases: Anatase (the most wanted phase, since it is more stable at low temperatures and more photo-active), Rutile (more stable at high temperatures with lower band-gap energy), and Brookite phase (does not have catalytic properties and is rare) [54-56].

The costs related to photolysis or photocatalysis can be a drawback for its application, since the artificial UV light is expensive [57], and some semiconductor materials, like the $\mathrm{TiO}_{2}$ P25, requires this type of light, since this catalyst presents high band-gap energy, which can only be activated by UV [57]. Furthermore, the UV radiation represents only $3-5 \%$ of the solar spectrum which can make the use of solar light inefficient, despite the fact that it ensures new advantages as mentioned before [57-59]. The solar spectrum is mainly constituted by visible radiation (about 45\%) [44], so the use of catalysts that can be activated by this type of radiation can reduce the operational costs of photocatalysis.

One possibility to decrease the catalyst's band-gap energy is doping the material with metals or non-metals elements due to the introduction of oxygen vacancies or impurity energy levels [59], although this makes the catalyst production more expensive. Cationic metals (such as $\mathrm{Fe}, \mathrm{Ag}, \mathrm{Cu}, \mathrm{Pd}, \mathrm{Pt}$, and $\mathrm{Au}$ ) can create an intermediate band between $\mathrm{CB}$ and VB, which will decrease the band-gap energy $[44,60]$. Non-metal doping (as C, N, F, S, ... ) allows the use of solar radiation and can promote better electron trapping $[44,61]$. 


\subsection{Ozone Based Technologies}

Ozonation uses a powerful oxidant, the ozone, to remove organic pollutants. This technology is $\mathrm{pH}$-dependent, since it may involve two different pathways: direct reaction between the ozone and the pollutants (that occurs at $\mathrm{pH}<7$ ), or indirect reaction, by radical generation and interaction (at $\mathrm{pH}>7$ ) [41,49]. The use of ozonation at $\mathrm{pH}>7$ is desired, since the hydroxyl radical generation leads to a quicker reaction and generally to better removal of pollutants [41].

Ozone has a special preference for electron-rich molecules, like double and triple bonds, amines, or aromatic rings, and reacts the most with these molecules [49]. Ozonation can present different advantages, such as pollutant oxidation into $\mathrm{H}_{2} \mathrm{O}$ and $\mathrm{CO}_{2}$, quick reaction, easy ozone production, and oxidation of different and persistent molecules. However, as disadvantages, ozone is a corrosive, explosive, and toxic compound, its generation must occur in situ, it is expensive, and it is not efficient for the removal of saturated compounds. Furthermore, the ozonation system needs an $\mathrm{O}_{3}$ destroyer for safety reasons, and this technology may not lead to high mineralization (COD and BOD removal rates are usually low) $[46,62]$.

The combination of single ozonation with $\mathrm{H}_{2} \mathrm{O}_{2}$, UV radiation, or catalyst can enhance the radical generation, can increase the pollutants removal rate, and can also improve the mineralization efficiency $[41,63]$. Heterogeneous catalysts may initiate the hydroxyl radical generation and help in the initiation of ozone decomposition, enhancing the production of radicals [41].

Peroxone $\left(\mathrm{H}_{2} \mathrm{O}_{2} / \mathrm{O}_{3}\right)$ improves the generation of hydroxyl radicals and can increase the pollutants oxidation efficiency, since the transformation of $\mathrm{O}_{3}$ into $\cdot \mathrm{OH}$, and the mass transference of ozone to the liquid phase is better [42]. $\mathrm{H}_{2} \mathrm{O}_{2}$ interacts with $\mathrm{O}_{3}$, or vice versa, and produces $\cdot \mathrm{OH}$ or $\cdot \mathrm{HO}_{2}$. The existence of acidic $\mathrm{pH}$ can negatively affect the $\cdot \mathrm{OH}$ generation, so this technology is better when used at higher $\mathrm{pH}$, since the $\mathrm{H}_{2} \mathrm{O}_{2}$ usually reacts and is transformed into $\mathrm{HO}_{2}$, which in turn increases $\mathrm{O}_{3}$ transformation into $\cdot \mathrm{OH}$ and $\mathrm{OH}^{-}$[42].

Equations (1)-(3) present the general reactions of peroxone technology [42]:

$$
\begin{gathered}
\mathrm{H}_{2} \mathrm{O}_{2}+\mathrm{O}_{3}->\cdot \mathrm{OH}+\cdot \mathrm{HO}_{2}+\mathrm{O}_{2} \\
\cdot \mathrm{OH}+\mathrm{O}_{3}->\cdot \mathrm{HO}_{2}+\mathrm{O}_{2} \\
\cdot \mathrm{HO}_{2}+\mathrm{O}_{3}->\cdot \mathrm{OH}+2 \mathrm{O}_{2}
\end{gathered}
$$

However, the use of $\mathrm{H}_{2} \mathrm{O}_{2}$ in peroxone must be careful, since this compound can act as a scavenger of hydroxyl radical and decrease its generation, which could lead to a worse technology performance than single ozonation [41]. Regarding this process, some researchers have considered the optimum $\mathrm{H}_{2} \mathrm{O}_{2} / \mathrm{O}_{3}$ ratio to be $0.5 \mathrm{~mol} / \mathrm{mol}$ [49]. The use of $\mathrm{UV}$ with peroxone can increase the pollutants removal, due to higher generation of $\mathrm{OH}$ radicals, as presented in Equation (4) [42].

$$
\mathrm{H}_{2} \mathrm{O}_{2}+2 \mathrm{O}_{3}+h v->2 \mathrm{HO}+3 \mathrm{O}_{2}
$$

Catalytic ozonation combines the power of ozone with a catalyst. The presence of catalysts can initiate and enhance the decomposition of ozone molecules into oxidizing radicals, can allow a better absorption of ozone into the liquid phase [41], and, in general, can lead to lower ozone consumption, when compared to single ozonation [49].

Photocatalytic ozonation has a synergetic effect, since it combines the power of photocatalysis with ozone, allowing a higher production of radicals [64]. In this technology, the ozone molecule will react with the catalyst conduction band forming ozonide radicals $\left(\cdot \mathrm{O}_{3}{ }^{-}\right)$, which will posteriorly generate $\cdot \mathrm{OH}$ radicals [65]. Other radicals such as oxygen atom radicals $(\cdot \mathrm{O})$ or superoxide radicals $\left(\cdot \mathrm{O}_{2}{ }^{-}\right)$can also be produced as intermediate radicals, interacting directly with the pollutants or forming hydroxyl radicals [66]. This technology can also prevent the recombination of generated electron-hole pairs [67]. 


\subsection{Fenton's Reagent}

The traditional Fenton's reaction uses $\mathrm{H}_{2} \mathrm{O}_{2}$ and $\mathrm{Fe}^{2+}$ as a catalyst for $\cdot \mathrm{OH}$ radical generation. During this process, $\mathrm{Fe}^{2+}$ is oxidized to $\mathrm{Fe}^{3+}$ and regenerated to $\mathrm{Fe}^{2+}$, through the reaction of $\mathrm{H}_{2} \mathrm{O}_{2}$ and $\mathrm{Fe}^{3+}$ [40]. The decomposition of $\mathrm{H}_{2} \mathrm{O}_{2}$ is catalyzed by $\mathrm{Fe}^{2+}$, forming the oxidative radicals that are going to attack the pollutants. However, the use of $\mathrm{Fe}^{2+}$ must be done with care, since it can react with the generated radicals, producing $\mathrm{Fe}^{3+}$, and work as a scavenger of the reaction itself [46]. Furthermore, in Fenton's technology, the iron can be used in homogeneous or heterogeneous form [48]. Equations (5) and (6) present Fenton's process mechanism $[40,41]$ :

$$
\begin{gathered}
\mathrm{H}_{2} \mathrm{O}_{2}+\mathrm{Fe}^{2+}->\cdot \mathrm{OH}+\mathrm{HO}^{-}+\mathrm{Fe}^{3+} \\
\mathrm{H}_{2} \mathrm{O}_{2}+\mathrm{Fe}^{3+}->\cdot \mathrm{HO}_{2}+\mathrm{H}^{+}+\mathrm{Fe}^{2+}
\end{gathered}
$$

The Fenton's oxidation rate is higher at $\mathrm{pH}=3$ since the hydroxyl radicals are more present at acidic $\mathrm{pH}$, allowing a fast reaction [48]. This technology is effective but can present negative aspects related to the operational costs, due to the reagent's consumption and $\mathrm{pH}$ adjustments [46]. As disadvantages, it also presents difficult recovery and reuse of iron and limited operational $\mathrm{pH}$ range, which can restrict Fenton's applications and decrease its efficiency $[68,69]$.

Moreover, the use of $\mathrm{H}_{2} \mathrm{O}_{2}$ can present negative effects. In low amounts, it can decrease the efficiency of pollutants degradation due to insufficient radical's production, and in excessive quantities, it can form less reactive radicals, such as $\mathrm{HO}_{2} \cdot$, and decompose itself into water and oxygen, reducing the technology performance, as presented in Equations (7)-(11) [62,70].

$$
\begin{gathered}
\cdot \mathrm{OH}+\cdot \mathrm{OH}->\mathrm{H}_{2} \mathrm{O}_{2} \\
\mathrm{H}_{2} \mathrm{O}_{2}+\cdot \mathrm{OH}->\mathrm{H}_{2} \mathrm{O}+\cdot \mathrm{HO}_{2} \\
\cdot \mathrm{HO}_{2}+\cdot \mathrm{HO}_{2}->\mathrm{H}_{2} \mathrm{O}_{2}+\mathrm{O}_{2} \\
\cdot \mathrm{OH}+\mathrm{O}_{2}->\cdot \mathrm{HO}_{2}+\cdot \mathrm{O} \\
2 \mathrm{H}_{2} \mathrm{O}_{2}->2 \mathrm{H}_{2} \mathrm{O}+\mathrm{O}_{2}
\end{gathered}
$$

The advantages of Fenton's reaction are the use of environmentally friendly reagents, and the fact that the technology is easy to operate and implement, is efficient, and does not need energy to initiate the reaction. However, this technology also allows a quicker consumption of $\mathrm{Fe}^{2+}$ than its regeneration, has a limited operation $\mathrm{pH}$ range, and the complexation of iron species and the production of secondary sludge generally occur [71].

The use of photo-Fenton (UV and Fenton) could lead to lower reagent costs since the generation of radicals is enhanced, the reaction time is lower, and it requires less reagent compared to single Fenton's [48]. Photo-Fenton reactions are presented in Equations (12) and (13) [41]:

$$
\begin{gathered}
\mathrm{H}_{2} \mathrm{O}_{2}+h v->2 \mathrm{HO} . \\
\mathrm{H}_{2} \mathrm{O}+\mathrm{Fe}^{3+}+h v->\cdot \mathrm{OH}+\mathrm{H}^{+}+\mathrm{Fe}^{2+}
\end{gathered}
$$

This technology also leads to a lower generation of secondary iron sludge, and to a faster iron regeneration [71]. The use of heterogeneous catalysts in Fenton's technology allows the occurrence of this reaction at higher $\mathrm{pH}$ [46].

Other methodologies can be used to overtake the traditional Fenton's drawbacks. The use of other metals (such as $\mathrm{Cu}, \mathrm{Mn}, \mathrm{Cr}, \mathrm{Ce}, \mathrm{Co}, \mathrm{Ru}$, or $\mathrm{Al}$ ) instead of Iron (II) can be an option, and this substitution is widely known as Fenton-like processes [68,69,72].

Equations (14)-(20) present the Fenton's mechanism using $\mathrm{Cu}^{2+}$ and $\mathrm{Mn}^{2+}[69,72]$ :

$$
\begin{gathered}
\mathrm{Cu}^{2+}+\mathrm{H}_{2} \mathrm{O}_{2}->\mathrm{Cu}^{+}+\cdot \mathrm{HO}_{2}+\mathrm{H}^{+} \\
\mathrm{HO}_{2}{ }^{-}<->\cdot \mathrm{O}_{2}{ }^{-}+\mathrm{H}^{+}
\end{gathered}
$$




$$
\begin{gathered}
\mathrm{Cu}^{2+}+\cdot \mathrm{O}_{2}^{-}->\mathrm{Cu}^{+}+\mathrm{O}_{2} \\
\mathrm{Cu}^{2+}+\cdot \mathrm{HO}_{2}{ }^{-}<->\mathrm{Cu}^{+}+\mathrm{O}_{2}+\mathrm{H}^{+} \\
\mathrm{Cu}^{+}+\mathrm{H}_{2} \mathrm{O}_{2}->\mathrm{Cu}^{2+}+\cdot \mathrm{OH}+\mathrm{OH}^{-} \\
\mathrm{Mn}^{2+}+\mathrm{H}_{2} \mathrm{O}_{2}+\mathrm{H}^{+}->\mathrm{Mn}^{3+}+\mathrm{H}_{2} \mathrm{O}+\cdot \mathrm{OH} \\
\mathrm{Mn}^{3+}+\mathrm{e}^{-} \rightarrow \mathrm{Mn}^{2+}
\end{gathered}
$$

Catalyst regeneration also occurs when $\mathrm{Cu}^{2+}$ and $\mathrm{Mn}^{2+}$ are used, due to the interaction with $\mathrm{H}_{2} \mathrm{O}_{2}$. The use of copper allows the existence of neutral and alkaline $\mathrm{pH}$ operations [69], which can be an advantage over the traditional Fenton's since this $\mathrm{pH}$ range would cause the precipitation of $\mathrm{Fe}^{3+}$ (in $\mathrm{Fe}(\mathrm{OH})_{3}$ form) in the conventional Fenton [40]. Moreover, an increase in hydroxyl radical's generation can occur when magnetite substituents with transition metals are used [72].

However, Fenton-like processes also present disadvantages such as the existence of cytotoxic characteristics of metals, complex mechanisms, related high-costs, difficult anaerobic conditions, $\mathrm{pH}$ limitations, metal leaching, and loss of catalyst efficiency, depending on the type of metal used [72]. In general, metals do not allow good catalyst reuse and their reuse is only possible for a few cycles [72].

\subsection{Persulfate, Peroxymonosulfate, and Hydrogen Peroxide}

Oxidizing agents can be used in AOP, such as the persulfate anion $\left(\mathrm{S}_{2} \mathrm{O}_{8}{ }^{2-}\right)$, hydrogen peroxide $\left(\mathrm{H}_{2} \mathrm{O}_{2}\right)$, or peroxymonosulfate anion $\left(\mathrm{HSO}_{5}{ }^{-}\right)$, which are the most used oxidizing agents in wastewater treatment systems [73]. The objective is the same as other technologies, that is, the generation of hydroxyl and/or other radicals for the elimination of contaminants [42].

The ersulfate anion is stable at ambient temperatures, is selective, and is a strong oxidant, which can work in a wide $\mathrm{pH}$ range, but it is cost-effective [74]. Its high solubility and longer lifetime allow it to decompose several organic pollutants [42].

Persulfate (PS) can produce $\mathrm{SO}_{4}{ }^{-}$radicals when activated by heat, $\mathrm{UV}$ light, bases, transition metals (catalysts), or ultrasound [42,73,74], and its reaction is shown in Equation (21) [42].

$$
\mathrm{S}_{2} \mathrm{O}_{8}{ }^{2-}+h v\left(\text { heat } \text { or } 2 \mathrm{e}^{-}\right)->\cdot 2 \mathrm{SO}_{4}{ }^{-}
$$

Persulfate can react in an acidic medium, enhancing the production of sulfate radicals as presented in Equation (22) [42].

$$
\mathrm{S}_{2} \mathrm{O}_{8}{ }^{2-}+\mathrm{H}^{+}->\mathrm{H}^{+}+\mathrm{SO}_{4}{ }^{2-}+\cdot \mathrm{SO}_{4}^{-}
$$

Usually, the performance of persulfate alone is low, so to achieve good efficiency, the presence of catalyst, heat, or radiation is desired [42]. The presence of catalyst enhances the sulfate radical's production. The use of $\mathrm{Fe}^{2+}$ is an option, since this metal can activate the PS for contaminants degradation, but this is not so efficient, probably due to the generation and accumulation of $\mathrm{Fe}^{3+}$ [42].

Peroxymonosulfate (PMS) is also a strong oxidant. It can be used in a wide $\mathrm{pH}$ range, and in the presence of light, heat, or catalysts, it is activated and can generate hydroxyl and sulfate radicals as presented in Equations (23) and (24), and in Equation (25) when exposed in an acidic medium [42], which may represent an advantage compared to the persulfate reaction.

$$
\begin{gathered}
\mathrm{HSO}_{5}{ }^{-}+h v->\cdot \mathrm{OH}+\cdot \mathrm{SO}_{4} \\
\mathrm{HSO}_{5}{ }^{-}+h e a t->\cdot \mathrm{OH}+\cdot 2 \mathrm{SO}_{4} \\
\mathrm{HSO}_{5}{ }^{-}+\mathrm{H}^{+}+\mathrm{e}^{-}->\mathrm{H}_{2} \mathrm{O}+\cdot \mathrm{SO}_{4}{ }^{-}
\end{gathered}
$$

Additionally, the sulfate radicals can be decomposed into more hydroxyl radicals in basic $\mathrm{pH}$ conditions, as shown in Equations (26) and (27) [42]. Furthermore, the radical's 
production is favorable at basic $\mathrm{pH}$ regarding PS and PMS reactions, since this $\mathrm{pH}$ allows the formation of hydroxyl radicals, which are more reactive than the sulfate radicals formed in acidic media [42].

$$
\begin{gathered}
\cdot \mathrm{SO}_{4}{ }^{-}+\mathrm{H}_{2} \mathrm{O}->\cdot \mathrm{OH}+\cdot \mathrm{HSO}_{4}{ }^{-} \\
\mathrm{SO}_{4}{ }^{-}+\mathrm{HO}^{-}->\cdot \mathrm{OH}+\mathrm{SO}_{4}{ }^{2}
\end{gathered}
$$

Hydrogen peroxide is a reagent with relatively high oxidative power that is used for radical's generation but may be inefficient when used alone since it cannot produce hydroxyl radicals by itself. It can also decompose into water and oxygen (as mentioned in Equations (28)-(30)), showing low performance in the removal of recalcitrant and refractory compounds [42].

$$
\begin{gathered}
\mathrm{H}_{2} \mathrm{O}_{2}->\mathrm{HO}_{2}^{-}+\mathrm{H}^{+} \\
\mathrm{H}_{2} \mathrm{O}_{2}+\mathrm{HO}_{2}^{-}->\mathrm{H}_{2} \mathrm{O}+\mathrm{O}_{2}+\mathrm{HO}^{-} \\
2 \mathrm{H} 2 \mathrm{O} 2->2 \mathrm{H} 2 \mathrm{O}+\mathrm{O}_{2}
\end{gathered}
$$

The radicals generated by hydrogen peroxide are less reactive than $\cdot \mathrm{OH}$ radicals [45], and its oxidation potential is higher at low $\mathrm{pH}$, so this reagent is favored when used in an acidic medium, and the combination of $\mathrm{H}_{2} \mathrm{O}_{2}$ with other reagents or radiation can enhance its efficiency [42]. However, the presence of hydrogen peroxide must be carefully dosed, since high and low amounts can negatively affect its performance, as explained in Section 2.3. The optimum ratio of $\mathrm{H}_{2} \mathrm{O}_{2}$ needs to be determined experimentally, and it is dependent on the experimental conditions [42,45,62] and effluent characteristics.

This reagent can only be used as an AOP technology when it is in the presence of radiation (UV, solar, etc.) or catalyst [42], and its good characteristics include good market availability, good thermal stability, infinite solubility in water, its ability to be stored in the operational site, and lack of mass transfer problems associated with gases [42,45].

The use of UV with $\mathrm{H}_{2} \mathrm{O}_{2}$ reagent leads to the generation of two hydroxyl radicals (Equation (31)) which should enhance the removal performance $[35,75,76]$ compared to a single $\mathrm{H}_{2} \mathrm{O}_{2}$ reagent that cannot produce these types of radicals. Furthermore, organic and inorganic peroxyl radicals can be generated using $\mathrm{H}_{2} \mathrm{O}_{2} / \mathrm{UV}$ in the presence of oxygen and other organic compounds [45]. However, this technology also shows disadvantages, since low-pressure UV lamps require high concentrations of $\mathrm{H}_{2} \mathrm{O}_{2}$ for good $\mathrm{OH}$ generation, but the existence of $\mathrm{H}_{2} \mathrm{O}_{2}$ at high concentrations can lead to a scavenging effect of hydroxyl radicals [49]. Therefore, the use of $\mathrm{H}_{2} \mathrm{O}_{2}$ with $\mathrm{UV}$ radiation may not be recommended since it can have a high scavenging effect in secondary and tertiary wastewater treatments [49].

$$
\mathrm{H}_{2} \mathrm{O}_{2}+h v->2 \mathrm{HO} \text {. }
$$

At alkaline $\mathrm{pH}$, several studies report an interesting behavior of $\mathrm{H}_{2} \mathrm{O}_{2}$ reagent, even when it is used alone. In fact, it has already obtained degradation efficiencies higher than $90 \%$ in 60 min regarding dibutylsulfide (DBS) degradation [77], higher DBS disappearance rate for single $\mathrm{H}_{2} \mathrm{O}_{2}$ when compared to single ozone or $\mathrm{O}_{3} / \mathrm{H}_{2} \mathrm{O}_{2}$ system for $\mathrm{pH}<12$ [77], and about $52 \%$ of 4-chloro- 2 nitrophenol degradation at $\mathrm{pH}=10$ [78], which showed better results than at $\mathrm{pH}<10$, with $\mathrm{UV}$ use, or in Fenton's (from $\mathrm{pH}=6$ until $\mathrm{pH}=10$ ) [78].

Regarding its use in real wastewater treatments, $\mathrm{H}_{2} \mathrm{O}_{2}$ achieved COD reduction of about $35 \%, 29 \%$, and $27 \%$ in $180 \mathrm{~min}$ for $\mathrm{pH}=5,7$, and 9 , respectively, regarding the treatment of linear alkyl benzene industrial wastewater [79]. Furthermore, olive wastewater treatment allowed a maximum phenol degradation around $65 \%, 78 \%$, and $81 \%$ and COD maximum abatement of about $20 \%, 25 \%$, and $23 \%$ for $\mathrm{pH}=9,10$, and 11 , respectively [80]. Other work for olive oil wastewater treatment led to a phenol degradation result of $65 \%$, $74.4 \%$, and $64.4 \%$ using single $\mathrm{H}_{2} \mathrm{O}_{2}$, while the $\mathrm{UV} / \mathrm{H}_{2} \mathrm{O}_{2}$ system achieved $66 \%, 59.2 \%$, and $72.3 \%$ for $\mathrm{H}_{2} \mathrm{O}_{2}$ concentrations of $0.11,0.55$, and $2 \mathrm{M}$ in $150 \mathrm{~min}$ at $\mathrm{pH}=9$, which can show a bit better behavior in the single hydrogen peroxide system when compared to $\mathrm{UV} / \mathrm{H}_{2} \mathrm{O}_{2}$ [81]. 


\subsection{Electrochemical Oxidation}

Electrochemical oxidation (EO) is the most used electrochemical technology for wastewater treatment [82]. In EO, an electric charge is produced between two electrodes (solid conductors) and is discharged in an electrolyte solution used as a medium [46]. One of the electrodes is positively charged (anode), while the other is negatively charged (cathode), and the oxidation of pollutants occurs in the anode, while the reduction occurs in the cathode [46]. This technology has the advantages of requiring less space, needing lower temperatures in the operation, and having a low by-product generation rate [83].

The organic compounds oxidation can occur by direct anodic oxidation (classified as "heterogeneous" when it occurs the direct electron transfer to the anode or classified as "homogeneous" when the oxidants are produced on anode surface from components of the electrolyte solution) or by chemical reaction with electrogenerated species (. $\mathrm{OH}$ radicals or other oxidizing species). The first one leads to weak removal, while the second leads to high-performance removal $[41,82,84]$.

The $\cdot \mathrm{OH}$ radicals generation starts with the oxidation of water in the anode, and only occurs at $2 \mathrm{~V}$ or above. Below this value, only direct oxidation can happen [46]. The indirect oxidation can also occur by the interaction of the pollutants with strong oxidants (such as chlorine), which must be generated during electrolysis by $\mathrm{Cl}^{-}$-containing species present in the water matrix and/or in the electrolyte solution $[41,82,85]$.

The occurrence of oxidative species is dependent on the anode oxygen-evolutionoverpotential, in which the anodes can be classified as "active", presenting low oxygenoverpotential, or as "non-active", showing high oxygen-overpotential [41]. The "nonactive" anodes produce hydroxyl radicals adsorbed on their surface as presented in Equation (32), allowing the direct oxidation of the pollutants with $\mathrm{M}(\cdot \mathrm{OH})$, while in the "active" anodes, the $\mathrm{M}(\cdot \mathrm{OH})(\mathrm{M}$ is the anode material) is chemisorbed and transformed into superoxide or a higher oxide (MO) as presented in Equation (33) [41,82].

$$
\begin{gathered}
\mathrm{M}+\mathrm{H}_{2} \mathrm{O}->\mathrm{M}(\cdot \mathrm{OH})+\mathrm{H}^{+}+\mathrm{e}^{-} \\
\mathrm{M}(\cdot \mathrm{OH})->\mathrm{MO}+\mathrm{H}^{+}+\mathrm{e}^{-}
\end{gathered}
$$

$\mathrm{MO}$ can decompose into oxygen as presented in Equation (34) and $\mathrm{M}(\cdot \mathrm{OH})$ can have side reactions as presented in Equations (35) and (36) [82].

$$
\begin{gathered}
2 \mathrm{MO}->2 \mathrm{M}+\mathrm{O}_{2} \\
2 \mathrm{M}(\cdot \mathrm{OH})->2 \mathrm{M}+\mathrm{O}_{2}+2 \mathrm{H}^{+}+2 \mathrm{e}^{-} \\
2 \mathrm{M}(\cdot \mathrm{OH})->2 \mathrm{M}+\mathrm{H}_{2} \mathrm{O}_{2}
\end{gathered}
$$

A "non-active" anode can only act as an inert substrate and a sink for electron removal, and, consequently, it cannot participate in direct anodic oxidation or provide catalytic active sites for the adsorption of organic molecules from the reactional medium [82].

One important parameter is the anode material, since it can influence the selectivity and efficiency of this technology [82]. The most used and investigated electrodes are doped-SnO $\mathrm{S}_{2}, \mathrm{PbO}_{2}, \mathrm{RuO}_{2}, \mathrm{IrO}_{2}$, boron-doped diamond (BDD), sub-stoichiometric and doped- $\mathrm{TiO}_{2}, \mathrm{Pt}$, and dimensionally stable anodes (DSA) $[41,49,86]$.

The BDD electrode presents the advantage of high stability even in strongly acidic media, low adsorption properties, inert surface, and high $\mathrm{O}_{2}$ evolution overvoltage, being the most preferable anode of electrochemical oxidation. The most responsible pathway for pollutants degradation using this electrode is by $\mathrm{OH}$ generation, and the BDD oxidation power is higher than for other anodes $[49,82,87]$. However, this material also presents disadvantages such as high cost and electrode instability during operation, and it is not easy to obtain BDD with large dimensions [88]. For wastewater treatment, only high voltages are used, since the use of low voltages can cause anode poisoning, because the direct anodic oxidation promotes by-products formation, which can be adsorbed into the anode [82]. 
The advantages of the electrochemical AOP are that the removal of the pollutants and the mineralization occurs using the $\mathrm{OH}$ radical in situ. However, as disadvantages, in general, these technologies are associated with considerable electric costs, they need specific $\mathrm{pH}$ to obtain optimal conditions, the polluted solution must have good conductivity or it will need electrolytes to be added, and the catalyst is not usually recyclable or reused [89]. Other technologies are also part of the group of electrochemical AOPs, such as electrocoagulation, electrochemical reduction, electro-Fenton, electro-PS, electro-PMS, and electro-peroxone, among others, as well as the integration of radiation with these processes $[41,89,90]$.

\subsection{Sonochemical Methods}

Sonication or sonochemical methods, also known as sonolysis when it is used as a single technology, is an AOP technology where the $\cdot \mathrm{OH}$ radicals are generated from water pyrolysis due to the high intensity of acoustic cavity bubbles [40]. This technology, a type of hydrodynamic cavitation, is a cavitation method (i.e., a process involving the formation of micro-bubbles or cavities and quick collapse of bubbles to release energy), but until now, only ultrasound is used at the industrial level [46].

This process uses ultrasound frequencies $(16 \mathrm{kHz}-100 \mathrm{MHz})$ to produce a great amount of energy and promote substrate oxidation due to the formation and collapse of microbubbles from acoustical-wave-induced compression and rarefaction [46,49]. A violent implosion occurs after these microbubbles reach a critical resonance size, releasing high pressure and temperatures ( $>5000 \mathrm{~K}$ and $>1000 \mathrm{~atm})$, leading to highly reactive radical generation, due to the dissociation of water molecules into hydroxyl ions and hydroxyl radicals $[46,49]$. Furthermore, these radicals can react with the substrate, forming substrate radicals [46]. The oxidation of pollutants mainly occurs due to the action of the generated radicals but can also happen by thermal decomposition [49]. However, in this case, the chemical structure of the pollutant must also be considered.

Equations (37)-(40) present the general reactions of these sonochemical methods [46].

$$
\begin{gathered}
2 \mathrm{H}_{2} \mathrm{O}+\mathrm{O}_{2}->2 \mathrm{HO}+2 \mathrm{OH}^{-} \\
\mathrm{RH}+\cdot \mathrm{OH}->\cdot \mathrm{R}+\mathrm{H}_{2} \mathrm{O} \\
\cdot \mathrm{R}+\mathrm{O}_{2}->\mathrm{ROO} \cdot \\
\mathrm{R}_{1} \mathrm{OO} \cdot+\mathrm{R}_{2} \mathrm{H}->\mathrm{R}_{1} \mathrm{OOH}+\cdot \mathrm{R}_{2}
\end{gathered}
$$

This technology presents as advantages a low interference from water matrix, low heat transfer required, and not needing chemicals. However, it has the disadvantage of using high amounts of energy ad having low efficiency and mineralization, so this technology must be combined with other AOPs to overcome these problems, benefiting also from synergistic effects $[40,46,49]$. Therefore, other ultrasounds-based technologies such as sonophotolysis (UV + ultrasounds), sonocatalysis (catalyst + ultrasounds), sonophotocatalysis (UV + catalyst + ultrasounds), or even the presence of oxidation reagents with ultrasounds can present advantages compared to the single sonolysis [49].

\section{AOP for Parabens Removal}

After considering the characteristics of several AOPs technologies, this section overviews their application for paraben's abatement.

\subsection{Photolysis and Photocatalysis}

The use of radiation is known to increase the oxidizing radical's generation, but it is also needed when a semi-conductor catalyst is present, since it requires energy to be activated (i.e., to overpass the catalyst's bandgap). Although these technologies have disadvantages related to the application of UV radiation, the results of the reviewed studies show in general a good performance regarding the parabens abatement, with photocatalysis 
showing better efficiency. Furthermore, overall, the parabens adsorption or their removal by photolysis presents poor results, although some experiments using photolysis have led to interesting removal outcomes. Some authors already report studies using solar radiation, although most studies use solar simulators.

In the literature, there are some studies using photolysis and particularly photocatalysis with different catalysts for parabens removal.

\subsubsection{Parabens Abatement by Photolysis}

Photolysis only uses radiation for contaminants degradation. UVA, UVC, and solar light (natural and simulated) have already been used in parabens abatement.

Regarding the parabens abatement, the photolysis performed by Gomes et al. [91] showed negligible results (lower than $4 \%$ ), while the use of catalyst and radiation led to better results. Lin et al. [7] removed MP using photolysis with UV radiation, achieving less than 5\% after $120 \mathrm{~min}$ in a pilot plant, while Lin et al. [32] removed $10 \%$ of BeP in a laboratory installation.

Gmurek et al. [35] used photolysis with UVC radiation, achieving 10\% removal for $\mathrm{MP}, \mathrm{EP}, \mathrm{PP}$, and BuP and about 60\% degradation for BeP in $120 \mathrm{~min}$ for individual parabens and about $20 \%$ for $\mathrm{MP}$ and $\mathrm{BuP}, 30 \%$ for $\mathrm{EP}$ and PP in $120 \mathrm{~min}$, and $80 \%$ for $\mathrm{BuP}$ in $20 \mathrm{~min}$, when the parabens mixture was considered. Complete mixture removal was achieved at 480 min of UVC photolysis.

In general, several studies such as those of Gomes et al. [58], Lin et al. [7], Lin et al. [32], and Gomes et al. [91] present low performance when UVA photolysis was used in parabens abatement. Solar light studies by Gomes et al. [58] led to $16 \%$ of removal of MP, EP, and $\mathrm{PP}$ in $60 \mathrm{~min}$, and the study by Vela et al. [3] led to 30\% and 35\% of MP and EP removal in 240 min using real wastewater effluent as water matrix, suggesting an interesting behavior of solar light by itself, although the study by Zúñiga-Benitez et al. [92] led to poor EP abatement.

The study by Gomes et al. [93] led to almost complete removal of PP and BuP using UVVis radiation, and the study by Álvarez et al. [94] achieved 80-99.8\% of single degradation for MP, EP, or BuP in 120 min using UV (254 nm) radiation. Both studies performed good results regarding the parabens degradation, but the study by Gmurek et al. [35] using UVC radiation only led to about $20-30 \%$ mixture degradation for $\mathrm{MP}, \mathrm{EP}, \mathrm{PP}$, and $\mathrm{BuP}$ removal in $120 \mathrm{~min}$ (BeP was $80 \%$ in $20 \mathrm{~min}$ ), and the total removal was only achieved after $480 \mathrm{~min}$.

In fact, Gmurek et al. [35] used a higher concentration of parabens $(10 \mathrm{mg} / \mathrm{L}$ of $\mathrm{MP}$, $\mathrm{EP}, \mathrm{PP}, \mathrm{BuP}$, and BeP each and $10 \mathrm{mg} / \mathrm{L}$ of p-HBA), while Gomes et al. [93] only applied $10 \mathrm{mg} / \mathrm{L}$ of PP and BuP each (20 mg/L total). Moreover, Álvarez et al. [94] only used about $45.65 \mathrm{mg} / \mathrm{L}$ of MP, $49.85 \mathrm{mg} / \mathrm{L}$ of EP, and $58.29 \mathrm{mg} / \mathrm{L}$ of BuP. This should be responsible for the differences in the results, and, the presence of more compounds may make the degradation of each compound difficult.

In general, it seems that UVC must be preferred to UVA light when used alone to achieve better results. However, this implies higher energy costs, besides the danger associated with such strongly energetic radiation.

Table 2 presents several studies' results using photolysis in parabens abatement. 
Table 2. Parabens removal by photolysis.

\begin{tabular}{|c|c|c|c|}
\hline Pollutant & $\begin{array}{c}\text { Test } \\
\text { Conditions }\end{array}$ & $\begin{array}{l}\text { Results and } \\
\text { Conclusions }\end{array}$ & Reference \\
\hline $\begin{array}{l}\text { Bisphenol A, Bisphenol B, } \\
\text { Diamylphthalate, } \\
\text { Butylbenzylphthalate, MP, } \\
\text { and EP }\end{array}$ & $\begin{array}{l}\text { - } \quad \text { Sun radiation in a pilot plant. } \\
0.3 \mathrm{mg} / \mathrm{L} \text { of each pollutant in } \\
\text { real wastewater effluent. }\end{array}$ & $\begin{array}{l}\text { Degradation of about } 30 \%, 35 \% \text {, } \\
55 \%, 50 \%, 30 \% \text {, and } 30 \% \text { for } \mathrm{MP} \text {, } \\
\mathrm{EP}, \mathrm{BA}, \mathrm{BB}, \mathrm{BP} \text {, and } \mathrm{DP}, \\
\text { respectively, in } 240 \mathrm{~min} .\end{array}$ & [3] \\
\hline $\mathrm{MP}$ & $\begin{array}{l}\text { - UVA radiation } \\
10 \mathrm{mg} / \mathrm{L} \text { of } \mathrm{MP} \text { in deionized } \\
\text { water. }\end{array}$ & - Degradation $<5 \%$ in 120 min. & [7] \\
\hline $\mathrm{BeP}$ & $\begin{array}{l}\text { - UVA radiation. } \\
10 \mathrm{mg} / \mathrm{L} \text { of } \mathrm{BeP} \text { in deionized } \\
\text { water. }\end{array}$ & - Degradation of $10 \%$ in $120 \mathrm{~min}$. & [32] \\
\hline $\begin{array}{c}\mathrm{MP}, \mathrm{EP}, \mathrm{PP}, \mathrm{BuP}, \mathrm{BeP} \text {, and } \\
\text { p-HBA }\end{array}$ & $\begin{array}{l}\text { - } 10 \mathrm{mg} / \mathrm{L} \text { each paraben in } \\
\text { distilled water. } \\
\text { - } \quad \text { UVC radiation. }\end{array}$ & $\begin{array}{l}\text { - Individual parabens } \\
\text { degradation of about } 10 \% \text { for } \\
\mathrm{MP}, \mathrm{EP}, \mathrm{PP} \text {, and } \mathrm{BuP} \text { and about } \\
60 \% \text { for BeP in } 2 \mathrm{~min} \text {. About } \\
95 \% \text { for all in } 120 \mathrm{~min} \text {. } \\
\text { Mixture degradation of about } \\
20 \%, 30 \%, 30 \% \text {, and } 20 \% \text { in } \\
120 \mathrm{~min}(2 \mathrm{~h}) \text { for } \mathrm{MP}, \mathrm{EP}, \mathrm{PP} \text {, and } \\
\mathrm{BuP} \text { and } 80 \% \text { BeP removal in } \\
20 \mathrm{~min} \text {. Total removal in } \\
480 \mathrm{~min} .\end{array}$ & [35] \\
\hline $\mathrm{MP}, \mathrm{EP}$, and $\mathrm{PP}$ & $\begin{array}{l}\text { Parabens mixture solution of } \\
1 \mathrm{mg} / \mathrm{L} \text { each in ultrapure water. } \\
\text { - } \quad \text { UVA and Solar radiation. }\end{array}$ & $\begin{array}{l}\text { Degradation of } 0 \% \text { using UVA } \\
\text { and } 16 \% \text { achieved by solar light } \\
\text { in } 60 \mathrm{~min} .\end{array}$ & [58] \\
\hline $\mathrm{MP}, \mathrm{EP}, \mathrm{PP}, \mathrm{BuP}$, and BeP & $\begin{array}{l}\text { - Paraben mixture solution of } \\
10 \mathrm{mg} / \mathrm{L} \text { each in ultrapure } \\
\text { water. } \\
\text { - UVA radiation. }\end{array}$ & - Degradation: < 4\% in $180 \mathrm{~min}$. & [91] \\
\hline $\mathrm{EP}$ & $\begin{array}{l}\text { - Solar radiation } \\
\text { - Simulated solar radiation in the } \\
\text { laboratory experiments }\end{array}$ & $\begin{array}{l}\text { Degradation of } 0.46 \% \text { at lab } \\
\text { scale in } 2 \mathrm{~h} \text {. } \\
\text { - } \quad \text { At pilot scale was } 1.5 \% \text { and } \\
2.72 \% \text { in } 2 \mathrm{~h} \text { and } 6 \mathrm{~h} .\end{array}$ & [92] \\
\hline $\mathrm{PP}$ and $\mathrm{BuP}$ & $\begin{array}{l}\text { - } \quad \text { P and BuP in demineralized } \\
\text { water or river water, at } 10 \mathrm{mg} / \mathrm{L} \\
\text { each. } \\
\text { - UV-Vis radiation. }\end{array}$ & $\begin{array}{l}\text { Deionized water: removal of } \\
97-99 \% \text { and } 98-99 \% \text { for PP and } \\
\text { BuP, and the paraben mixture } \\
\text { had } 96-99 \% \text { and } 97-99 \% \text { for PP } \\
\text { and BuP, respectively, in } 95 \text { min. } \\
\text { River water: }>97 \% \text { and }>99 \% \text { for } \\
\text { PP and BuP, while for the } \\
\text { mixture of parabens was } 90-99 \% \\
\text { and } 92-99 \% \text { for PP and BuP, } \\
\text { respectively. }\end{array}$ & [93] \\
\hline
\end{tabular}


Table 2. Cont.

\begin{tabular}{|c|c|c|c|}
\hline Pollutant & $\begin{array}{c}\text { Test } \\
\text { Conditions }\end{array}$ & $\begin{array}{l}\text { Results and } \\
\text { Conclusions }\end{array}$ & Reference \\
\hline $\mathrm{MP}, \mathrm{EP}$ and $\mathrm{BuP}$ & $\begin{array}{ll}\text { - } & \text { UV radiation }(254 \mathrm{~nm}) \\
\text { - } & 0.3 \times 10^{-3} \mathrm{~mol} / \mathrm{L} \text { single } \\
& \text { paraben solution. }\end{array}$ & $\begin{array}{l}\text { Degradation of } 77.2 \%, 88 \% \text { and } \\
96.3 \% \text { in } 90 \text { min and } 79.9 \% \text {, } \\
95.2 \% \text { and } 99.8 \% \text { of } \mathrm{MP}, \mathrm{EP} \text { and } \\
\text { BuP in } 120 \text { min. } \\
\text { Water matrix: EP removal of } \\
88 \%, 61.8 \% \text { and } 37.9 \% \text { in } 90 \text { min } \\
\text { for ultrapure water, tap water } \\
\text { and wastewater, respectively. }\end{array}$ & [94] \\
\hline $\mathrm{EP}$ and $\mathrm{BuP}$ & $\begin{array}{l}\text { - } \quad \text { UVA radiation. } \\
\text { - } 6 \mathrm{mg} / \mathrm{L} \text { paraben concentration. }\end{array}$ & - Degradation: $<5 \%$ in $24 \mathrm{~h}$. & [95] \\
\hline
\end{tabular}

\subsubsection{Parabens Abatement by Photocatalysis}

The presence of catalysts should improve the degradation of parabens, particularly when UVA radiation is used since it seems that this kind of light poorly removes parabens when only light is applied. With this, it is expected to obtain better results when UVA photocatalysis is used.

Gomes et al. [91] used doped $\mathrm{TiO}_{2}$ catalysts and pure $\mathrm{TiO}_{2}$ to remove methylparaben $(\mathrm{MP})$, ethylparaben (EP), propylparaben (PP), butylparaben (BuP), and benzylparaben (BeP) by UVA photocatalysis, reaching parabens degradation values higher than $15 \%$. In fact, this was higher than the results obtained by the photolysis of the same mixture, which proves their good catalyst effect.

Lin et al. [7] removed MP using photocatalysis with UV radiation catalyzed with $\mathrm{TiO}_{2}$ P25, reaching 94\% degradation after $120 \mathrm{~min}$, and Lin et al. [32] achieved 85\% degradation of BeP. In both works, photocatalysis was clearly better than photolysis.

Vela et al. [3] used $\mathrm{TiO}_{2}$ catalysts (P25 and Vlp-7000) for the degradation of six CECs, including MP and EP. Results showed that P25 is the most efficient catalyst, with degradations higher than $65 \%$, and for which has the best dose of $200 \mathrm{mg} / \mathrm{L}$ and whose $\mathrm{pH}$ efficiency is in the order $7>5.5>8.5$. Moreover, the experiments using a pilot installation led to good results regarding the pollutants removal as well. Better degradation was achieved in the presence of catalyst as well.

Comparing these results to the photolysis results presented in Section 3.1.1, the presence of catalyst seems to show an obvious improvement in parabens abatement. The studies of Gomes et al. [91], Lin et al. [7], and Lin et al. [32] used UVA radiation, while Vela et al. [3] applied sunlight instead. The presence of UVA light (also present in the solar spectrum) is important, since this radiation is the only one able to activate the $\mathrm{TiO}_{2}$ catalyst due to the high bandgap that is associated with this material. In fact, if its bandgap is reduced, then the more efficient use of visible radiation or solar light should be possible, which could decrease the operational costs of this technology. With this, several studies using doped $\mathrm{TiO}_{2}$ catalyst or also other catalysts are also discussed.

Zúñiga-Benítez and Peñuela [92] used $\mathrm{TiO}_{2}$ catalyst to remove EP through photocatalysis, using simulated solar radiation in laboratory experiments and sunlight for experiments at pilot scale. The use of catalyst under lab conditions led to $63.1 \%$ removal in $120 \mathrm{~min}$ reaction, with the application of $0.95 \mathrm{~g} / \mathrm{L}$ of catalyst and initial EP concentration of $1 \mathrm{mg} / \mathrm{L}$. Regarding the pilot-scale experiment, $45.88 \%$ degradation was achieved after $6 \mathrm{~h}$, using the same experimental conditions, but a higher volume (100 L). The authors also used hydrogen peroxide with $\mathrm{TiO}_{2}$, resulting in a better EP removal performance using the best operational conditions, achieving 96.9\% removal in $2 \mathrm{~h}$ and $81.38 \%$ in $6 \mathrm{~h}$, for laboratory and pilot-scale experiments, respectively. Frontistis et al. [96] achieved better results, reaching almost total removal in 20 min using $\mathrm{ZnO}$, while $\mathrm{TiO}_{2}$ P25 led to about 90\% 
abatement in $30 \mathrm{~min}$, using $1 \mathrm{mg} / \mathrm{L}$ of EP and $0.25 \mathrm{~g} / \mathrm{L}$ of catalyst with a solar simulator as a radiation source. Although the experiments present several differences, these studies led to interesting results using solar radiation or solar simulated radiation, which should encourage more studies using these catalysts with the sun as a source of light. Furthermore, the study of Frontistis et al. [96] suggests a better performance of $\mathrm{ZnO}$ over the traditional titanium dioxide.

Several authors such as Gomes et al. [91], Kotzamanidi et al. [34], and Petala et al. [97] experimented with doped $\mathrm{TiO}_{2}$ catalysts in parabens abatement. Kotzamanidi et al. [34] tested $\mathrm{Al}-\mathrm{TiO}_{2}$, which had the best PP removal using a catalyst dose of $1 \mathrm{~g} / \mathrm{L}$ with $95 \%$ abatement in 90 min, while Petala et al. [97] used $\mathrm{N}-\mathrm{TiO}_{2}$ getting EP abatement of 32\% and $13 \%$ in $240 \mathrm{~min}$ for $\mathrm{N}-\mathrm{TiO}_{2}$ and $\mathrm{TiO}_{2}$ with Vis radiation, while solar radiation was used for $10 \mathrm{~min}$ and achieved about $34 \%$ and $43 \%$ for $\mathrm{TiO}_{2}$ and $\mathrm{N}-\mathrm{TiO}_{2}$, respectively, for the best calcination temperature. In fact, the use of $\mathrm{N}-\mathrm{TiO}_{2}$ seems to enhance the parabens degradation under visible or solar radiation compared to pure $\mathrm{TiO}_{2}$. Although the experiment by Kotzamanidi et al. [34] achieved almost complete removal, the authors did not perform experiments with pure $\mathrm{TiO}_{2}$, and say that the presence of $\mathrm{Al}$ did not considerably change the band-gap energy. Moreover, for the best $\mathrm{Al}-\mathrm{TiO}_{2}(0.04 \mathrm{Al} \mathrm{w} \%)$, the band-gap energy was about $3 \mathrm{eV}$, while the common $\mathrm{TiO}_{2}$ catalyst usually has about $3.2 \mathrm{eV}$. This may suggest that $\mathrm{Al}$ it is not advantageous to make titanium dioxide more efficient under Vis or solar radiation.

Kotzamanidi et al. [34] used $1 \mathrm{~g} / \mathrm{L}$ of catalyst and initial PP dose of $0.42 \mathrm{mg} / \mathrm{L}$, and Petala et al. [97] used $0.5 \mathrm{~g} / \mathrm{L}$ of catalyst and $0.3 \mathrm{mg} / \mathrm{L}$ of EP, while Gomes et al. [91] used $0.07 \mathrm{~g} / \mathrm{L}$ of catalyst, $10 \mathrm{mg} / \mathrm{L}$ of each paraben (MP, EP, PP, BuP, and BeP), and UVA radiation. In Gomes et al.'s [91] study, they used a mixture with higher parabens concentrations and had lower catalyst concentration, but obtained removals of about $35-70 \%, 40-48 \%$, 25-40\%, $5-15 \%$, and $1-10 \%$ for $\mathrm{Pd}, \mathrm{Ag}, \mathrm{Pt}, \mathrm{Au}$, and pure $\mathrm{TiO}_{2}$, respectively, after $180 \mathrm{~min}$. In this work, the presence of metals enhanced the degradation when compared to bare $\mathrm{TiO}_{2}$, and $\mathrm{Pd}$ and $\mathrm{Ag}$ catalysts had better performance than the one obtained by Petala et al. [97] using Vis radiation. In fact, the use of these noble metals seems to enhance the photocatalytic activity of titanium dioxide, which the authors suggest may be related to the electron charge transfer from the $\mathrm{CB}$ to the metallic nanoparticles band, less electron-hole recombination, or higher hydroxyl radical's production. The authors did not determine the catalysts' band-gap energy, but studies have shown where the deposition of metals could lower the catalyst band-gap energy. However, the presence of noble metals should increase the catalysts' price, since these metals are usually expensive, so the $\mathrm{N}-\mathrm{TiO}_{2}$ may probably be more economically attractive, and it also showed good results under Vis and sunlight. Nevertheless, more tests using different concentrations and/or mixtures should be performed to confirm this theory.

Other catalysts have also been investigated for the same purpose. Fernandes et al. [6] tested single and mixture degradation of three parabens (MP, EP, and PP) using $\mathrm{TiO}_{2} \mathrm{P} 25$ and metal-free, graphite-like carbon nitride as catalysts with $417 \mathrm{~nm}$ radiation provided by LEDs. The GNC-500 catalyst had better performance, with about total removal in $20 \mathrm{~min}$ for single parabens and 99\% removal for parabens mixture in $25 \mathrm{~min}$. $\mathrm{TiO}_{2} \mathrm{P} 25$ only had total removal after $120 \mathrm{~min}$ for both experiments. Xiao et al. [33] removed single MP, EP, $\mathrm{PP}$, and $\mathrm{BuP}$ by photocatalysis using $\mathrm{I}_{\mathrm{x}}-\mathrm{Bu}_{4} \mathrm{O}_{5} \mathrm{Br}_{2}$ as a catalyst, leading to a higher PP removal of $94.5 \%$ for $\mathrm{I}_{0.7}-\mathrm{Bu}_{4} \mathrm{O}_{5} \mathrm{Br}_{2}$ in $60 \mathrm{~min}$. The authors used $>420 \mathrm{~nm}$ radiation, $1 \mathrm{~g} / \mathrm{L}$ of catalyst, and $10 \mathrm{mg} / \mathrm{L}$ initial concentration of each paraben. In fact, this catalyst led to better abatement and had $2.51 \mathrm{eV}$, although not being the catalyst with lower band-gap energy $\left(\mathrm{I}_{1}-\mathrm{Bu}_{4} \mathrm{O}_{5} \mathrm{Br}_{2}\right.$ with $2.41 \mathrm{eV}$ that led to $\left.91.2 \%\right)$. Furthermore, Petala et al. [98] achieved a better EP removal value of $97.6 \%$, using $\mathrm{CuO}_{0.75} / \mathrm{BiVO}_{4}$, by photocatalysis in $60 \mathrm{~min}$, when the catalyst dose was $0.5 \mathrm{~g} / \mathrm{L}$ and the paraben concentration was $0.5 \mathrm{mg} / \mathrm{L}$, using a solar simulator as a radiation source $(>280 \mathrm{~nm})$. Kumar et al. [99] used $\mathrm{Fe}_{3} \mathrm{O}_{4} / \mathrm{BiVO}_{4}$ heterostructure (bandgap of $\mathrm{Fe}_{3} \mathrm{O}_{4}$ of $2.57 \mathrm{eV}$ and of $\mathrm{BiVO}_{4}$ of $2.36 \mathrm{eV}$ ) for MP abatement, reaching $75 \%$ of degradation in $60 \mathrm{~min}$, with $0.1 \mathrm{~g} / \mathrm{L}$ of catalyst and 
$5 \mathrm{mg} / \mathrm{L}$ of MP using solar light. These studies suggest interesting results for different catalysts compared to the traditional semiconductors, which may be also an option in the application of photocatalysis. Moreover, some of these catalysts present lower bandgaps than the traditional $\mathrm{TiO}_{2}$, which may be mainly responsible for the good results using radiation such as solar, simulated solar, or Vis light. Thus, this can be an advantage for the use of natural light and simplify the industrial implementation powered by the sun.

The use of catalysts in powder form makes photocatalysis implementation and catalyst use difficult at an industrial level. This drawback can be overcome using powder catalyst immobilized in a support material, which can allow a good recovery and easy separation of the solid material from the reactional medium. With this, several supported and innovative catalysts have already been used, even for parabens degradation.

Gomes et al. [58] tested $\mathrm{TiO}_{2}$ nanotubes (NT) arrays for photocatalytic degradation of paraben's mixture. In general, the catalyst presence improved the pollutants' degradation, but only $20 \%$ of removal was achieved in 60 min reaction, with $7 \mathrm{TiO}_{2} / \mathrm{NT}$ plates and UVA. The maximum degradation was $25 \%$ when 14 plates were used. The usage of solar radiation enhanced the parabens mixture degradation compared to UVA, allowing a maximum parabens degradation of $80 \%$ using seven plates, although the operational installation was different. Furthermore, Sousa et al. [100] used photocatalysis catalyzed by nanostructures (titanate nanowires (TNW) and modified titanate nanowires with $\mathrm{Mn}$ ) for MP removal in $90 \mathrm{~min}$. The initial pollutant concentration was $10 \mathrm{mg} / \mathrm{L}$, and the technology removed $62 \%, 50 \%$, and $40 \%$ for Mn-doped TNW, Mn-adsorbed TNW, and single TNW, respectively, using UV-Vis ( $40-48 \%$ UV and $40-43 \%$ Vis). The use of these types of structures seems to allow good removal rates, combining also important advantages for industrial application. Gomes et al. [58] had 80\% parabens mixture degradation using $\mathrm{TiO}_{2} / \mathrm{NT}$, Zúñiga-Benítez and Peñuela [92] had $45.88 \%$ of EP degradation in $6 \mathrm{~h}$ using $\mathrm{TiO}_{2}$, Petala et al. [97] determined about $34 \%$ and $43 \%$ EP degradation for $\mathrm{TiO}_{2}$ and $\mathrm{N}-\mathrm{TiO}_{2}$ in

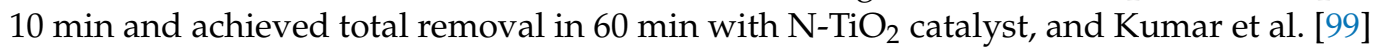
used $\mathrm{Fe}_{3} \mathrm{O}_{4} / \mathrm{BiVO}_{4}$ reaching $75 \%$ of MP degradation in $60 \mathrm{~min}$. In all these studies, solar light was used as an energy source. Comparing these studies, the study of Gomes et al. [58] had better results than Zúñiga-Benítez and Peñuela [92] and Kumar et al. [99], and although total degradation was never achieved, contrary to what happened in Petala et al.'s [97] work, it should be noticed that in this study, it was used a parabens mixture, while in the others, only single parabens degradation was evaluated. Thus, the complexity of the reaction mixture highly influences the process efficiency.

Table 3 summarizes photocatalysis studies in parabens abatement.

Table 3. Parabens removal by photocatalysis.

\begin{tabular}{|c|c|c|c|c|}
\hline Pollutant & Catalyst & $\begin{array}{c}\text { Test } \\
\text { Conditions }\end{array}$ & $\begin{array}{l}\text { Results and } \\
\text { Conclusions }\end{array}$ & Reference \\
\hline $\begin{array}{l}\text { Bisphenol A, Bisphenol } \\
\text { B, Diamylphthalate, } \\
\text { Butylbenzylphthalate, } \\
\text { MP, and EP }\end{array}$ & $\begin{array}{c}\mathrm{TiO}_{2} \mathrm{P} 25 \\
\mathrm{TiO}_{2} \text { Vlp-7000 }\end{array}$ & $\begin{array}{l}\text { - } \quad \text { Sun radiation in pilot plant. } \\
0.3 \mathrm{mg} / \mathrm{L} \text { of each pollutant in } \\
\text { real wastewater effluent. } \\
\text { - } 200 \mathrm{mg} / \mathrm{L} \text { of catalyst }\end{array}$ & $\begin{array}{l}\text { Degradation in } 240 \mathrm{~min} \text { of } \\
\text { about } 85 \%, 85 \%, 100 \%, 100 \% \text {, } \\
65 \% \text {, and } 75 \% \text { for } \mathrm{MP}, \mathrm{EP}, \mathrm{BA}, \\
\mathrm{BB}, \mathrm{BP} \text {, and DP respectively, } \\
\text { using } \mathrm{TiO}_{2} \mathrm{P} 25 \text {, while for } \\
\mathrm{TiO}_{2} \text { vlp-7000, the } \\
\text { degradation was about } 70 \% \text {, } \\
68 \% 100 \%, 100 \%, 40 \% \text {, and } \\
45 \% \text {, respectively. }\end{array}$ & [3] \\
\hline $\mathrm{MP}, \mathrm{EP}$, and $\mathrm{PP}$ & $\begin{array}{l}\text { Metal free graphite-like } \\
\text { carbon nitride } \\
\mathrm{TiO}_{2} \text { P25 }\end{array}$ & $\begin{array}{l}\text { - } \quad 0.08 \mathrm{mM} \text { of each paraben in } \\
\text { ultrapure, tap and river } \\
\text { water. } \\
\text { - } \quad \text { Catalyst dose of } 1 \mathrm{~g} / \mathrm{L} . \\
\text { - } \quad 417 \mathrm{~nm} \text { radiation (LED). }\end{array}$ & $\begin{array}{l}\text { - For parabens mixture, the } \\
\text { degradation was about } 99 \% \\
\text { in } 25 \text { min for } \mathrm{GNC}^{-} 500 \text { and } \\
\text { about } 94 \% \text { for } \mathrm{TiO}_{2} \text { in } \\
120 \mathrm{~min} .\end{array}$ & [6] \\
\hline
\end{tabular}


Table 3. Cont

\begin{tabular}{|c|c|c|c|c|}
\hline Pollutant & Catalyst & $\begin{array}{c}\text { Test } \\
\text { Conditions }\end{array}$ & $\begin{array}{l}\text { Results and } \\
\text { Conclusions }\end{array}$ & Reference \\
\hline MP & $\mathrm{TiO}_{2} \mathrm{P} 25$ & $\begin{array}{l}-\quad \text { UVA radiation. } \\
10 \mathrm{mg} / \mathrm{L} \text { of } \mathrm{MP} \text { in deionized } \\
\text { water. } \\
\text { - } 2 \mathrm{~g} / \mathrm{L} \text { of catalyst. }\end{array}$ & $\begin{array}{l}\text { - Degradation of } 94 \% \text { in } \\
120 \text { min. }\end{array}$ & [7] \\
\hline MP & $\begin{array}{l}\text { Monolith-supported } \\
\text { perovskite }\end{array}$ & $\begin{array}{l}-\quad \text { UV radiation } \\
\text { - } 5 \mathrm{mg} / \mathrm{L} \text { of MP solution in } \\
\text { ultrapure water. }\end{array}$ & $\begin{array}{l}\text { Best degradation for } \mathrm{BiFeO}_{3} \\
\text { of } 82.8 \% \text { under optimum } \\
\text { conditions. } \\
\text { MP removal: } 14.62 \%, 37.8 \% \text {, } \\
45.7 \%, 49.2 \% \text {, and } 54.5 \% \text { for } \\
\text { without catalyst, } \\
\mathrm{LaTi}_{0.15} \mathrm{Fe}_{0.85} \mathrm{O}_{3}, \\
\mathrm{BiTi}_{0.15} \mathrm{Fe}_{0.85} \mathrm{O}_{3}, \mathrm{LaFeO}_{3} \text {, and } \\
\mathrm{BiFeO}_{3} \text {, respectively. }\end{array}$ & [31] \\
\hline $\mathrm{BeP}$ & $\mathrm{TiO}_{2}$ & $\begin{array}{ll}\text { - } & \text { UVA radiation. } \\
& 10 \mathrm{mg} / \mathrm{L} \text { of } \mathrm{BeP} \text { in deionized } \\
& \text { water } \\
\text { - } & 2.5 \mathrm{~g} / \mathrm{L} \text { of catalyst. }\end{array}$ & $\begin{array}{l}\text { Removal of about } 5 \% \text { and } \\
85 \% \text { for adsorption (dark) } \\
\text { and photocatalysis in } \\
120 \text { min. }\end{array}$ & [32] \\
\hline $\mathrm{MP}, \mathrm{EP}, \mathrm{PP}$, and BuP & $\mathrm{I}-\mathrm{Bi}_{4} \mathrm{O}_{5} \mathrm{Br}_{2}$ & $\begin{array}{l}\text { - UV lamp with Vis radiation } \\
\text { - } \quad 1 \mathrm{~g} / \mathrm{L} \text { of catalyst } \\
\text { - } \quad 10 \mathrm{mg} / \mathrm{L} \text { of parabens. }\end{array}$ & $\begin{array}{l}\text { PP removal: } 24.4 \%, 49.4 \% \text {, } \\
90.6 \%, 90.7 \%, 94.5 \%, 91.8 \% \text {, } \\
\text { and } 91.2 \% \text { for } \mathrm{Bi}_{4} \mathrm{O}_{5} \mathrm{Br}_{2} \text { and } \\
\mathrm{I}_{\mathrm{x}}-\mathrm{Bi}_{4} \mathrm{O}_{5} \mathrm{Br}_{2}(\mathrm{x}=0.2,0.4,0.6 \\
0.7,0.8 \text {, and } 1), \text { in } 60 \mathrm{~min} .\end{array}$ & [33] \\
\hline PP & $\mathrm{Al}-\mathrm{TiO}_{2}$ & $\begin{array}{l}\text { - } \quad \text { Solar simulator. } \\
420 \mu \mathrm{g} / \mathrm{L} \text { PP solution in } \\
\text { ultrapure water, secondary } \\
\text { treated wastewater, and } 50 \% \\
\text { diluted secondary treated } \\
\text { wastewater. } \\
\quad \text { Water matrix experiment } \\
\text { using } 500 \mathrm{mg} / \mathrm{L} \text { of catalyst. }\end{array}$ & $\begin{array}{l}\text { PP removal: about } 95 \%, 88 \% \text {, } \\
75 \%, 45 \% \text {, and } 22 \% \text { for } 1000 \text {, } \\
1500,500,250 \text {, and } 125 \mathrm{mg} / \mathrm{L} \\
\text { of catalyst, respectively, in } \\
90 \text { min. } \\
\text { Removal of about } 75 \%, 30 \% \text {, } \\
28 \%, 23 \% \text {, and } 17 \% \text { for } \\
\text { ultrapure water, bottled } \\
\text { water, river water, } 50 \% \\
\text { wastewater, and } 100 \% \\
\text { wastewater, respectively, in } \\
90 \text { min. }\end{array}$ & [34] \\
\hline MP, EP and PP & $\mathrm{TiO}_{2} / \mathrm{NT}$ & $\begin{array}{l}\text { Parabens mixture solution of } \\
1 \mathrm{mg} / \mathrm{L} \text { each in ultrapure } \\
\text { water. } \\
\text { - UVA and Solar radiation. }\end{array}$ & $\begin{array}{l}\text { Maximum degradation } \\
\text { (60 } \mathrm{min} \text { ) was } 25 \% \text { for UVA } \\
\text { and } 80 \% \text { using solar light. }\end{array}$ & [58] \\
\hline MP, EP, PP, BuP, BeP & $\begin{array}{c}\mathrm{TiO}_{2} \\
\mathrm{Ag}-\mathrm{TiO}_{2} \\
\mathrm{Au}-\mathrm{TiO}_{2} \\
\mathrm{Pd}-\mathrm{TiO}_{2} \\
\mathrm{Pt}-\mathrm{TiO}_{2}\end{array}$ & $\begin{array}{l}\text { Parabens mixture solution of } \\
10 \mathrm{mg} / \mathrm{L} \text { each in ultrapure } \\
\text { water. } \\
\text { - Catalyst dose of } 70 \mathrm{mg} / \mathrm{L} \\
\text { (0.07 g/L). } \\
\text { - UVA radiation. }\end{array}$ & $\begin{array}{l}\text { Degradation of parabens of }< \\
70 \%,<48 \%,<40 \%,<15 \% \text {, } \\
\text { and }<10 \% \text { for } \mathrm{Pd}, \mathrm{Ag}, \mathrm{Pt}, \mathrm{Au}, \\
\text { and pure } \mathrm{TiO}_{2} \text {, respectively. }\end{array}$ & [91] \\
\hline $\mathrm{EP}$ & $\mathrm{TiO}_{2}$ & $\begin{array}{l}\text { - } \quad \text { Solar radiation and similar } \\
\text { for lab experiment. } \\
\text { - } \quad 1 \mathrm{mg} / \mathrm{L} \text { of paraben. } \\
\text { - } \quad 0.95 \mathrm{~g} / \mathrm{L} \text { catalyst dose. }\end{array}$ & $\begin{array}{l}\text { EP removal was } 63.1 \% \text { for lab } \\
\text { in } 2 \mathrm{~h} \text {, and about } 17.94 \% \text { and } \\
45.88 \% \text { at pilot scale, after } 2 \mathrm{~h} \\
\text { and } 6 \mathrm{~h} \text {, respectively. }\end{array}$ & [92] \\
\hline $\mathrm{EP}$ and $\mathrm{BuP}$ & $\mathrm{TiO}_{2} \mathrm{P} 25$ & $\begin{array}{ll}- & \text { UVA radiation. } \\
- & 6 \mathrm{mg} / \mathrm{L} \text { paraben } \\
\text { concentration. } \\
\text { - } \quad 2 \mathrm{~g} / \mathrm{L} \text { of catalyst. }\end{array}$ & $\begin{array}{l}\text { Best results at } \mathrm{pH}=4 \text { with } \\
43.6 \% \text { and } 45.3 \% \text { for } \mathrm{EP} \text { and } \\
\text { BuP, respectively, in } 24 \mathrm{~h} \text {. }\end{array}$ & [95] \\
\hline
\end{tabular}


Table 3. Cont.

\begin{tabular}{|c|c|c|c|c|}
\hline Pollutant & Catalyst & $\begin{array}{c}\text { Test } \\
\text { Conditions }\end{array}$ & $\begin{array}{l}\text { Results and } \\
\text { Conclusions }\end{array}$ & Reference \\
\hline $\mathrm{EP}$ & $\begin{array}{c}\mathrm{ZnO} \\
\mathrm{TiO}_{2} \mathrm{P} 25\end{array}$ & $\begin{array}{l}\text { - Solar simulator ( } 5 \% \text { UVA } \\
\text { and } 0.1 \% \text { UVB). } \\
\text { EP solution of } 1 \mathrm{mg} / \mathrm{L} \text { in } \\
\text { ultrapure water. } \\
250 \mathrm{mg} / \mathrm{L} \text { of catalyst. }\end{array}$ & $\begin{array}{l}\text { - } \mathrm{ZnO} \text { led to total removal in } \\
20 \mathrm{~min}, \text { while } \mathrm{TiO}_{2} \mathrm{P} 25 \text { led to } \\
\text { about } 90 \% \text { removal in } 30 \mathrm{~min}, \\
\text { respectively. }\end{array}$ & [96] \\
\hline $\mathrm{EP}$ & $\mathrm{N}-\mathrm{TiO}_{2}$ & $\begin{array}{l}\text { - } \quad \text { Solar simulator } \\
\text { - } \quad 300 \mu \mathrm{g} / \mathrm{L} \text { of EP. }\end{array}$ & $\begin{array}{l}\text { At best conditions, the EP } \\
\text { removal was about } 13 \%, 32 \% \text {, } \\
34 \% \text { and } 43 \% \text { for } \mathrm{TiO}_{2}+\mathrm{Vis}, \\
\mathrm{N}-\mathrm{TiO}_{2}+\mathrm{Vis}, \mathrm{TiO}_{2}+\mathrm{Solar}_{\text {, and }} \\
\mathrm{N}-\mathrm{TiO}_{2} / \text { Solar, respectively. }\end{array}$ & [97] \\
\hline $\mathrm{EP}$ & $\mathrm{CuO}_{\mathrm{x}} / \mathrm{BiVO}_{4}$ & $\begin{array}{ll}\text { - } & \text { Solar simulator } \\
\text { - } & 500 \mu \mathrm{g} / \mathrm{L} \text { of EP } \\
& 500 \mathrm{mg} / \mathrm{L} \text { of catalyst }\end{array}$ & $\begin{array}{l}\text { - } 97.6 \% \text { removal was achieved } \\
\text { in } 60 \mathrm{~min} .\end{array}$ & [98] \\
\hline MP and pesticide & $\mathrm{Fe}_{3} \mathrm{O}_{4} / \mathrm{BiVO}_{4}$ & $\begin{array}{ll}- & 0.1 \mathrm{~g} / \mathrm{L} \text { of catalyst. } \\
- & 5 \mathrm{mg} / \mathrm{L} \text { MP solution } \\
& \text { Solar radiation. }\end{array}$ & $\begin{array}{l}\text { MP removal: } 74.98 \% \text { and } \\
95.64 \% \text { in } 2 \mathrm{~h} \text { for } \\
\mathrm{Fe}_{3} \mathrm{O}_{4} / \mathrm{BiVO}_{4} \text { and } \\
\mathrm{Fe}_{3} \mathrm{O}_{4} / \mathrm{BiVO}_{4} / \text { biochar. }\end{array}$ & [99] \\
\hline MP & $\begin{array}{c}\text { TNW } \\
\text { Mn-TNW } \\
\text { Mn/TNW }\end{array}$ & $\begin{array}{l}\text { - } \quad 40-48 \% \text { UV and } 40-43 \% \text { Vis } \\
\text { radiation. } \\
133.3 \mathrm{mg} / \mathrm{L} \text { of catalyst. } \\
\text { - } 10 \mathrm{mg} / \mathrm{L} \text { of MP in distilled } \\
\text { water. }\end{array}$ & $\begin{array}{l}\text { MP removal of } 40 \% \text { for TWN } \\
\text { (titanate nanowires) and } 62 \% \\
\text { and } 50 \% \text { for Mn-TNW } \\
\text { (doped Mn) and TNW/Mn } \\
\text { (adsorbed Mn), respectively, } \\
\text { in } 90 \text { min. }\end{array}$ & [100] \\
\hline $\mathrm{MP}, \mathrm{EP}$, and $\mathrm{PP}$ & Fe ions & $\begin{array}{l}\text { - } \quad 350-410 \mathrm{~nm} \text { radiation. } \\
\text { - } \quad 5 \mathrm{mg} / \mathrm{L} \text { of Fe for EP and PP, } \\
\text { and } 25 \mathrm{mg} / \mathrm{L} \text { of Fe for MP. }\end{array}$ & $\begin{array}{l}\text { - } \quad \text { Removal of EP and PP was } \\
40 \% \text { and } 60 \% \text { in } 90 \text { min. } \\
\text { - } \quad \text { MP removal was about } 35 \% \text {. }\end{array}$ & [101] \\
\hline
\end{tabular}

\subsection{Ozone-Based Technologies}

The treatment of parabens has been also investigated with the oxidant power of ozone to ensure the degradation of pollutants. Ozone-based techniques can bring different treatment perspectives and features, since the use of this molecule can allow good performance in the removal of different and persistent pollutants but can also bring problems related to ozone properties (explosive, toxic, and corrosive). Moreover, generally high production costs are necessary, the $\mathrm{O}_{3}$ generation must be in situ, and there is usually a low efficiency of generation.

\subsubsection{Single Ozonation}

The ozone molecule is known for being a powerful oxidant with very effective degradation results for organic molecules in wastewater treatment, despite having some drawbacks as poor mineralization. Besides wastewater treatment, this technology is also used for water disinfection.

Tay et al. [25] used ozonation to remove a mixture of five parabens. The authors achieved $99 \%$ parabens degradation in $12 \mathrm{~min}$ and $61 \%$ and $32 \%$ for COD and TOC removal in $3 \mathrm{~h}$. As expected, while ozone was able to efficiently remove unsaturated molecules (such as the parabens), total mineralization was not possible to achieve. In fact, from the abatement of the parent molecules, saturated compounds were produced, which are refractory to further ozone oxidation. Furthermore, Gomes et al. [26] performed ozonation using the same mixture but with a concentration of $10 \mathrm{mg} / \mathrm{L}$ of each paraben, achieving total removal in $120 \mathrm{~min}$. In fact, the results of ozonation should be analyzed as a function of transferred ozone dose (TOD), since this parameter allows one to understand 
the amount of ozone transferred to the reactional medium and it represents an important parameter for the economic evaluation using ozone [102].

Cuerda-Correa et al. [23] treated a mixture of four parabens (MP, EP, PP, and BuP), achieving $82 \%$ removal in 20 min reaction. Asgari et al. [28] only achieved $47-52 \%$ removal for the best results. In fact, these results were obtained at $\mathrm{pH}=9$ and were higher than those reached for $\mathrm{pH}=3$ or $\mathrm{pH}=5$. This should be expected, since, in a basic medium, the generation of radicals is enhanced. This radical pathway is desired due to its higher performance when compared to direct ozone reaction at acidic $\mathrm{pH}$ [41]. Fernandes et al. [103] also removed $10 \mathrm{mg} / \mathrm{L}$ of parabens mixture, reaching a degradation higher than $97 \%$ in $120 \mathrm{~min}$ (a natural parabens solution has $\mathrm{pH}$ of 5 [104]), and Asgari et al. [28] achieved 36-42\% for similar $\mathrm{pH}$ in $60 \mathrm{~min}$, which is a concordant result. Furthermore, Gomes et al. [102] had total removal of $1 \mathrm{mg} / \mathrm{L}$ of each paraben (in mixture) in $15 \mathrm{~min}$, which represents 10 times less than the concentration used by Asgari et al. [28] and Fernandes et al. [103].

In general, it seems that ozonation is able to eliminate parabens for whichever concentration is used. However, this does not imply that total mineralization was reached. In fact, ozone can react with unsaturated molecules, leading to low-molecular-weight by-products refractory to further ozonation. Thus, the results of the parent compounds degradation should be complemented with some information about COD or TOC removal as well as toxicological studies. This w]could be very important regarding the potential environmental impact of the treated water.

An overview of works dealing with single ozonation for parabens abatement is presented in Table 4.

Table 4. Parabens removal by single ozonation.

\begin{tabular}{|c|c|c|c|}
\hline Pollutant & $\begin{array}{c}\text { Test } \\
\text { Conditions }\end{array}$ & $\begin{array}{l}\text { Results and } \\
\text { Conclusions }\end{array}$ & Reference \\
\hline $\mathrm{MP}, \mathrm{EP}, \mathrm{PP}$ and $\mathrm{BuP}$ & $\begin{array}{l}\text { - } 5 \mathrm{mg} / \mathrm{L} \text { of each paraben } \\
\text { in ultrapure water. }\end{array}$ & $\begin{array}{l}\text { Degradation of about } \\
82 \% \text { in } 20 \mathrm{~min} .\end{array}$ & [23] \\
\hline $\mathrm{MP}, \mathrm{EP}, \mathrm{PP}, \mathrm{BuP}$, and BeP & $\begin{array}{l}500 \mu \mathrm{M} \text { of parabens in } \\
\text { deionized ultrapure } \\
\text { water. }\end{array}$ & - $\quad 99 \%$ removal in $12 \mathrm{~min}$. & [25] \\
\hline MP, EP, PP, BuP and BeP & $\begin{array}{l}\text { - } \quad 10 \mathrm{mg} / \mathrm{L} \text { of each paraben } \\
\text { in ultrapure water }\end{array}$ & $\begin{array}{l}\text { Total paraben removal } \\
\text { was achieved for } \\
\text { TOD }=170 \mathrm{mg} / \mathrm{L} \text { in } \\
120 \mathrm{~min} .\end{array}$ & [26] \\
\hline $\mathrm{MP}, \mathrm{EP}, \mathrm{PP}, \mathrm{BuP}$ and BeP & - $\quad 10 \mathrm{mg} / \mathrm{L}$ of each paraben & $\begin{array}{l}\text { Parabens removal: } \\
32-38 \%(\mathrm{pH}=3), 36-42 \% \\
(\mathrm{pH}=5) \text { and } 47-52 \% \\
(\mathrm{pH}=9) \text { in } 60 \mathrm{~min} .\end{array}$ & [28] \\
\hline $\mathrm{MP}, \mathrm{EP}$ and $\mathrm{PP}$ & $\begin{array}{l}1 \mathrm{mg} / \mathrm{L} \text { parabens } \\
\text { mixture in ultrapure } \\
\text { water. }\end{array}$ & $\begin{array}{l}\text { - Single ozone led to } \\
\text { parabens total removal } \\
\text { in } 15 \mathrm{~min} \text { with TOD of } \\
\text { about } 4.5 \mathrm{mg} / \mathrm{L} .\end{array}$ & [102] \\
\hline $\mathrm{MP}, \mathrm{EP}, \mathrm{PP}, \mathrm{BuP}$ and BeP & $\begin{array}{l}\text { - } \quad 10 \mathrm{mg} / \mathrm{L} \text { of each paraben } \\
\text { in ultrapure water. }\end{array}$ & $\begin{array}{l}\text { - } \quad>97 \% \text { removal for TOD } \\
\text { of } 46.2 \mathrm{mg} / \mathrm{L} \text { in } 120 \mathrm{~min} .\end{array}$ & [103] \\
\hline
\end{tabular}

\subsubsection{Catalytic and Photocatalytic Ozonation}

The performance of single ozonation can be enhanced using catalysts, radiation, and reagents, leading to higher degradation rates and reducing some disadvantages of this 
technology. There are not many studies regarding the abatement of parabens by catalytic and photocatalytic ozonation. However, in general, the presence of catalysts and radiation plus catalyst seems to lead to better results.

Cuerda-Correa et al. [23] used photolytic and photocatalytic ozonation with $\mathrm{TiO}_{2}$ to remove four parabens. The results showed $95 \%$ and $100 \%$ removal for photocatalytic ozonation and photolytic ozonation in $20 \mathrm{~min}$, respectively. In fact, these results were higher than for single ozonation ( $82 \%$ degradation) in the same study. Furthermore, the same occurred in the study of Asgari et al. [28], who used ZnO as photocatalyst and had $47-52 \%$ degradation $(\mathrm{pH}=9)$ in $60 \mathrm{~min}$ for single ozonation, while photolytic and photocatalytic ozonation led to $53-65 \%$ and $96-98 \%$ degradation, respectively. This behavior was also verified by Gomes et al. [26], who studied the degradation of a mixture of five parabens by ozonation and catalytic ozonation. The presence of catalyst required a lower ozone dose compared to single ozonation. Moreover, a treated solution with lower toxicity was achieved by the catalytic process. These results prove a clear improvement of ozonation when coupled with radiation and/or catalyst. However, in the study of Cuerda-Correa et al. [23], the catalyst did not improve the parabens degradation, which can be related to the generation of radicals ( $\mathrm{OH}$ or ozonide) or even to a negative interaction between the ozone and the catalyst. The same was reported in the study by Gomes et al. [102], in which they used photocatalytic and catalytic ozonation for the degradation of a parabens mixture in different water matrices using $\mathrm{TiO}_{2} / \mathrm{NT}$ and carried out toxicity assessment analysis using Allivibrio fischeri bacteria and Lepidium sativum seeds. The presence of catalyst only decreased the solutions' toxicity since the luminescence inhibition for A. fischeri was lower and the germination index for L. sativum was higher when the ozone was used with the catalyst.

In addition, Gomes et al. [102] used UVA and sun as light sources. When sunlight was used, the objective was quickly achieved, but more ozone was consumed, while the use of UVA seemed to slightly enhance parabens degradation, although the difference was not as significant. Total parabens removal was achieved for TOD $=4.5 \mathrm{mg} / \mathrm{L}$ and TOD $=8.5 \mathrm{mg} / \mathrm{L}$ for UVA and sunlight, respectively, using an initial concentration of $1 \mathrm{mg} / \mathrm{L}$.

Gomes et al. [26] required TOD $=70 \mathrm{mg} / \mathrm{L}\left(\mathrm{Pt}-\mathrm{TiO}_{2}\right)$ for the removal of $10 \mathrm{mg} / \mathrm{L}$ of each paraben (MP, EP, PP, BuP, and BeP) using catalytic ozonation, while the study of Gomes et al. [27] needed about $40 \mathrm{mg} / \mathrm{L}$ of TOD $\left(\mathrm{Ag}-\mathrm{TiO}_{2}\right)$ using photocatalytic ozonation for the same paraben's mixture and concentration. Both studies reached total removal of parabens. Furthermore, in the study of Gomes et al. [26], about $94 \mathrm{mg} / \mathrm{L}$ of TOD were necessary for catalytic ozonation using $\mathrm{Ag}-\mathrm{TiO}_{2}$, while in Gomes et al.'s [27] study, the presence of UVA led to a lower TOD of $40 \mathrm{mg} / \mathrm{L}$ using the same catalyst [27]. Moreover, in Gomes et al.'s [26] experiment, the best catalysts were $\mathrm{Pd}$ and $\mathrm{Pt}-\mathrm{TiO}_{2}$ in the catalytic experiments, while in the photocatalytic experiments of Gomes et al. [27], this was not verified, since the best catalysts were $\mathrm{Ag}$ and $\mathrm{Pt}_{-} \mathrm{TiO}_{2}$ [27]. The catalyst's performance and behavior can be influenced by the photogenerated electrons and the generation of radicals. In fact, the authors suggest that the $\mathrm{Au}-\mathrm{TiO}_{2}$ had low performance in photocatalytic ozonation due to a higher retention of photogenerated electrons related to its higher electronegativity, which could lower the generation of ozonide radicals, and, therefore, the generation of hydroxyl radicals [27]. Furthermore, $\mathrm{Ag}-\mathrm{TiO}_{2}$ has lower electronegativity, so its good performance could also be related to this fact, and this can explain why the presence of UVA did not have any effect on $\mathrm{Au}-\mathrm{TiO}_{2}$ [27]. In addition, in the study of Gomes et al. [27], $\mathrm{TiO}_{2}$ also did not have any improvement when UVA was added, which could be related to poor photoactivity of the catalyst due to its high band-gap, while in the other doped catalysts, the results were better than the pure $\mathrm{TiO}_{2}$ and without UVA, which means that UVA had a positive influence on them, maybe to their lower band-gap and high photoactivity $[26,27]$.

Fernandes et al. [103] had almost total removal using $10 \mathrm{mg} / \mathrm{L}$ for different synthesis methods of $\mathrm{N}-\mathrm{TiO}_{2}$ reaching TOD of 30-44 mg/L, and about $26-45 \mathrm{mg} / \mathrm{L}$, for the different methods, using photocatalytic ozonation. These results were better than the ones provided 
by Gomes et al. [27], who used a catalyst doped with noble metals (best results for Ag$\mathrm{TiO}_{2}$ with $\mathrm{TOD}=40 \mathrm{mg} / \mathrm{L}$ ). This may suggest a good behavior of non-metal doping for photocatalytic ozonation, which may be interesting due to the costs associated with noble metals.

Table 5 overviews works dealing with ozone-based technologies for parabens removal.

Table 5. Parabens removal by catalytic and photocatalytic ozonation.

\begin{tabular}{|c|c|c|c|c|c|}
\hline Pollutant & AOP & Catalyst & $\begin{array}{c}\text { Test } \\
\text { Conditions }\end{array}$ & $\begin{array}{l}\text { Results and } \\
\text { Conclusions }\end{array}$ & Reference \\
\hline $\begin{array}{c}\mathrm{MP}, \mathrm{EP}, \mathrm{PP} \text {, and } \\
\mathrm{BuP}\end{array}$ & $\begin{array}{l}\text { Photolytic } \\
\text { ozonation } \\
\text { Photocatalytic } \\
\text { ozonation } \\
\text { Other ozone } \\
\text { techniques }\end{array}$ & $\mathrm{TiO}_{2}$ & $\begin{array}{l}\text { - } 5 \mathrm{mg} / \mathrm{L} \text { of each } \\
\text { paraben in } \\
\text { ultrapure water. } \\
\text { UV radiation. }\end{array}$ & $\begin{array}{l}\text { Degradation of about } 65 \%, 70 \% \text {, } \\
91 \%, 94 \%, 95 \%, 100 \% \text {, and } 100 \% \\
\text { for } \mathrm{O}_{3} / \mathrm{H}_{2} \mathrm{O}_{2} / \mathrm{Fe}^{2+}, \mathrm{O}_{3} / \mathrm{H}_{2} \mathrm{O}_{2}, \\
\mathrm{O}_{3} / \mathrm{UV} / \mathrm{H}_{2} \mathrm{O}_{2} / \mathrm{Fe}^{2+}, \\
\mathrm{O}_{3} / \mathrm{UV} / \mathrm{H}_{2} \mathrm{O}_{2}, \mathrm{O}_{3} / \mathrm{UV} / \mathrm{TiO}_{2}, \\
\mathrm{O}_{3} / \mathrm{UV} / \mathrm{H}_{2} \mathrm{O}_{2} / \mathrm{TiO}_{2} \text {, and } \\
\mathrm{O}_{3} / \mathrm{UV}, \text { respectively in } 20 \text { min. }\end{array}$ & [23] \\
\hline $\begin{array}{c}\mathrm{MP}, \mathrm{EP}, \mathrm{PP}, \mathrm{BuP}, \\
\text { and } \mathrm{BeP}\end{array}$ & $\begin{array}{l}\text { Catalytic } \\
\text { ozonation }\end{array}$ & $\begin{array}{c}\mathrm{TiO}_{2} \\
\mathrm{Au}-\mathrm{TiO}_{2} \\
\mathrm{Ag}-\mathrm{TiO}_{2} \\
\mathrm{Pd}-\mathrm{TiO}_{2} \\
\mathrm{Pt}-\mathrm{TiO}_{2} \\
\end{array}$ & $\begin{array}{l}10 \mathrm{mg} / \mathrm{L} \text { of each } \\
\text { paraben in } \\
\text { ultrapure water. } \\
70 \mathrm{mg} / \mathrm{L} \text { of catalyst. }\end{array}$ & $\begin{array}{l}\text { - } \mathrm{TOD}=70 \mathrm{mg} / \mathrm{L} \text { for } 0.5 \% \mathrm{Pt}-\mathrm{TiO}_{2} \\
\text { and } \mathrm{TiO}_{2} \text {, and } \mathrm{TOD}=80 \mathrm{mg} / \mathrm{L} \\
\text { for } 0.5 \% \mathrm{Pd}_{-} \mathrm{TiO}_{2} \text { in } 120 \mathrm{~min} .\end{array}$ & [26] \\
\hline $\begin{array}{c}\mathrm{MP}, \mathrm{EP}, \mathrm{PP}, \mathrm{BuP} \\
\text { and } \mathrm{BeP}\end{array}$ & $\begin{array}{c}\text { Photocatalytic } \\
\text { Ozonation }\end{array}$ & $\begin{array}{l}\mathrm{TiO}_{2} \\
\mathrm{Ag}-\mathrm{TiO}_{2} \\
\mathrm{Au}-\mathrm{TiO}_{2} \\
\mathrm{Pd}-\mathrm{TiO}_{2} \\
\mathrm{Pt}-\mathrm{TiO}_{2}\end{array}$ & $\begin{array}{l}\text { - } \quad 10 \mathrm{mg} / \mathrm{L} \text { of each } \\
\text { paraben in } \\
\text { ultrapure water. } \\
\text { - } \quad 70 \mathrm{mg} / \mathrm{L} \text { of catalyst } \\
\text { dose. } \\
\text { - } \quad \text { UVA radiation. }\end{array}$ & $\begin{array}{l}\text { Photocatalytic ozonation led to } \\
\text { total paraben degradation. } \\
\text { Catalysts efficiency: Ag }(\mathrm{TOD}= \\
40 \mathrm{mg} / \mathrm{L})<\mathrm{Pt}(\mathrm{TOD}=58 \mathrm{mg} / \mathrm{L}) \\
>\mathrm{Pd}(\mathrm{TOD}=64 \mathrm{mg} / \mathrm{L}) \mathrm{TiO}_{2} \\
(\mathrm{TOD}=70 \mathrm{mg} / \mathrm{L})> \\
0.5 \% \mathrm{Au}-\mathrm{TiO}_{2}(\mathrm{TOD}=84 \mathrm{mg} / \mathrm{L})\end{array}$ & [27] \\
\hline $\begin{array}{l}\mathrm{MP}, \mathrm{EP}, \mathrm{PP}, \mathrm{BuP} \\
\text { and } \mathrm{BeP}\end{array}$ & $\begin{array}{l}\text { Photolytic } \\
\text { Ozonation } \\
\text { Photocatalytic } \\
\text { Ozonation }\end{array}$ & $\mathrm{ZnO}$ & $\begin{array}{l}\text { - } \quad 10 \mathrm{mg} / \mathrm{L} \text { paraben } \\
\text { - } \quad \text { UVlution. } \\
\quad \text { UV radiation. }\end{array}$ & $\begin{array}{l}\text { Photocatalytic ozonation } \\
\text { removed 96-98\% }(\mathrm{pH}=9) \text { and } \\
\text { 74-80\% }(\mathrm{pH}=3), \text { while } \\
\text { photolytic ozonation obtained } \\
50-53 \%(\mathrm{pH}=3) \text { and } 53-65 \% \\
(\mathrm{pH}=9) . \\
\text { MP degradation: } 34.5 \% \text { and } 98 \% \\
(15 \text { min), and } 65 \% \text { and } 100 \% \\
(45 \mathrm{~min}) \text { for } \mathrm{O}_{3}+\mathrm{UV} \text { and } \mathrm{O}_{3}+ \\
\mathrm{UV}+\mathrm{ZnO} \text {, respectively. }\end{array}$ & {$[28]$} \\
\hline $\mathrm{MP}, \mathrm{EP}$, and PP & $\begin{array}{c}\text { Photocatalytic } \\
\text { ozonation }\end{array}$ & $\mathrm{TiO}_{2} / \mathrm{NT}$ & $\begin{array}{l}1 \mathrm{mg} / \mathrm{L} \text { parabens } \\
\text { mixture in } \\
\text { ultrapure water. } \\
\text { UVA and Solar } \\
\text { radiation. }\end{array}$ & $\begin{array}{l}\text { Photocatalytic ozonation led to } \\
\text { total removal with UVA using } \\
\text { about TOD }=4.5 \mathrm{mg} / \mathrm{L} \text { and } \\
\text { solar radiation about TOD }= \\
8.5 \mathrm{mg} / \mathrm{L}(10 \mathrm{~min})\end{array}$ & {$[102]$} \\
\hline $\begin{array}{l}\mathrm{MP}, \mathrm{EP}, \mathrm{PP}, \mathrm{BuP}, \\
\text { and } \mathrm{BeP}\end{array}$ & $\begin{array}{c}\text { Photocatalytic } \\
\text { ozonation }\end{array}$ & $\begin{array}{c}\mathrm{N}-\mathrm{TiO}_{2} \\
\mathrm{TiO}_{2}\end{array}$ & $\begin{array}{l}\text { - } \quad 10 \mathrm{mg} / \mathrm{L} \text { of each } \\
\text { paraben. } \\
\text { - } \quad 70 \mathrm{mg} / \mathrm{L} \text { of catalyst } \\
\text { dose. } \\
\text { - UVA radiation. }\end{array}$ & $\begin{array}{l}\text { - Almost total removal achieved } \\
\text { for TOD between about } 30 \text { and } \\
44 \mathrm{mg} / \mathrm{L} \text {, and about } 26 \text { and } \\
45 \mathrm{mg} / \mathrm{L} \text {, for different catalyst } \\
\text { synthesis methods. }\end{array}$ & [103] \\
\hline $\begin{array}{l}\mathrm{MP}, \mathrm{EP}, \mathrm{PP}, \mathrm{BuP}, \\
\text { and } \mathrm{BeP}\end{array}$ & $\begin{array}{c}\text { Photocatalytic } \\
\text { ozonation }\end{array}$ & $\mathrm{N}-\mathrm{TiO}_{2}$ & $\begin{array}{l}\text { - } \quad 10 \mathrm{mg} / \mathrm{L} \text { of each } \\
\text { paraben in } \\
\text { ultrapure water. } \\
\text { 70-140 mg/L of } \\
\text { catalyst dose. } \\
\text { - UVA radiation }\end{array}$ & $\begin{array}{l}\text { Total removal was achieved for } \\
\text { TOD of about } 44-60 \mathrm{mg} / \mathrm{L} \text { for } \\
70 \mathrm{mg} / \mathrm{L} \text { of catalyst, while for } \\
140 \mathrm{mg} / \mathrm{L} \text { of catalyst, TOD was } \\
\text { about } 62 \mathrm{mg} / \mathrm{L} \text {. } \\
\text { In } 120 \mathrm{~min} \text {, total removal of MP } \\
\text { and EP was practically achieved } \\
\text { using TOD of about } 44,48 \text {, and } \\
62 \mathrm{mg} / \mathrm{L} \text { for river, wastewater, } \\
\text { and ultrapure water, } \\
\text { respectively. }\end{array}$ & [104] \\
\hline
\end{tabular}




\subsection{Fenton's Process}

There are not many studies regarding the paraben's abatement using Fenton's process. The most conventional Fenton's oxidation uses $\mathrm{Fe}^{2+}$ and $\mathrm{H}_{2} \mathrm{O}_{2}$ for the elimination of organic molecules through the generation of oxidative radicals. The presence of iron allows the continuous generation of hydroxyl radicals that are the most wanted radicals for pollutants removal.

Gmurek et al. [30] used Fenton for the degradation of a mixture of parabens $(10 \mathrm{mg} / \mathrm{L})$. In this experiment, the initial $\mathrm{pH}$ was 6 , and after the addition of $\mathrm{Fe}^{2+}$ and $\mathrm{H}_{2} \mathrm{O}_{2}$, the $\mathrm{pH}$ decreased to 3 , which is generally the optimal condition for this reaction, due to a better generation of oxidizing radicals. This reaction led to the complete removal of parabens. Zúñiga-Benítez et al. [105] used Fenton's reagent to remove 3-benzophenone and methylparaben. Several conditions were tested, and the MP removal was between $45.39 \%$ and $89.96 \%$ after 30 min. Using Fenton's reagent and light, the removal was $98 \%$ for the best operational conditions, while the use of $\mathrm{Fe}^{2+}$ and $\mathrm{H}_{2} \mathrm{O}_{2}$ only removed $35 \%$, which shows a clear improvement when UV radiation was applied to the Fenton's process.

Dominguez et al. [106] treated $150 \mathrm{~mL}$ mixture with $5 \mathrm{mg} / \mathrm{L}$ of each paraben (MP, EP, $\mathrm{PP}$, and $\mathrm{BuP})$. An experimental design was applied in which the initial concentration of the reagents $\left(\mathrm{Fe}^{2+}\right.$ and $\left.\mathrm{H}_{2} \mathrm{O}_{2}\right)$ were variable. Best performance achieved $95.8 \%, 97.7 \%, 98.0 \%$, and $98.6 \%$ of MP, EP, PP, and BuP removal for concentrations of $2.70 \times 10^{-4} \mathrm{~mol} / \mathrm{L}$ and $2.70 \times 10^{-5} \mathrm{~mol} / \mathrm{L}$ for $\mathrm{H}_{2} \mathrm{O}_{2}$ and $\mathrm{Fe}^{2+}$, respectively.

In general, the studies suggest a good performance of Fenton's over parabens abatement, since high removal rates were generally reported. Table 6 presents an overview of the use of Fenton's technology regarding parabens removal.

Table 6. Parabens removal by Fenton's process.

\begin{tabular}{|c|c|c|c|c|c|}
\hline Pollutant & AOP & Iron Source & Test Conditions & $\begin{array}{l}\text { Results and } \\
\text { Conclusions }\end{array}$ & Reference \\
\hline $\begin{array}{l}\mathrm{MP}, \mathrm{EP}, \mathrm{PP}, \mathrm{BuP} \\
\text { and } \mathrm{BeP}\end{array}$ & Fenton & $\begin{array}{l}\text { Iron (II) sulfate } \\
\text { heptahydrated }\end{array}$ & $\begin{array}{l}\text { - Parabens mixture in } \\
\text { ultrapure water at } \\
10 \mathrm{mg} / \mathrm{L} \text { each. } \\
120 \mathrm{~min} \text { reaction and } \\
\text { initial } \mathrm{pH}=6 .\end{array}$ & $\begin{array}{l}\text { - Fenton's process led to total } \\
\text { parabens abatement in } \\
120 \mathrm{~min} .\end{array}$ & {$[30]$} \\
\hline $\begin{array}{l}\text { 3-Benzophenone } \\
\text { and MP }\end{array}$ & Fenton & $\begin{array}{l}\text { Iron (II) chloride } \\
\text { tetrahydrate }\end{array}$ & $\begin{array}{l}\text { - } \quad 300-800 \mathrm{~nm} \text { radiation. } \\
\text { - } \quad 1 \mathrm{mg} / \mathrm{L} \text { of pollutants } \\
\text { and } \mathrm{pH}=3 .\end{array}$ & $\begin{array}{l}\text { MP removal in } 120 \mathrm{~min} \\
\text { using best parameters: } \\
\text { about } 98 \%, 35 \%, 15 \%, 2 \% \text {, } \\
0 \% \text { and } 0 \% \text { for light }+\mathrm{Fe}^{2+}+ \\
\mathrm{H}_{2} \mathrm{O}_{2}, \mathrm{Fe}^{2+}+\mathrm{H}_{2} \mathrm{O}_{2}, \mathrm{Fe}^{2+}+ \\
\text { light, light }+\mathrm{H}_{2} \mathrm{O}_{2}, \mathrm{H}_{2} \mathrm{O}_{2} \\
\text { and photolysis, respectively. }\end{array}$ & [105] \\
\hline $\begin{array}{c}\mathrm{MP}, \mathrm{EP}, \mathrm{PP} \text {, and } \\
\text { BuP }\end{array}$ & Fenton & $\begin{array}{l}\text { Iron (II) sulfate } \\
\text { heptahydrated }\end{array}$ & $\begin{array}{l}\text { Parabens mixture using } \\
\text { MilliQ water with } \\
5 \mathrm{mg} / \mathrm{L} \text { each. }\end{array}$ & $\begin{array}{l}\text { Using } 2.70 \times 10^{-4} \mathrm{~mol} / \mathrm{L} \text { of } \\
\mathrm{H}_{2} \mathrm{O}_{2} \text { and } \\
2.70 \times 10^{-5} \mathrm{~mol} / \mathrm{L} \text { of } \mathrm{Fe}^{2+}, \\
\text { the removal efficiency was } \\
95.8 \%, 97.7 \%, 98.0 \% \text {, and } \\
98.6 \% \text { being the higher } \\
\text { values obtained. } \\
32.8 \%, 37.9 \%, 39.5 \% \text { and } \\
41.5 \% \text { degradation for same } \\
\text { parabens order was } \\
\text { achieved using } \\
0.46 \times 10^{-4} \mathrm{~mol} / \mathrm{L} \text { of } \mathrm{H}_{2} \mathrm{O}_{2} \\
\text { and } 0.46 \times 10^{-5} \mathrm{~mol} / \mathrm{L} \\
\text { of } \mathrm{Fe}^{2+} .\end{array}$ & [106] \\
\hline
\end{tabular}




\subsection{PS, PMS, and $\mathrm{H}_{2} \mathrm{O}_{2}$ Oxidation}

PS and PMS anions are widely used oxidizing reagents. In fact, these agents are applied as other compounds in their molecular form (such as sodium persulfate (SPS) or potassium peroxymonosulfate), in which their dissociation into the anions and their interaction with light, heat, or catalysts generates sulfate radicals that will promote the pollutant's oxidation. However, the efficiency of persulfate anions alone is not as good, and the presence of other materials is required to enhance the generation of sulfate radicals, so, in general, and as presented in the referred studies, the use of these agents is accompanied by the presence of radiation and/or catalyst. Furthermore, the basic $\mathrm{pH}$ is favorable when these anions are used, since at this $\mathrm{pH}$ it is possible to form $\mathrm{OH}$ radicals that are more reactive than the $\cdot \mathrm{SO}_{4}{ }^{2-}$ radicals.

Hydrogen peroxide is another widely used reagent for the generation of oxidizing radicals, and, at low or high amounts, its efficiency can be negatively affected due to low pollutants oxidation or scavenging behavior of hydroxyl radicals. This reagent is mainly used in the presence of other materials considered as an AOP technology, and its presence can enhance the technology's efficiency, particularly with the use of UV radiation, which allows the generation of hydroxyl radicals.

Gmurek et al. [35] used hydrogen peroxide for the degradation of a mixture of five parabens and p-HBA. The individual parabens using $\mathrm{UVC} / \mathrm{H}_{2} \mathrm{O}_{2}$ technology occurred in about $6 \mathrm{~min}$, and the mixture of parabens was totally removed in $30 \mathrm{~min}$.

Dhaka et al. [73] tested ethylparaben conversion using radiation and three different reagents (persulfate, peroxymonosulfate, and hydrogen peroxide). In $90 \mathrm{~min}$, EP removal was about $97 \%, 98.1 \%, 81.3 \%$ and $36 \%$ for $\mathrm{UV} / \mathrm{H}_{2} \mathrm{O}_{2}$, UV $/ \mathrm{PS}$, UV $/ \mathrm{PMS}$, and UVC photolysis, respectively. Furthermore, Dhaka et al. [74] removed about $98.9 \%$ and $34 \%$ of methylparaben using UV/PS and UVC at the same time. These results are very similar and prove the good performance of persulfate anion when coupled with UVC light. Compared to photolysis results, the existence of oxidizing agent seems to significantly increase the oxidation of the parabens compounds, which may be related to a higher generation of oxidizing radicals. Moreover, the use of UV/PMS was less effective than UV/PS in the study of Dhaka et al. [73], which is not expected, since PMS can generate hydroxyl and sulfate radicals and PS can only produce sulfate radicals [42]. Total removal of PP using UV/PS oxidation was obtained by Ioannidi et al. [107], which used UVA radiation and simulated solar light, but only $12 \%$ was achieved using Vis radiation. However, these results suggest a good performance of these technologies regarding the parabens abatement for different radiation sources, which may be an advantage for this purpose.

The presence of a catalyst may also enhance this degradation. Yang et al. [108] removed $\mathrm{BuP}$ by peroxymonosulfate oxidation with $\mathrm{Mn}$-Fe oxycarbide catalyst, achieving the highest removal of $99 \%$ on $180 \mathrm{~min}$, while Bekris et al. [109] used graphene-based catalysts with PS to remove $1 \mathrm{mg} / \mathrm{L}$ of PP, achieving 95\% degradation for the best catalyst in $20 \mathrm{~min}$. Moreover, the use of SPS alone was tested, reaching 10\% degradation in $120 \mathrm{~min}$, which shows the poor performance of this agent when used alone. Matthaiou et al. [110] used $1 \mathrm{~g} / \mathrm{L}$ of SPS and different iron materials as a catalyst for the removal of $0.4 \mathrm{mg} / \mathrm{L}$ of $\mathrm{PP}$, achieving the best degradation, $90 \%$, in $90 \mathrm{~min}$. Comparing these studies shows that the presence of catalyst led to almost total removal in general, which shows a good degradation performance when a catalyst material is present, and the study by Bekris et al. [109] also presented a poor performance for SPS when used alone, which is the expected behavior. Moreover, these performances were also obtained for different types of catalysts, which may suggest that it is possible to use a wide range of different catalytic materials.

Table 7 presents the use of reagents for parabens abatement. 
Table 7. Parabens degradation by PS, PMS or $\mathrm{H}_{2} \mathrm{O}_{2}$ oxidation.

\begin{tabular}{|c|c|c|c|c|c|}
\hline Pollutant & AOP & $\begin{array}{c}\mathrm{PS} / \mathrm{PMS} / \mathrm{H}_{2} \mathrm{O}_{2} \\
\text { Source }\end{array}$ & Test Conditions & Results and Conclusions & Reference \\
\hline $\begin{array}{l}\text { MP, EP, PP, } \\
\text { BuP, BeP, and } \\
\text { p-HBA }\end{array}$ & $\mathrm{H}_{2} \mathrm{O}_{2}$ & $\mathrm{H}_{2} \mathrm{O}_{2}(30 \%)$ & $\begin{array}{l}\text { - } 10 \mathrm{mg} / \mathrm{L} \text { each paraben } \\
\text { in distilled water. } \\
\text { UVA and UVC } \\
\text { radiation. }\end{array}$ & $\begin{array}{l}\text { Individual parabens } \\
\text { degradation by UVC of } \\
10-60 \% \text { in } 120 \text { min, while } \\
\text { the use of UVA and } 0.5 \mathrm{M} \\
\mathrm{H}_{2} \mathrm{O}_{2} \text { allowed total } \\
\text { parabens removal in } 6 \mathrm{~min} \text {. } \\
\text { Degradation of parabens } \\
\text { mixture of } 30 \% \text { in } 2 \mathrm{~h}(8 \mathrm{~h} \\
\text { for total removal) by } \\
\mathrm{UVA} / \mathrm{H}_{2} \mathrm{O}_{2} \text {, while } \\
\mathrm{UVC} / \mathrm{H}_{2} \mathrm{O}_{2} \text { removes } 100 \% \\
\text { in } 30 \text { min. }\end{array}$ & [35] \\
\hline
\end{tabular}

\begin{tabular}{|c|c|c|c|c|c|}
\hline $\mathrm{EP}$ & $\begin{array}{l}\mathrm{UV} / \mathrm{H}_{2} \\
\mathrm{O}_{2} \mathrm{UV} / \mathrm{PS} \\
\mathrm{UV} / \mathrm{PMS}\end{array}$ & $\begin{array}{l}\qquad \mathrm{H}_{2} \mathrm{O}_{2}(30 \%) \\
\text { Sodium } \\
\text { persulfatePotassium } \\
\text { monoperoxysulfate }\end{array}$ & $\begin{array}{ll}- & \mathrm{UVC} \text { radiation } \\
- & 30 \mu \mathrm{M} \text { of } \mathrm{EP} \text { and } 1 \mathrm{mM} \\
\text { of oxidizing agent. }\end{array}$ & $\begin{array}{l}\text { In } 90 \mathrm{~min}, \mathrm{EP} \text { removal was } \\
97 \%, 98.1 \%, 81.3 \% \text {, and } \\
\text { about } 36 \% \text { for } \mathrm{UV} / \mathrm{H}_{2} \mathrm{O}_{2} \\
\mathrm{UV} / \mathrm{PS}, \mathrm{UV} / \mathrm{PMS} \text {, and UV. }\end{array}$ & [73] \\
\hline MP & $\mathrm{UV} / \mathrm{PS}$ & Sodium persulfate & $\begin{array}{l}-\quad \text { UVC radiation } \\
-\quad 32.8 \mu \mathrm{M} \text { of } \mathrm{MP} \text { and } \\
1 \mathrm{mM} \text { of persulfate. }\end{array}$ & $\begin{array}{l}\text { MP removal: } 98.9 \% \text { for } \\
\text { UV / persulfate and about } \\
34 \% \text { for UV in } 90 \mathrm{~min} \text {. }\end{array}$ & [74] \\
\hline PP & $\mathrm{UV} / \mathrm{PS}$ & Sodium persulfate & $\begin{array}{l}\text { - UVA radiation and } \\
\text { Solar simulator } \\
\text { PP solution in ultrapure } \\
\text { water, real effluent, and } \\
\text { bottled water. } \\
200 \mu \mathrm{\mu g} / \mathrm{L} \text { of PP and } \\
250 \mathrm{mg} / \mathrm{L} \text { of SPS }\end{array}$ & $\begin{array}{l}\text { PP removal was about } 100 \% \text {, } \\
98 \% \text { and } 5 \% \text { for bottled, } \\
\text { ultrapure water, and } \\
\text { wastewater, in } 60 \text { min. } \\
\text { UVA and Solar simulate } \\
\text { light led to total PP removal, } \\
\text { while the SPS (dark), } \\
\text { photolysis, and Vis } \\
\text { radiation + SPS removed } \\
\text { about } 9 \%, 0 \% \text {, and } 12 \% \text {, } \\
\text { respectively, in } 60 \mathrm{~min} .\end{array}$ & [107] \\
\hline $\mathrm{BuP}$ & PMS oxidation & $\begin{array}{c}\text { Potassium } \\
\text { monoperoxysulfate }\end{array}$ & $\begin{array}{l}\text { Aqueous solutions and } \\
\text { Mn-Fe oxycarbide. }\end{array}$ & $\begin{array}{l}0 \%, 49 \%, 91 \%, 96 \%, 99 \%, \\
\text { and } 99 \% \text { removal were } \\
\text { achieved in } 180 \text { min for no } \\
\text { material, mMFS, mMFC- } 2 \text {, } \\
\text { mMFC- } 8 \text {, mMFC- } 4 \text {, and } \\
\text { mMFC- } 6 \text {, respectively. } \\
\text { mMFC-6/PMS removed } \\
73 \% \text { and } 81 \% \text { of BuP for real } \\
\text { wastewater. }\end{array}$ & [108] \\
\hline PP & PS oxidation & Sodium persulfate & $\begin{array}{l}\text { Oxidation using several } \\
\text { catalysts (PureG+ } \\
\text { graphene, UltraG+ } \\
\text { graphene, Elicarb } \\
\text { graphene and Graphene } \\
\text { oxide }(\mathrm{GO}) \text { ) and } \\
\text { sodium persulfate. }\end{array}$ & $\begin{array}{l}\text { For } 1 \mathrm{mg} / \mathrm{L} \mathrm{PP}, 500 \mathrm{mg} / \mathrm{L} \\
\text { catalyst dose, and } 20 \mathrm{mg} / \mathrm{L} \\
\text { of SPS, the degradation } \\
\text { results were: } 95 \% \text { for } \\
\text { PureG+ and UltraG+, } 70 \% \\
\text { for GO and Elicarb was less } \\
\text { than } 10 \% \text {, in } 20 \text { min. } \\
\text { SPS alone led to } 10 \% \\
\text { removal in } 2 \mathrm{~h}, \text { while } \\
\text { catalyst led to removals of } \\
\text { about } 10-95 \% .\end{array}$ & [109] \\
\hline PP & PS oxidation & Sodium persulfate & $\begin{array}{l}\text { - Iron materials were } \\
\text { used for sodium } \\
\text { persulfate activation. } \\
0.4 \mathrm{mg} / \mathrm{L} \text { of PP in } \\
\text { ultrapure water. } \\
\text { - } \quad 1 \mathrm{~g} / \mathrm{L} \text { of } S P S \text { and } \\
50 \mathrm{mg} / \mathrm{L} \text { of catalysts. }\end{array}$ & $\begin{array}{l}\text { PP removal was about } 90 \% \\
\text { for S1, S2, and S3 catalyst in } \\
90 \text { min and was 50-55\% for } \\
\text { S4 and S5 catalyst. }\end{array}$ & [110] \\
\hline
\end{tabular}




\subsection{Electrochemical Technologies}

Electrochemical methods are also part of advanced oxidation processes and are widely used for degradation of pollutants. The use of these technologies on an industrial scale can be difficult, due to high costs, since one of the most used anodes is the boron-doped diamond (BDD), which is a very expensive material.

Martins et al. [36] used photo-electrocatalysis for PP removal using $\mathrm{TiO}_{2}$ nanotubes as a catalyst. At $\mathrm{pH}=3$, total removal was achieved in only $30 \mathrm{~min}$. The authors also showed that the presence of $\mathrm{WO}_{3}$ in $\mathrm{TiO}_{2}$ nanotubes enhances the photo-activity by $20 \%$. Frontistis et al. [85] used electrochemical oxidation with BDD anode and achieved total EP removal in about $15 \mathrm{~min}$ for $200 \mu \mathrm{g} / \mathrm{L}$ of $\mathrm{EP}$ and $30 \mathrm{~min}$ when $600 \mu \mathrm{g} / \mathrm{L}$ was used as the initial concentration.

Dionisio et al. [111], Steter et al. [112], and Dionisio et al. [113] removed $100 \mathrm{mg} / \mathrm{L}$ of methylparaben using electrochemical oxidation with $\mathrm{BDD}[111,112]$ and $\mathrm{DSA}-\mathrm{Cl}_{2}$ [113]. Dionisio et al. [111] had 100\% removal in $20 \mathrm{~min}$ for electrochemical oxidation and photoelectrocatalysis with UVC radiation, while photochemical degradation led to $20 \%$ removal in almost $500 \mathrm{~min}$ reaction. When $3 \mathrm{~g} / \mathrm{L}$ of $\mathrm{Na}_{2} \mathrm{SO}_{4}$ was used as an electrolyte solution, the efficiency decreased, since total removal was achieved for photo-electrocatalysis in about $240 \mathrm{~min}$, for electrocatalysis in $300 \mathrm{~min}$, and the photochemical oxidation led to less than $10 \%$ in almost $500 \mathrm{~min}$. This clearly shows the influence of electrolyte solution on the technology's performance. Moreover, it seems that $\mathrm{NaCl}$ presents a good behavior for these experiments. Dionisio et al. [113] used $0.15 \mathrm{~mol} / \mathrm{L}$ of $\mathrm{NaCl}$ as electrolyte solution, which also had $100 \%$ MP removal, but it was obtained in $40 \mathrm{~min}$ for electrocatalysis and photoelectrocatalysis, which did not show improvement when UVC radiation was added to the degradation process. UVC photolysis was also tested, but only $17 \%$ of MP was removed in $120 \mathrm{~min}$. In the studies by Dionisio et al. [111,113], the presence of radiation was not able to increase the electrochemical experiments' efficiency, but when compared to single radiation, the high performance of the electrochemical route was noticed [113]. Steter et al. [112] used $\mathrm{BDD}$ as an anode and $0.05 \mathrm{~mol} / \mathrm{L}$ of $\mathrm{K}_{2} \mathrm{SO}_{4}$ as an electrolyte solution but only achieved $34.65 \%$ of MP removal in $20 \mathrm{~min}$ for the best conditions. In fact, compared to the study of Dionisio et al. [111], the choice of electrolyte solution may explain the difference in the obtained results. With this, it is possible to notice that $\mathrm{NaCl}$ and $\mathrm{Na}_{2} \mathrm{SO}_{4}$ are good choices at a first sight, and the use of $\mathrm{K}_{2} \mathrm{SO}_{4}$ should not be considered due to low performance.

The removal of BuP by electrochemical technologies was also investigated. Pueyo et al. [114] used electrochemical oxidation, using different materials as anode and stainless-steel as cathode, to remove $0.5 \mathrm{mg} / \mathrm{L}$ of $\mathrm{BuP}$ in an electrolyte solution of $0.1 \mathrm{M}^{-} \mathrm{Na}_{2} \mathrm{SO}_{4}$. BDD anode allowed a BuP removal of $100 \%$ in $15 \mathrm{~min}$, while stainless steel and platinum only achieved $40 \%$ and $18 \%$ degradation, respectively. Gomes et al. [115] also removed $\mathrm{BuP}$ in river water with this technology, but using platinum or glassy carbon anodes, for different electrolyte solution $\left(\mathrm{KCl}, \mathrm{H}_{2} \mathrm{SO}_{4}\right.$ and $\left.\mathrm{K}_{4} \mathrm{P}_{2} \mathrm{O}_{7}\right)$. In this condition, $95 \%$ of $\mathrm{BuP}$ was degraded in $180 \mathrm{~min}$ in the presence of $0.1 \mathrm{M}$ of $\mathrm{K}_{4} \mathrm{P}_{2} \mathrm{O}_{7}$ as electrolyte and $40 \mu \mathrm{M}$ of CTAC on glassy carbon. The study by Pueyo et al. [114] proved the good performance of BDD over platinum and stainless-steel anodes. This should be expected, since one of the good characteristics of BDD is its good working performance, but the disadvantages such as its high cost can make it difficult to implement electrochemical experiments with this anode. Furthermore, the study of Gomes et al. [115] suggested an easy degradation of the target compound when used in a real water matrix, which is a positive sign for real application purposes.

As well as electrochemical oxidation or photoelectrocatalysis methodologies, electroFenton and photo-electro Fenton were also used in parabens abatement. Steter et al. [88] removed MP, EP, and PP by photo-electro Fenton with $\mathrm{BDD}$ or $\mathrm{RuO}_{2}$ anode. Regarding the $\mathrm{BDD}$ anode, a removal of 65\% (360 $\mathrm{min}), 100 \%$ (360 $\mathrm{min}$ ), and 100\% (180 $\mathrm{min}$ ) was achieved for $\mathrm{H}_{2} \mathrm{O}_{2}$, electro-Fenton, and photoelectron-Fenton with solar radiation. Furthermore, the authors studied the influence of the water matrix in the paraben's abatement. When real wastewater was tested, BDD led to total removal in $150 \mathrm{~min}$, while the $\mathrm{RuO}_{2}$ anode led to a removal higher than $95 \%$ in $180 \mathrm{~min}$, using solar light photoelectron-Fenton. This study 
proved the good efficiency of electro-Fenton and Photo-electro Fenton, since the removal rate was higher when Fenton's reagent was used compared to single $\mathrm{H}_{2} \mathrm{O}_{2}$, and the same conclusion was reached when radiation was added. These results can be explained by an improvement in the generation of hydroxyl radicals. Furthermore, this study also showed high degradation results when real wastewater was use,d which may suggest a good efficiency for these experimental conditions when applied to real treatment approaches. Rosales et al. [116] tested the MP abatement for electro-Fenton and anodic oxidation, using $\mathrm{BDD} / \mathrm{Nb}$ anode, and graphite felt (GF) or $\mathrm{Nb}$ as cathode. Results showed that anodic oxidation led to about $60 \%$ removal for $\mathrm{Ru}$ and GF cathodes, while the electro-Fenton using the same cathodes led to about $78 \%$ and $98 \%$ removal, respectively, in which the electro-Fenton process led to higher performance when compared to anodic oxidation. The results are related to the different technologies' mechanisms.

Table 8 presents the use of electrochemical technologies in parabens removal.

Table 8. Parabens degradation by electrochemical technologies.

\begin{tabular}{|c|c|c|c|c|c|}
\hline Pollutant & AOP & Material & $\begin{array}{c}\text { Test } \\
\text { Conditions }\end{array}$ & $\begin{array}{l}\text { Results and } \\
\text { Conclusions }\end{array}$ & Reference \\
\hline PP & $\begin{array}{l}\text { Photo- } \\
\text { Electrocatalysis }\end{array}$ & $\begin{array}{c}\mathrm{TiO}_{2} / \mathrm{NT} \\
\mathrm{WO}_{3}-\mathrm{TiO}_{2} / \mathrm{NT}\end{array}$ & $\begin{array}{l}\text { - } \quad \mathrm{TiO}_{2} / \mathrm{NT} \text { as working } \\
\text { electrode. } \\
50 \mathrm{mg} / \mathrm{L} \mathrm{PP} \text { in } \\
\text { electrolyte solution of } \\
0.1 \mathrm{~mol} / \mathrm{L} \text { of } \mathrm{Na}_{2} \mathrm{SO}_{4} \text { in } \\
\text { ultrapure water. }\end{array}$ & $\begin{array}{l}\text { - } 100 \% \text { removal in } 30 \text { min at } \\
\mathrm{pH}=3 \text {. } \\
\text { The presence of } \mathrm{WO}_{3} \\
\text { improves the photo-activity } \\
\text { by } 20 \% \text {. }\end{array}$ & [36] \\
\hline $\begin{array}{l}\mathrm{MP}, \mathrm{EP}, \mathrm{PP}, \mathrm{BuP}, \\
\text { and } \mathrm{BeP}\end{array}$ & $\begin{array}{c}\text { Electrochemical } \\
\text { oxidation }\end{array}$ & $\mathrm{Ti} / \mathrm{Pt}$ anode & $\begin{array}{l}\text { - Mixture of parabens at } \\
10 \mathrm{mg} / \mathrm{L} \text { each. } \\
\text { - } \mathrm{Ti} / \mathrm{Pt} \text { used as anode } \\
\text { and stainless steel as } \\
\text { cathode. }\end{array}$ & $\begin{array}{l}\text { The best result was } \\
125 \mathrm{~A} / \mathrm{m}^{2} \text { and } 3 \mathrm{~g} / \mathrm{L} \mathrm{NaCl} \\
\text { achieving total parabens } \\
\text { removal in } 10 \mathrm{~min} .\end{array}$ & [83] \\
\hline $\mathrm{EP}$ & $\begin{array}{c}\text { Electrochemical } \\
\text { Oxidation }\end{array}$ & BDD anode & $\begin{array}{l}\text { BDD anode and } \\
\text { stainless-steel cathode } \\
\text { 200-600 } \mu \mathrm{g} / \mathrm{L} \text { of EP in } \\
\text { electrolyte solution of } \\
\text { 0.1 M. }\end{array}$ & $\begin{array}{l}\text { Total removal achieved for } \\
\text { all experiments within } \\
15-30 \text { min. }\end{array}$ & [85] \\
\hline $\begin{array}{c}\mathrm{MP}, \mathrm{EP}, \mathrm{PP} \text {, and } \\
\mathrm{BuP}\end{array}$ & Electrolysis & BDD anode & $\begin{array}{l}\text { BDD as anode and } \\
\text { stainless steel as } \\
\text { cathode }\end{array}$ & $\begin{array}{l}\text { Best results of } 100 \% \\
\text { degradation. The next best } \\
\text { results were } 98.3,97.7,100 \text {, } \\
\text { and } 100 \text { for MP, EP, PP, and } \\
\text { BuP, respectively. } \\
\text { Degradation: } 24.4-100 \% \\
(\mathrm{MP}), 25.9-100 \%(\mathrm{EP}), \\
28.4-100 \%(\mathrm{PP}), \text { and } \\
34.3-100 \%(\mathrm{BuP}) .\end{array}$ & [87] \\
\hline $\mathrm{MP}, \mathrm{EP}$ and PP & $\begin{array}{l}\text { Photoelectro- } \\
\text { Fenton }\end{array}$ & $\begin{array}{l}\text { BDD anode } \\
\mathrm{RuO}_{2} \text { anode }\end{array}$ & $\begin{array}{l}\text { Electrolyte solution of } \\
5 \mathrm{mM} \text { of } \mathrm{Na}_{2} \mathrm{SO}_{4} \text { in } \\
\text { simulated water matrix } \\
(\mathrm{SWM}) \text { or real } \\
\text { wastewater }(\mathrm{RWW}) \text {. } \\
\text { Parabens solution with } \\
0.3 \mathrm{mM} \text { each. } \\
\text { - } \quad \text { Solar radiation } \\
\text { BDD or } \mathrm{RuO}_{2} \text { plate as } \\
\text { anode, PTFE air } \\
\text { diffusion as cathode. }\end{array}$ & $\begin{array}{l}\text { Electrolysis using BDD with } \\
\mathrm{H}_{2} \mathrm{O}_{2} \text { led to } 65 \% \text { removal in } \\
360 \mathrm{~min} \text {, electro-Fenton led } \\
\text { to } 100 \% \text { removal in } 360 \mathrm{~min}, \\
\text { and } 100 \% \text { achieved by solar } \\
\text { photo electro-Fenton (SPEF) } \\
\text { in } 180 \text { min. } \\
\text { Using BDD in SWM and } \\
\text { RWW, total removal was } \\
\text { achieved in } 180 \text { and } 150 \mathrm{~min}, \\
\text { respectively, and the } \mathrm{RuO}_{2} \text {, } \\
\text { SPEF SWM, and RWW at } \\
10 \mathrm{~mA} / \mathrm{cm}^{2}, \text { the removal } \\
\text { rate was }>95 \% \text { ( } 240 \mathrm{~min}) \\
\text { and }>95 \%(180 \text { min). }\end{array}$ & [88] \\
\hline
\end{tabular}


Table 8. Cont.

\begin{tabular}{|c|c|c|c|c|c|}
\hline Pollutant & AOP & Material & $\begin{array}{c}\text { Test } \\
\text { Conditions }\end{array}$ & $\begin{array}{l}\text { Results and } \\
\text { Conclusions }\end{array}$ & Reference \\
\hline MP & $\begin{array}{c}\text { Electrolysis } \\
\text { Photo-electrolysis }\end{array}$ & BDD anode & $\begin{array}{ll}\text { - } & \text { BDD used as anode and } \\
\text { stainless steel as } \\
\text { cathode. } \\
\text { - } \quad \text { UVC radiation. } \\
\text { - } \quad 300 \mathrm{mg} / \mathrm{L} \text { of } \mathrm{MP} . \\
\quad 3.7 \mathrm{~g} / \mathrm{L} \text { of } \mathrm{NaCl} \\
\text { electrolyte solution. }\end{array}$ & $\begin{array}{l}\text { Total MP removal for } \\
\text { electrocatalysis and } \\
\text { photoelectrocatalysis in } \\
20 \text { min, and about } 20 \% \\
\text { removal in almost } 500 \text { min } \\
\text { for photochemical process. }\end{array}$ & [111] \\
\hline MP & $\begin{array}{l}\text { Electrochemical } \\
\text { oxidation }\end{array}$ & BDD anode & $\begin{array}{l}\text { - } 100 \mathrm{mg} / \mathrm{L} \text { of } \mathrm{MP} \text { in } \\
0.05 \mathrm{~mol} / \mathrm{L} \text { of } \mathrm{K}_{2} \mathrm{SO}_{4} \\
\text { electrolyte solution. } \\
\text { BDD thin film used as } \\
\text { anode, Ti as cathode, } \\
\text { and the reference } \\
\text { electrode was } \\
\mathrm{Ag} / \mathrm{AgCl} .\end{array}$ & $\begin{array}{l}\text { MP removal was } 30.12 \text {, } \\
34.65,31.61,30.07 \text {, and } 19.85 \\
\text { for } 1.35,2.70,5.44,10.8 \text {, and } \\
21.6 \mathrm{~mA} / \mathrm{cm}^{2} \text { in } 120 \mathrm{~min} \text {. }\end{array}$ & [112] \\
\hline MP & $\begin{array}{c}\text { Electrochemical } \\
\text { oxidation } \\
\text { Photo-electrolysis }\end{array}$ & $\begin{array}{l}\text { DSA-Cl } \mathrm{Cl}_{2} \text { of } \\
\mathrm{Ti} / \mathrm{Ru}_{0.3} \mathrm{Ti}_{0.7} \mathrm{O}_{2} \\
\text { anode }\end{array}$ & $\begin{array}{l}\text { - } \quad \mathrm{Ti} / \mathrm{Ru}_{0.3} \mathrm{Ti}_{0.7} \mathrm{O}_{2} \text { used as } \\
\text { anode and Ti plate used } \\
\text { as cathode. } \\
\text { - } \quad 100 \mathrm{mg} / \mathrm{L} \text { of MP in } 0.15 \\
\text { mol/L NaCl solution. } \\
\text { - UVC radiation. }\end{array}$ & $\begin{array}{l}\text { Total removal in } 80 \text { and } 40 \\
\text { min for } 5 \text { and } 10 \mathrm{~mA} / \mathrm{cm}^{2} \text {, } \\
\text { respectively. } \\
\text { Photo electrocatalysis led to } \\
31,78, \text { and } 100 \% \text { removal } \\
\text { for } 1,2.5 \text {, and } 5 \mathrm{~mA} / \mathrm{cm}^{2}, \\
\text { respectively. Photolysis led } \\
\text { to } 17 \% \text { removal in } 2 \mathrm{~h} \text {. }\end{array}$ & [113] \\
\hline $\mathrm{BuP}$ & $\begin{array}{l}\text { Electrochemical } \\
\text { Oxidation }\end{array}$ & $\begin{array}{c}\text { BDD } \\
\text { Stainless- } \\
\text { steelPlatinum }\end{array}$ & $\begin{array}{l}\text { BDD, stainless-steel, } \\
\text { and platinum as anode } \\
\text { and stainless-steel as } \\
\text { cathode. } \\
0.5 \mathrm{mg} / \mathrm{L} \text { of } \mathrm{BuP} \text { in } \\
\text { electrolyte solution of } \\
0.1 \mathrm{M} \text { of } \mathrm{Na}_{2} \mathrm{SO}_{4} \text {. }\end{array}$ & $\begin{array}{l}\text { BuP total removal achieved } \\
\text { by BDD in } 15 \mathrm{~min} \text {, while for } \\
\text { the stainless-steel and } \\
\text { platinum anode, the } \\
\text { degradation was } 40 \% \text { and } \\
18 \% \text { respectively. }\end{array}$ & [114] \\
\hline $\mathrm{BuP}$ & $\begin{array}{l}\text { Electrochemical } \\
\text { Oxidation }\end{array}$ & $\begin{array}{l}\text { Platinum } \\
\text { Glassy carbon }\end{array}$ & $\begin{array}{l}\text { Platinum foil or glassy } \\
\text { carbon as working } \\
\text { electrode, the counter } \\
\text { electrode was platinum } \\
\text { wire and } \mathrm{Ag} / \mathrm{AgCl} \\
\text { electrode in } 3 \mathrm{M} \mathrm{KCl} \\
\text { solution was used as } \\
\text { reference electrode. } \\
\text { Electrolyte solutions: } 0.1 \\
\mathrm{M} \mathrm{KCl}_{1} \mathrm{H}_{2} \mathrm{SO}_{4} \text {, or } \\
\mathrm{K}_{4} \mathrm{P}_{2} \mathrm{O}_{7} .\end{array}$ & $\begin{array}{l}\text { Using a real water sample } \\
\text { from river, electrolysis led to } \\
95 \% \text { BuP removal in } 2.5 \mathrm{~h} \text {. }\end{array}$ & [115] \\
\hline MP & $\begin{array}{l}\text { Electro- } \\
\text { FentonAnodic } \\
\text { Oxidation }\end{array}$ & BDD anode & $\begin{array}{l}\text { BDD as anode and } \\
\text { graphite felt (GF) or Ru } \\
\text { as cathode. } \\
150 \mathrm{mg} / \mathrm{L} \mathrm{MP} \mathrm{solution} \\
\text { in } 10 \mathrm{mM} \mathrm{Na}_{2} \mathrm{SO}_{4} \\
\text { electrolyte solution. }\end{array}$ & $\begin{array}{l}\text { MP removal of } 60 \% \text { using } \\
\text { GF and Ru in anodic } \\
\text { oxidation. } \\
\text { Electro-Fenton using Ru } \\
\text { and GF led to about } 78 \% \\
\text { and } 98 \% \text { removal in } 60 \mathrm{~min} \text {. }\end{array}$ & [116] \\
\hline MP & $\begin{array}{l}\text { Dielectric barrier } \\
\text { discharge induced } \\
\text { non-thermal } \\
\text { plasma }\end{array}$ & $\begin{array}{l}\text { ZnO-rGO } \\
\text { nanosheets }\end{array}$ & $\begin{array}{l}\text { - } \quad \text { MP concentration of } 20 \\
\text { mg/L. } \\
\text { - } \mathrm{ZnO} / \mathrm{GO}=10: 1 .\end{array}$ & $\begin{array}{l}\text { - Best MP removal of } 99 \% \text {, } \\
55 \% \text {, and } 8 \% \text { in } 15 \text { min for } \\
\text { NTP with } \mathrm{ZnO}-\mathrm{rGO} \text {, single } \\
\text { NTP, and catalyst alone. }\end{array}$ & [117] \\
\hline
\end{tabular}

\subsection{Sono-Based Technologies}

Ultrasound can generate oxidizing radicals from water pyrolysis due to the creation and collapse of microbubbles. This technology can present good advantages but has the 
disadvantages of high amount of energy needed, low mineralization, and low efficiency, which can make this technology infeasible with difficult implementation at industrial scale.

Daghrir et al. [37] used photosonochemical degradation for BuP abatement $(20 \mathrm{mg} / \mathrm{L})$. The experiments led to a removal of $61.3 \%, 60.02 \%$, and $87.96 \%$ for single UV light, ultrasound, and the combination of both in $120 \mathrm{~min}$. Furthermore, for different experimental conditions (BuP concentration $=10 \mathrm{mg} / \mathrm{L}$, US/UV experiment, $40 \mathrm{~W}, \mathrm{pH}=7$ ) a removal of $99.2 \%$ removal was achieved. Nikolau et al. [38] removed about $92 \%$ of MP using the best operational parameters of $\mathrm{T}=20^{\circ} \mathrm{C}, \mathrm{pH}=6$, power density of $60 \mathrm{~W} / \mathrm{L}$ and the presence of biochar. This result was similar to the conclusions obtained by Sasi et al. [118], which showed $99 \%$ MP removal using an ultrasound frequency of 350 and $620 \mathrm{kHz}$, or a power density of 40.25 and $22.75 \mathrm{~W} / \mathrm{mL}$.

Ultrasound was also tested in the presence of a catalyst. Zanias et al. [119] studied sonocatalysis for MP removal using bimetallic Co-Fe carbon xerogel as a catalyst. Adsorption into catalyst was $29.2 \%$ of MP in $60 \mathrm{~min}$, and sonocatalysis led to $54.6 \%$ removal in $60 \mathrm{~min}$ for a power density of $25 \mathrm{~W} / \mathrm{L}$, but almost full removal was obtained in 45-60 min, when the power density was increased to $52 \mathrm{~W} / \mathrm{L}$.

In general, the removal of parabens was achieved, and high parabens degradation was reported. Nevertheless, the drawbacks associated with sonochemical processes as the high energy requirement or poor mineralization may affect their choice and their use in pollutants degradation at full-scale. In fact, other AOPs with better performances and lower energy requirements can be used in wastewater treatments. Table 9.

An overview of parabens degradation by sono-based technologies is presented in

Table 9. Parabens degradation using sono-based technologies.

\begin{tabular}{|c|c|c|c|c|c|}
\hline Pollutant & AOP & Catalyst & Test Conditions & Results and Conclusions & Reference \\
\hline $\mathrm{BuP}$ & Photosonochemical & (no catalyst) & $\begin{array}{l}\text { - } \quad \text { BuP concentration of } \\
20 \mathrm{mg} / \mathrm{L} \text {. } \\
\text { - } 120 \mathrm{~min} \text { reaction. }\end{array}$ & $\begin{array}{l}\text { BuP removal: } 61.3 \%, 60.02 \% \text {, } \\
\text { and } 87.96 \% \text { for UV, US (best } \\
\text { value), and US/UV (best } \\
\text { value). } \\
\text { 99.2\% best removal for } \\
\text { optimized conditions. }\end{array}$ & {$[37]$} \\
\hline $\mathrm{PP}$ & Sonochemical & (no catalyst) & $\begin{array}{l}1 \mathrm{mg} / \mathrm{L} \text { of PP in } \\
\text { ultrapure water }(\mathrm{UPW}), \\
\text { bottled water }(\mathrm{BW}), \\
\text { ground water }(\mathrm{GW}), \\
\text { and wastewater }(\mathrm{WW}) . \\
125 \mathrm{mg} / \mathrm{L} \text { of biochar } \\
\text { (BC) }\end{array}$ & $\begin{array}{l}\text { In } 60 \text { min, degradation was } \\
\text { about } 42 \%, 55 \%, 55 \% \text {, and } \\
78 \% \text { for } \mathrm{WW}, \mathrm{GW}, \mathrm{BW} \text {, and } \\
\mathrm{UPW} \text {, respectively, using } \\
20 \mathrm{~W} / \mathrm{L} \text { and BC. }\end{array}$ & {$[38]$} \\
\hline $\mathrm{MP}$ & Sonochemical & (No catalyst) & $\begin{array}{ll}- & 1.52 \mathrm{mg} / \mathrm{L} \text { of } \mathrm{MP} \\
- & \mathrm{MP} \text { removal in } 1 \mathrm{~h} \\
\text { - } & 22.75 \mathrm{~W} / \mathrm{mL} \text { for } \\
& \text { different frequencies } \\
& (200,350,620 \text { and } 1000 \\
\mathrm{kHz}) .\end{array}$ & $\begin{array}{l}\text { Degradation: } 350 \text { (about } \\
99 \% \text { removal) > } 620(99 \%)> \\
1000(95 \%)>200 \mathrm{kHz}(85 \%) \text {. } \\
\text { Power density: } 40.25(100 \% \\
\text { in } 1 \mathrm{~h})>22.75(100 \%)> \\
7 \mathrm{~W} / \mathrm{mL}(80 \%) .\end{array}$ & {$[118]$} \\
\hline MP & Sonocatalysis & $\begin{array}{l}\text { Bimetallic Co-Fe } \\
\text { carbon xerogel }\end{array}$ & $\begin{array}{l}\text { - } \quad 20 \mathrm{kHz} \text { ultrasound } \\
\text { coupled with catalyst } \\
(25 \mathrm{mg} / \mathrm{L}) . \\
\text { Power density of } 25 \text { and } \\
52 \mathrm{~W} / \mathrm{L} .\end{array}$ & $\begin{array}{l}\text { Ultrasound removes } 10 \% \\
\text { and } 64 \% \text { in } 60 \text { min for } \\
25 \mathrm{~W} / \mathrm{L} \text { and } 52 \mathrm{~W} / \mathrm{L} \text {, } \\
\text { respectively. } \\
\text { Sonocatalysis led to removal } \\
\text { of } 54.6 \% \text { in } 60 \text { min for } \\
25 \mathrm{~W} / \mathrm{L} \text { and led to almost } \\
\text { total degradation within } \\
45-60 \text { min for } 52 \mathrm{~W} / \mathrm{L} \text {. }\end{array}$ & [119] \\
\hline
\end{tabular}




\section{Toxicological Studies of Parabens Abatement}

As proven by the previous sections, the advanced oxidation processes can promote the total abatement of parabens (single or mixture), but some studies reveal that in some conditions, the total parabens removal cannot be achieved. Moreover, also the formation of by-products during these processes can interfere with the initial toxicity or even increase the toxic character of the treated solution $[24,30,75]$. In this way, it is important to consider the impact of treatments in target species, such as aquatic species, since the resulting by-products can be more toxic than the parent compounds [120]. With this, the toxicological study must be a parameter of consideration in the design and application of AOP technologies for wastewater treatment, since although the target substances may be eliminated, the solution toxicity can increase, causing negative impacts if discharged into the environment.

Table 9 presents toxicity studies of initial and treated solutions of single or mixtures of parabens, using different AOP technologies. In general, all the treated samples had less toxicity compared to the initial ones, concluding that photolysis, photocatalysis, and ozone-based technologies can help in reducing toxicity.

Gomes et al. [102] tested the abatement of MP, EP, and PP mixture at $1 \mathrm{mg} / \mathrm{L}$ each, by photocatalytic and catalytic ozonation, using $\mathrm{TiO}_{2} / \mathrm{NT}$. For catalytic ozonation, the light inhibition (LI) of $A$. fischeri decreased about $57 \%$, while L. sativum had a germination index (GI) increase of $90 \%$, while for single ozonation, the toxicity of $A$. fischeri decreased by $46 \%$ and occurred a GI increase of $79 \%$ for L. sativum seeds. For both species, the toxicity decreased when the treatments were applied.

Gomes et al. [121] treated $10 \mathrm{mg} / \mathrm{L}$ of each paraben in a five parabens mixture using photolysis and photocatalytic ozonation, and the toxicity was evaluated using $V$. fischeri, C. fluminea, and L. sativum. Regarding the $V$. fischeri, the treatment reduced the initial LI of $96 \%$ to $43 \%$ for the best catalyst, while C. fluminea's total mortality was reduced to zero mortality in $72 \mathrm{~h}$, except for $1 \% \mathrm{Pd}-\mathrm{TiO}_{2}$ catalyst, which led to a mortality of $29 \%$. L. sativum had an initial GI of $42 \%$ and the best results showed a GI of $112 \%$. Furthermore, Gomes et al. [26] removed a mixture of five parabens at $10 \mathrm{mg} / \mathrm{L}$ each by ozonation and catalytic ozonation using several doped $\mathrm{TiO}_{2}$ catalysts. Toxicity decreased for all the treated samples, achieving a maximum of $53.7 \%$ of inhibition decrease for $V$. fischeri, $79 \%$ mortality decrease for C. fluminea, and an increase of $50 \%$ for L. sativum, while Gomes et al. [27] tested the same but using ozonation, photolysis, photolytic ozonation, and photocatalytic ozonation, achieving a maximum decrease for photocatalytic ozonation of $60 \%$ for $V$. fischeri, $100 \%$ for C. fluminea (no mortality observed), and an increase of 70\%, achieving a maximum of $112 \%$ for L. sativum. Moreover, Gomes et al. [91] used photocatalysis with different $\mathrm{TiO}_{2}$ catalysts for the degradation of a mixture of five parabens, reaching the best results of decrease from $100 \%$ to $21 \%$ ( $79 \%$ decrease) in mortality of C. fluminea and an increase from $40 \%$ to $70 \%$ (30\% increase) for L. sativum, while $V$. fischeri showed $80 \%$ inhibition after treatment.

Comparing these studies, Gomes et al. [121] had a higher V. fischeri LI decrease of 53\%, which was similar to the results obtained by Gomes et al. [26] (53.7\%) and Gomes et al. [27] $(60 \%)$ for the same species. This represents an important behavior for the treatment technologies regarding toxicity removal, and the difference obtained by photocatalytic ozonation in Gomes et al. [121] and Gomes et al. [26] was similar to the ones obtained by catalytic ozonation of Gomes et al. [121] but better than the results obtained for photocatalysis performed by Gomes et al. [91], which showed about $80 \%$ light inhibition after treatment, which represent the worst result of these studies.

Moreover, photolytic ozonation seems to be worse than photocatalytic ozonation, which may suggest a good behavior of catalysts presence regarding the toxicity elimination. This may also suggest that the presence of catalyst can be an interesting advantage in wastewater treatment, since it can lower the treatment costs (when compared to single ozone) [27] and can also enhance the toxicity decrease. For C. fluminea total mortality, this was reduced to zero in almost all experiments in $72 \mathrm{~h}$ in the study of Gomes et al. [121], which was concordant with the results of Gomes et al. [27], but Gomes et al. [26] obtained 
mortality of $29 \%$ and $21 \%$ for single ozonation and catalytic ozonation with $\mathrm{TiO}_{2}$. Photocatalysis showed the worst results once again, with the worst clam mortality of 55\% [91]. These studies show a better behavior of photocatalytic ozonation and photolytic ozonation than catalytic ozonation and photocatalysis when doped $\mathrm{TiO}_{2}$ catalysts were used, which showed even worse results. In fact, this is interesting, since the use of ozone should easily generate intermediaries from parabens' abatement that can be more toxic than the parent compounds. However, these contaminants may have been completely degraded without affecting the toxicity. Furthermore, the behavior of photocatalytic ozonation regarding this species is similar to the one observed for A. fischeri. For L. sativum, Gomes et al. [121] achieved the best GI of $112 \%$, Gomes et al. [26] of $90 \%$, Gomes et al. [91] of 70\%, and best GI of $112 \%$ for Gomes et al. [27] study, which presents similar results and behaviors than the observed for the other species.

Fernandes et al. [103] treated the same solution than Gomes et al. [26,27,91,121] but used catalytic ozonation with $\mathrm{N}-\mathrm{TiO}_{2}$ and single ozone. The authors achieved better results of $30 \%, 30 \%$, and $20 \%$ for $C$. fluminea mortality using ozonation, catalytic ozonation with $\mathrm{TiO}_{2}$, and catalytic ozonation with $\mathrm{N}-\mathrm{TiO}_{2}$, respectively, while the initial mortality was $84 \%$ in 48 h. Regarding L. sativum, it showed an initial GI of $41.8 \%$ and had GI of $74.6 \%$, $108.6 \%$, and $123.4 \%$ for $\mathrm{O}_{3}, \mathrm{O}_{3}+\mathrm{TiO}_{2}$, and $\mathrm{O}_{3}+\mathrm{N}-\mathrm{TiO}_{2}$. The toxicity evaluation using A. fischeri showed an initial $\mathrm{LI}$ of $95.6 \%$ and $\mathrm{LI}$ of $70 \%, 73.9 \%$, and $63 \%$ for $\mathrm{O}_{3}, \mathrm{O}_{3}+\mathrm{TiO}_{2}$, and $\mathrm{O}_{3}+\mathrm{N}-\mathrm{TiO}_{2}$. In fact, compared to Gomes et al. [26], the results obtained by Fernandes et al. [103] were the worst, which may indicate a weak performance of $\mathrm{N}-\mathrm{TiO}_{2}$ for toxicity decreased when compared to $\mathrm{TiO}_{2}$ doped with noble metals.

Velegraki et al. [75] used photocatalysis for MP removal, and the toxicity was evaluated using Artemta franciscana nauplii. In this study, the formation of more toxic intermediaries occurred when the MP removal was about $39 \%$, in which an increase of $10 \%$ in toxicity was observed. However, after the complete MP removal, the intermediaries were also removed, and the solution's toxicity was similar to the initial one. Furthermore, Orak et al. [31] used cress seeds for toxicity evaluation of an MP solution that was treated with photo-Fentonlike reaction (using best operational conditions). In fact, the observed inhibition was about $1 \%$ for the treated water and about $30 \%$ for the initial MP solution.

Gmurek et al. [30] used several AOPs for the degradation of a mixture of MP, EP, PP, $\mathrm{BuP}$, and $\mathrm{BeP}$ at $10 \mathrm{mg} / \mathrm{L}$ each. Considering the treatments, regarding $A$. fischeri, the worst result was achieved for photocatalysis using several catalysts that had LI higher than $80 \%$, and the best results occurred for ozone with $\mathrm{Au}-\mathrm{TiO}_{2}$ with a $\mathrm{LI}$ of $31.4 \%$. For L. sativum, the worst GI was obtained by $43 \%$ for photocatalysis with $\mathrm{TiO}_{2}$ and the best was $112 \%$ for $\mathrm{O}_{3}$ with UVA radiation and $\mathrm{Ag}-\mathrm{TiO}_{2}$. Furthermore, the toxicity of $C$. fluminea was worst for UVA with $\mathrm{Pt}_{\mathrm{TiO}}$, with $55 \%$, and the best occurred for photocatalytic ozonation, in which all the catalysts led to $0 \%$ mortality.

A review of several toxicity studies is presented in Table 10. 
Table 10. Toxicity studies of parabens.

\begin{tabular}{|c|c|c|}
\hline Pollutant & Organism & AOP \\
\hline $\begin{array}{l}\text { Bisphenol A, Bisphenol } \\
\text { B, Diamylphthalate, } \\
\text { Butylbenzylphthalate, } \\
\text { Methylparaben, and } \\
\text { Ethylparaben }\end{array}$ & - $\quad$ Vibrio fischeri & $\begin{array}{ll}- & \text { Photolysis } \\
\text { - } & \text { Photocataly }\end{array}$ \\
\hline $\mathrm{MP}, \mathrm{EP}, \mathrm{PP}, \mathrm{BuP}$ and $\mathrm{BeP}$ & $\begin{array}{ll}\text { - } & \text { Vibrio fischeri } \\
\text { - } & \text { Corbicula } \\
\text { - } & \text { flumínea } \\
& \text { Lepidium sativum }\end{array}$ & $\begin{array}{ll}- & \text { Ozonation } \\
- & \text { Catalytic } \\
& \text { Ozonation }\end{array}$ \\
\hline
\end{tabular}

- $\quad$ Mixture of $0.3 \mathrm{mg} / \mathrm{L}$ of each pollutant in effluent from a WWTP.

- $\quad V$. fischeri showed initial toxicity of $67 \%$ and showed LI values of $48 \%$, $19 \%$, and $29 \%$ for photolysis, $\mathrm{TiO}_{2}$ $\mathrm{P} 25$, and $\mathrm{TiO}_{2}$ vlp-7000, respectively.

Reference

- Mixture of $10 \mathrm{mg} / \mathrm{L}$ each paraben in ultrapure water.

- $\quad V$. fischeri had initial inhibition of $95.1 \%$ and final inhibition of $53.6 \%$, $41.4 \%$ and $48.2 \%$ for ozonation, $\mathrm{TiO}_{2}$ and $0.5 \% \mathrm{Ag}-\mathrm{TiO}_{2}$.

- C. fluminea had initial lethal mortality in $72 \mathrm{~h}$, while for treated samples, the mortality was $29 \%$ and $21 \%$ for ozonation and $\mathrm{TiO}_{2}$.

- L. sativum showed an initial germination index (GI) of $40 \%$, while the GI was $90 \%$ for $\mathrm{Pd}$ and $\mathrm{Pt}-\mathrm{TiO}_{2}$, and $65 \%$ for $\mathrm{TiO}_{2}$.

- $\quad$ Mixture of $10 \mathrm{mg} / \mathrm{L}$ each paraben in ultrapure water.

- V. fischeri had initial light inhibition (LI) of $96 \%$. Photolytic ozonation showed LI of $60 \%$ while photocatalytic ozonation for $\mathrm{Au}-\mathrm{TiO}_{2}$, Pd-TiO $2, \mathrm{Ag}-\mathrm{TiO}_{2}, \mathrm{Pt}-\mathrm{TiO}_{2}$, and $\mathrm{TiO}_{2}$ had LI of $55 \%, 44 \%, 43 \%, 61 \%$, and $36 \%$, respectively.

- C. flumínea showed full mortality for the initial sample. All the treated samples using photolytic ozonation or photocatalytic ozonation did not show any mortality in $72 \mathrm{~h}$.

- L. sativum showed an initial GI of $42 \%$ and photolytic ozonation had GI of 93\%. Photocatalytic ozonation showed GI of $107 \%, 108 \%, 112 \%$, $107 \%$, and $90 \%$ for $\mathrm{Au}-\mathrm{TiO}_{2}, \mathrm{Pd}-\mathrm{TiO}_{2}$, $\mathrm{Ag}-\mathrm{TiO}_{2}, \mathrm{Pt}-\mathrm{TiO}_{2}$, and $\mathrm{TiO}_{2}$, respectively.

- Initial paraben mixture of $10 \mathrm{mg} / \mathrm{L}$ each paraben.

- $\quad$ The $\mathrm{EC}_{50}$ regarding C. fluminea mortality in $72 \mathrm{~h}\left(\left[\mathrm{Fe}^{2+}\right]=0.18 \mathrm{mM}\right.$ and $\left[\mathrm{H}_{2} \mathrm{O}_{2}\right]=8.8 \mathrm{mM}$ ) in MilliQ water was $40.43 \%$ for untreated samples and $80.87 \%$ for treated samples ( $1 \mathrm{~h})$.

- $\quad$ For $V$. fischeri, the $\mathrm{EC}_{50}$ using MilliQ water was $0.16 \%, 49.97 \%$ for 0 and 2 $\mathrm{min}$, respectively, while after $5 \mathrm{~min}$ the value inhibits $50 \%$ of LI. Regarding the use of river water values were $0.39 \%, 21.28 \%$, and $39.96 \%$ for 0,5 , and $60 \mathrm{~min}$. 
Table 10. Cont.

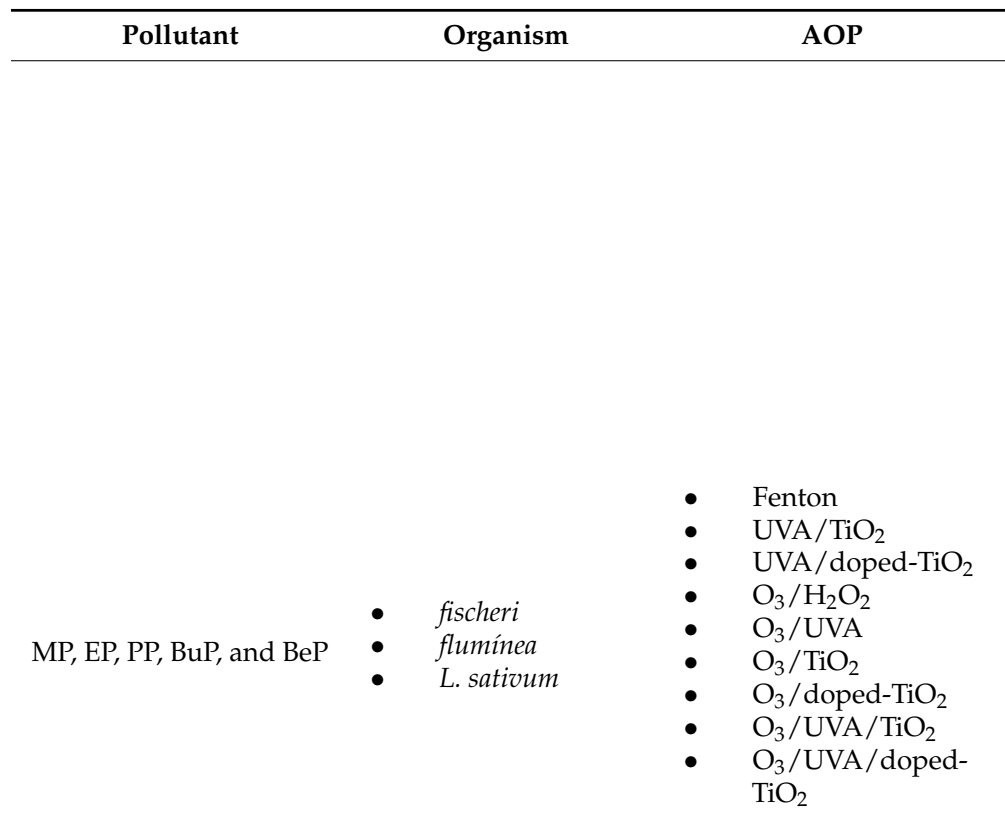

- Initial paraben mixture of $10 \mathrm{mg} / \mathrm{L}$ each paraben in ultrapure water.

- $\quad$ Fenton led to $37 \%$ mortality of $C$. fluminea.

- The use of UVA and all catalysts led to $>80 \%$ A. fischeri LI. $55 \%, 29 \%$, and $21 \%$ mortality for $C$. fluminea was achieved for UVA/ $\mathrm{Pt}-\mathrm{TiO}_{2}$, $\mathrm{UVA} / \mathrm{Pd}-\mathrm{TiO}_{2}$ and $\mathrm{UVA} / \mathrm{Ag}-\mathrm{TiO}_{2}$, respectively. The $L$ sativum GI was $43 \%, 57 \%, 70 \%, 61 \%$, and $44 \%$ for UVA with $\mathrm{TiO}_{2}, \mathrm{Pt}-\mathrm{TiO}_{2}, \mathrm{Pd}-\mathrm{TiO}_{2}$, $\mathrm{Ag}-\mathrm{TiO}_{2}$, and $\mathrm{Au}-\mathrm{TiO}_{2}$, respectively.

- The use of ozone with $\mathrm{H}_{2} \mathrm{O}_{2}, \mathrm{UVA}$, $\mathrm{TiO}_{2}$, and doped $\mathrm{TiO}_{2}(\mathrm{Pt}, \mathrm{Pd}, \mathrm{Ag}$, and $\mathrm{Au}$ ) led a $\mathrm{LI}$ of $57.1 \%, 59.9 \%$, $26.5 \%, 32.9 \%, 33.7 \%, 35.2 \%$, and $31.4 \%$, respectively, while for $C$. fluminea mortality, the values were $29 \%, 0 \%, 21 \%, 0 \%, 15 \%, 0 \%$, and $0 \%$ for the same order. Regarding the GI, values were $93 \%, 71 \%, 86 \%, 90 \% 80 \%$, and $71 \%$ for $\mathrm{O}_{3} / \mathrm{UVA}, \mathrm{O}_{3} / \mathrm{TiO}_{2}$, $\mathrm{O}_{3} / \mathrm{Pt}-\mathrm{TiO}_{2}, \mathrm{O}_{3} / \mathrm{Pd}-\mathrm{TiO}_{2}$, $\mathrm{O}_{3} / \mathrm{Ag}-\mathrm{TiO}_{2}$, and $\mathrm{O}_{3} / \mathrm{Au}-\mathrm{TiO}_{2}$, respectively.

- $\quad$ For $\mathrm{O}_{3}$ with UVA and catalysts, LI values were $36.3 \%, 61.4 \%, 44.2 \%$, $43.4 \%$, and $55.4 \%$ for $\mathrm{TiO}_{2}, \mathrm{Pt}_{-} \mathrm{TiO}_{2}$, $\mathrm{Pd}-\mathrm{TiO}_{2}, \mathrm{Ag}-\mathrm{TiO}_{2}$, and $\mathrm{Au}-\mathrm{TiO}_{2}$, respectively, while the mortality was $0 \%$ for all the catalysts. GI was $90 \%$, $107 \%, 108 \%, 112 \%$, and $107 \%$ for the same order.

- Inhibition of $30 \%$ and $1 \%$ was achieved for $5 \mathrm{mg} / \mathrm{L}$ of MP and treated water, respectively, using cress seeds.

- $\quad$ MP initial concentration of $0.1 \mathrm{~g} / \mathrm{L}$.

- Initial solution had a low toxicity. Intermediaries were formed reaching at higher toxicity of $10 \%$

MP

- Artemta franciscana nauplii

- Photocatalysis immobilization at 39\% MP removal.

- At $100 \%$ MP elimination, toxicity is practically the same as the initial solution. Intermediaries were removed.

- Mixture of $10 \mathrm{mg} / \mathrm{L}$ each paraben in ultrapure water.

- V. fischeri showed $80 \%$ inhibition after treatment.

- C. flumínea decrease from $100 \%$ (initial) to $55 \%, 21 \%$ and $29 \%$ for $0.5 \% \mathrm{Pt}-\mathrm{TiO}_{2} \mathrm{0}, 5 \%, \mathrm{Ag}-\mathrm{TiO}_{2} \mathrm{0.5} \%$ and $\mathrm{Pd}-\mathrm{TiO}_{2}$, respectively. Photolysis, $\mathrm{TiO}_{2}$ and $0.5 \% \mathrm{Au}-\mathrm{TiO}_{2}$ had

MP, EP, PP, BuP and BeP

- Vibrio fischeri

- Corbicula fluminea

- $\quad$ Lepidium sativum
- $\quad$ Photolysis - Photocatalysis initial sample.

- L. sativum had initial GI of $40 \%$, while $\mathrm{Ag}, \mathrm{Pt}$, and Pd catalysts showed GI of $61 \%, 57 \%$, and $70 \%$, respectively. Photolysis, $\mathrm{TiO}_{2}$ and $0.5 \% \mathrm{Au}-\mathrm{TiO}_{2}$ had similar results to the initial. 
Table 10. Cont.

\begin{tabular}{|c|c|c|c|c|}
\hline Pollutant & Organism & AOP & Results & Reference \\
\hline $\mathrm{PP}$ and $\mathrm{BuP}$ & $\begin{array}{l}\text { - Ceriodaphnia } \\
\text { dubia }\end{array}$ & - $\quad$ Photolysis & $\begin{array}{l}\text { - Untreated samples present acute } \\
\text { toxicity } 53.3 \% \text { and } 100 \% \text { for single PP } \\
\text { and BuP, respectively, and } 84 \% \text { for } \\
\text { the mixture of PP + BuP. } \\
\text { Photolysis led to a decrease in toxicity } \\
\text { for } 33.3 \% \text { and } 76.6 \% \text { for single PP and } \\
\text { BuP at half the time of reaction, and } \\
\text { at the end of treatment, toxicity was } \\
\text { residually } 3.3 \% \text { and } 8.3 \% \text { for the same } \\
\text { parabens. Regarding the mixture of } \\
\text { parabens, at half the time, toxicity } \\
\text { was } 72 \% \text { and at the end was } 4 \% \text {. }\end{array}$ & [93] \\
\hline $\mathrm{MP}, \mathrm{EP}$, and PP & $\begin{array}{ll}\text { - } & \text { Aliivibrio fischeri } \\
\text { - } & \text { Lepidium sativum }\end{array}$ & $\begin{array}{ll}- & \text { Ozonation } \\
- & \text { Photocatalytic } \\
& \text { Ozonation }\end{array}$ & $\begin{array}{l}\text { Mixture of } 1 \mathrm{mg} / \mathrm{L} \text { each paraben in } \\
\text { ultrapure water or in municipal } \\
\text { wastewater (MWW). } \\
\text { A. fischeri exhibited a LI of } 41 \% \text { for } \\
\text { MWW and } 100 \% \text { for MWW parabens } \\
\text { mixture, while the treated MWW } \\
\text { parabens mixture had LI of } 54 \% \text { and } \\
43 \% \text { for ozonation and photocatalytic } \\
\text { ozonation. } \\
\text { L. sativum showed an initial GI of } 70 \% \\
\text { and } 7 \% \text { for MWW and MWW } \\
\text { parabens mixture, respectively. } \\
\text { Treated samples had values of } 86 \% \\
\text { and } 97 \% \text { for ozonation and } \\
\text { photocatalytic ozonation, } \\
\text { respectively. }\end{array}$ & {$[102]$} \\
\hline $\mathrm{MP}, \mathrm{EP}, \mathrm{PP}, \mathrm{BuP}$, and BeP & $\begin{array}{ll}\text { - } & \text { V. fischeri } \\
\text { - } & \text { C.fluminea } \\
\text { - } & \text { L. sativum }\end{array}$ & $\begin{array}{ll}- & \text { Ozonation } \\
- & \text { Catalytic } \\
& \text { Ozonation }\end{array}$ & $\begin{array}{l}\text { - } 10 \mathrm{mg} / \mathrm{L} \text { of parabens in ultrapure } \\
\text { water. } \\
\text { C. fluminea mortality }(48 \mathrm{~h} \text { ) were } 84 \% \text {, } \\
30 \%, 30 \% \text {, and } 20 \% \text { for initial } \\
\text { solution, } \mathrm{O}_{3}, \mathrm{O}_{3}+\mathrm{TiO}_{2} \text { and } \mathrm{O}_{3}+ \\
2.5 \% \mathrm{~N}-\mathrm{TiO}_{2}, \text { using best results. } \\
\text { - } \text { sativum } \mathrm{GI} \text { presented } 41.8 \%, 74.6 \% \text {, } \\
108.6 \% \text {, and } 123.4 \% \text { for initial } \\
\text { solution, } \mathrm{O}_{3}, \mathrm{O}_{3}+\mathrm{TiO}_{2} \text { and } \mathrm{O}_{3}+ \\
5 \% \mathrm{~N}-\mathrm{TiO}_{2} \text {. } \\
\text { A. fischeri had } \mathrm{LI} \text { of } 95.6 \%, 70 \% \text {, } \\
73.9 \% \text {, and } 63 \% \text { for initial solution, } \\
\mathrm{O}_{3}, \mathrm{O}_{3}+\mathrm{TiO}_{2} \text { and } \mathrm{O}_{3}+10 \% \mathrm{~N}-\mathrm{TiO}_{2} \\
\text { for the best results. }\end{array}$ & {$[103]$} \\
\hline $\mathrm{MP}, \mathrm{EP}, \mathrm{PP}, \mathrm{BuP}$, and $\mathrm{BeP}$ & - $\quad$ L. sativum & $\begin{array}{l}\text { Photocatalytic } \\
\text { ozonation }\end{array}$ & $\begin{array}{l}\text { - } 10 \mathrm{mg} / \mathrm{L} \text { of parabens in river and } \\
\text { wastewater. } \\
\text { Initial GI of } 67 \% \text { and } 75 \% \text { for river } \\
\text { and wastewater, and after } 120 \mathrm{~min} \text {, } \\
\text { treatment was } 146 \% \text { and } 139 \% \text {, } \\
\text { respectively. }\end{array}$ & {$[104]$} \\
\hline $\mathrm{MP}, \mathrm{EP}, \mathrm{PP}, \mathrm{BuP}$, and BeP & $\begin{array}{ll}\text { - } & \text { Raphidocelis } \\
& \text { subcapitata } \\
\text { - } & \text { Lemna minor } \\
\text { - } & \text { Daphnia Magna } \\
\text { - } & \text { Corbicula } \\
& \text { fluminea } \\
\text { - } & \text { Lepidium sativum }\end{array}$ & $\begin{array}{l}-\quad \text { Ozonation } \\
-\quad \text { Catalytic } \\
\text { Ozonation }\end{array}$ & $\begin{array}{l}\text { Mixture of } 0.62,5 \text {, and } 10 \mathrm{mg} / \mathrm{L} \text { of } \\
\text { each paraben in ultrapure water. } \\
\text { For } 10 \mathrm{mg} / \mathrm{L} \text { solution, the } D . \text { magna } \\
\text { immobilization, C. fluminea mortality, } \\
\text { R. subcapitata yield inhibition, } L \text {. } \\
\text { sativum GI and L. minor yield } \\
\text { inhibition was } 100 \%, 100 \%, 84 \%, 49 \% \text {, } \\
\text { and } 52 \% \text { respectively, while for } 5 \\
\text { mg/L each paraben was } 95 \%, 47 \% \text {, } \\
83 \%, 68 \% \text {, and } 30 \% \text {, and for } 0.62 \\
\text { mg/L each, these parameters were } \\
0 \%, 0 \%, 13 \%, 100 \% \text {, and }-50 \% \text {. }\end{array}$ & {$[120]$} \\
\hline
\end{tabular}


Table 10. Cont.

\begin{tabular}{|c|c|c|c|c|}
\hline Pollutant & Organism & AOP & Results & Reference \\
\hline $\mathrm{MP}, \mathrm{EP}, \mathrm{PP}, \mathrm{BuP}$, and BeP & $\begin{array}{l}\text { - } \quad \text { Vibrio fischeri } \\
\text { - } \quad \text { Corbicula } \\
\text { flumínea } \\
\text { - Lepidium satioum }\end{array}$ & $\begin{array}{ll}- & \text { Photolysis } \\
-\quad & \text { Photocatalytic } \\
\text { Ozonation }\end{array}$ & $\begin{array}{l}\text { - Mixture of } 10 \mathrm{mg} / \mathrm{L} \text { each paraben in } \\
\text { ultrapure water. } \\
\text { V. fischeri exhibited initial inhibition } \\
\text { of } 96 \% \text {, while the best }\left(0.5 \% \mathrm{Ag}-\mathrm{TiO}_{2}\right) \\
\text { and worst }\left(1 \% \mathrm{Pd}-\mathrm{TiO}_{2}\right) \text { catalyst had } \\
43 \% \text { and } 72 \% \text { inhibition, respectively. } \\
\text { C. fluminea had } 100 \% \text { mortality in } 72 \\
\text { h for the initial mixture and } 29 \% \\
\text { mortality for } 1 \% \mathrm{Pd}-\mathrm{TiO}_{2} \text {. All the } \\
\text { other samples treated with the other } \\
\text { catalysts had } 0 \% \text { of mortality. } \\
\text { L. sativum showed an initial } \mathrm{GI} \text { of } \\
42 \% \text {, with best results of } 112 \% \\
\left(0.5 \% \mathrm{Ag}-\mathrm{TiO} \mathrm{O}_{2} \text { and } 0.1 \% \mathrm{Pt}-\mathrm{TiO}_{2}\right) \text { and } \\
\text { worst results of } 80 \%\left(1 \% \mathrm{Ag}-\mathrm{TiO}_{2}\right) \text {. }\end{array}$ & [121] \\
\hline $\begin{array}{l}\mathrm{MP}, \mathrm{PP}, \mathrm{BuP}, \mathrm{BeP} \text { and } \\
\text { 4-benzophenone }\end{array}$ & $\begin{array}{ll}\text { - } & \text { Daphnia Magna } \\
\text { - } & \text { Ptmephales } \\
\text { - } & \text { promelas } \\
& \text { Tetrahymena } \\
\text { - } \quad \text { Vibrio fischeri } \\
\text { - } \quad \text { Photobacterium } \\
\text { - } \quad \text { Orognathi } \\
\quad \text { Oryztas lattipes }\end{array}$ & - (non-applicable) & 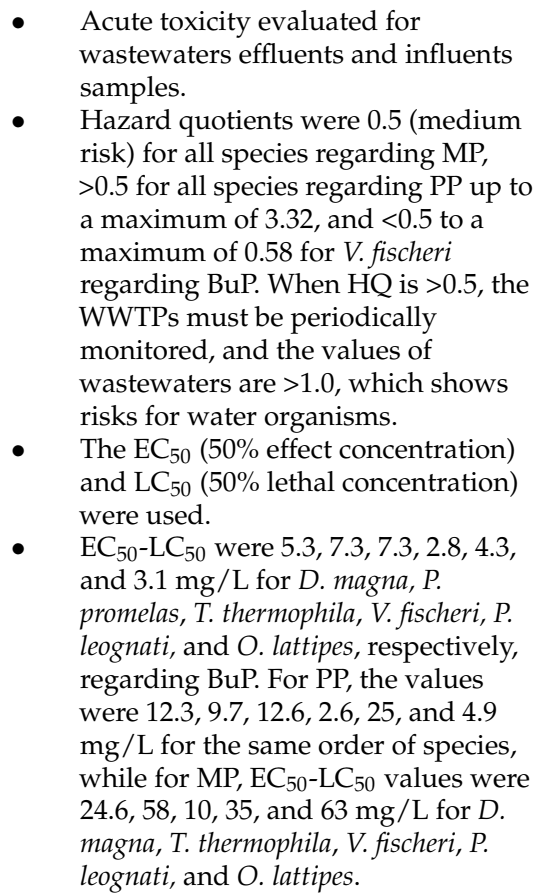 & [122] \\
\hline
\end{tabular}

\section{Treatment Costs}

Besides the efficiency of the paraben's abatement, it is important to evaluate the impact of AOPs in terms of economic aspect since these kinds of processes are mainly associated with high operational costs.

All the presented costs pertain to different paradigms, so the values themselves are affected by several issues such as the location of the study, quantity treated, effluent characteristics, energy price, types of equipment, treatment time, etc.

In this work, the $\mathrm{kWh}$ values were converted, considering the price of industrial electricity referred by Gomes et al. [123] of $0.1276 € / \mathrm{kWh}$, and dollars (\$) were converted to Euros $(€)$, considering $\$ 1=€ 0.84$. It should be noted that a complete economic analysis must consider maintenance and costs related to operators, among other factors, such as contingencies, cost of raw materials, utilities, etc. [124]. Furthermore, if it involves the treatment of effluents, it should be noted that the choice of technologies must include reactor design, maintenance costs, and other operating costs [27].

Vela et al. [3] removed $90 \%$ of a mixture of methylparaben, ethylparaben, bisphenol A, bisphenol B, diamylphthalate, and butyl-benzylphthalate by photocatalysis with $\mathrm{ZnO}$, 
$\mathrm{TiO}_{2} \mathrm{P} 25$, and $\mathrm{TiO}_{2} \mathrm{Vlp} 7000$. The treatment costs were $103 € / \mathrm{m}^{3}, 149 € / \mathrm{m}^{3}$, and $285 € / \mathrm{m}^{3}$, respectively, considering the facility and project contingency, engineering project, consumables, service, and overhead cost. For the use of $\mathrm{ZnO}$ and P25, the treatment related only to parabens costs about $30 € / \mathrm{m}^{3}$ and $84 € / \mathrm{m}^{3}$, respectively. This value is slightly more expensive than other values reported in Table 11, but this estimation may be more accurate since it already considers some important project (estimation) costs, and it is regarding a pilot-scale installation.

Table 11. Associated costs for different parabens removal technologies.

\begin{tabular}{|c|c|c|c|c|}
\hline Treatment & Contaminant & Associated Costs & Observations & Reference \\
\hline Photocatalysis w/ZnO & $\begin{array}{l}\text { MP, EP, Bisphenol A, } \\
\text { Bisphenol B, } \\
\text { Diamylphthalate and } \\
\text { Butyl-benzylphthalate }\end{array}$ & $103 € / \mathrm{m}^{3}$ & $\begin{array}{l}\text { - } \quad \text { Regarding Murcia, Spain } \\
\text { Considering treatment ( } 3000 \mathrm{~h} / \text { year } \\
\text { of sun; } 8 \mathrm{~h} / \text { day, } 365 \text { days / year), } \\
\text { consumable, service, and other costs } \\
\text { related to the project. } \\
\text { - } \quad 90 \% \text { contaminants removal. } \\
\text { - For parabens (MP and EP) the value } \\
\text { is } 30 € / \mathrm{m}^{3}\end{array}$ & [3] \\
\hline
\end{tabular}

- $\quad$ Regarding Murcia, Spain

- Considering treatment $(3000 \mathrm{~h} /$ year of sun; $8 \mathrm{~h}$ /day, 365 days/year),

Photocatalysis $\mathrm{w} / \mathrm{TiO}_{2}$ P25

MP, EP, Bisphenol A, Bisphenol B, Diamylphthalate and Butyl-benzylphthalate

, Be, Bisphenol A Bisphenol B,

Photocatalysis $\mathrm{w} / \mathrm{TiO}_{2}$ vlp 7000

Diamylphthalate and

Butyl-benzylphthalate

$285 € / \mathrm{m}^{3}$

- Consider Murcia, Spain consumable, service and other costs related to the project.

- $\quad 90 \%$ contaminants removal.

- $\quad$ For parabens (MP and EP) the value is $84 € / \mathrm{m}^{3}$

- Regarding Murcia, Spain

Considering treatment $(3000 \mathrm{~h} /$ year of sun; $8 \mathrm{~h} /$ day, 365 days/year), consumable, service, and other costs related to the project.

- $\quad 90 \%$ contaminants removal

\begin{tabular}{|c|c|c|c|c|}
\hline UVC & $\begin{array}{c}\mathrm{MP}, \mathrm{EP}, \mathrm{PP}, \mathrm{BuP}, \mathrm{BeP} \text { and } \\
\text { p-HBA }\end{array}$ & $7 € / \mathrm{gEDC}$ & $\begin{array}{l}\text { - } \quad 100 \% \text { contaminant removal in } 8 \mathrm{~h} \\
\text { Regarding a mixture of parabens and } \\
\text { p-HBA }\end{array}$ & [35] \\
\hline $\mathrm{UVC} / \mathrm{H}_{2} \mathrm{O}_{2}$ & $\begin{array}{l}\mathrm{MP}, \mathrm{EP}, \mathrm{PP}, \mathrm{BuP}, \mathrm{BeP} \text { and } \\
\text { p-HBA }\end{array}$ & $0.5 € / \mathrm{gEDC}$ & $\begin{array}{l}\text { - } \quad 100 \% \text { contaminant removal in } 0.5 \mathrm{~h} \\
\text { Regarding a mixture of parabens and } \\
\text { p-HBA }\end{array}$ & [35] \\
\hline $\mathrm{UV} / \mathrm{H}_{2} \mathrm{O}_{2}$ & $\mathrm{EP}$ & $5.93 € / \mathrm{m}^{3}$ & $\begin{array}{l}\text { - The total cost is } 7.06 \$ / \mathrm{m}^{3} \text {. } \\
\text { Regarding EP degradation with } \\
\text { initial concentration of } 30 \mu \mathrm{M} \text {, } \\
\text { reagent initial concentration of } 1 \mathrm{mM} \text {, } \\
\mathrm{pH}=6.5 \text {, and reaction time of } 90 \mathrm{~min} \text {. }\end{array}$ & [73] \\
\hline UV/PS & $\mathrm{EP}$ & $5.26 € / \mathrm{m}^{3}$ & $\begin{array}{l}\text { - The total cost is } 6.26 \$ / \mathrm{m}^{3} \text {. } \\
\text { Regarding EP degradation with } \\
\text { initial concentration of } 30 \mu \mathrm{M}, \\
\text { reagent initial concentration of } 1 \mathrm{mM} \text {, } \\
\mathrm{pH}=6.5 \text {, and reaction time of } 90 \mathrm{~min} \text {. }\end{array}$ & [73] \\
\hline UV/PMS & $\mathrm{EP}$ & $12.28 € / \mathrm{m}^{3}$ & $\begin{array}{l}\text { - The total cost is } 14.62 \$ / \mathrm{m}^{3} \text {. } \\
\text { Regarding EP degradation with } \\
\text { initial concentration of } 30 \mu \mathrm{M} \text {, } \\
\text { reagent initial concentration of } 1 \mathrm{mM} \text {, } \\
\mathrm{pH}=6.5 \text {, and reaction time of } 90 \mathrm{~min} \text {. }\end{array}$ & [73] \\
\hline
\end{tabular}


Table 11. Cont.

\begin{tabular}{|c|c|c|c|c|}
\hline Treatment & Contaminant & Associated Costs & Observations & Reference \\
\hline UV/PS & MP & $6.92 € / \mathrm{m}^{3}$ & $\begin{array}{l}\text { - The total cost is } 54.2 \mathrm{kWh} / \mathrm{m}^{3} \text {. } \\
\text { Regarding MP degradation with } \\
\text { initial concentration of } 32.8 \mu \mathrm{M} \text {, } \\
\text { initial persulfate concentration of } \\
1 \mathrm{mM}, \mathrm{pH}=6.5 \text {, and reaction time of } \\
90 \mathrm{~min} \text {. }\end{array}$ & [74] \\
\hline Electrocatalysis & MP & $0.19-4.59 € / \mathrm{kg}$ & $\begin{array}{l}\text { - Regarding MP removal }(100 \mathrm{mg} / \mathrm{L} \text { in } \\
0.05 \mathrm{~mol} / \text { of } \mathrm{K}_{2} \mathrm{SO}_{4} \text { electrolyte } \\
\text { solution) by electrochemical } \\
\text { oxidation using BDD anode. } \\
\text { MP removal between } 19.85 \text { and } \\
34.65 \% \text {. } \\
\text { Values were } 1.49,3.28,7.01,15.61, \\
\text { and } 36.0 \mathrm{kWh} / \mathrm{kg} \text { for } 1.35,2.70,5.44 \\
10.8, \text { and } 21.6 \mathrm{~mA} / \mathrm{cm}^{2} \text {. }\end{array}$ & [112] \\
\hline Electrocatalysis & MP & $0.03-0.92 € / \mathrm{m}^{3}$ & $\begin{array}{l}\text { - } \quad \text { Regarding MP removal }(100 \mathrm{mg} / \mathrm{L} \text { in } \\
0.05 \mathrm{~mol} / \text { of } \mathrm{K}_{2} \mathrm{SO}_{4} \text { electrolyte } \\
\text { solution) by electrochemical } \\
\text { oxidation using BDD anode. } \\
\text { MP removal between } 19.85 \text { and } \\
34.65 \% \text {. } \\
\text { Values were } 0.26,0.54,1.21,2.75, \text { and } \\
7.24 \mathrm{kWh} / \mathrm{m}^{3} \text { for } 1.35,2.70,5.44,10.8, \\
\text { and } 21.6 \mathrm{~mA} / \mathrm{cm}^{2} \text {. }\end{array}$ & [112] \\
\hline $\begin{array}{l}\text { DBD plasma with } \\
\text { ZnO-rGO nanosheets }\end{array}$ & MP & $0.01-0.14 € / g$ & $\begin{array}{l}\text { - The cost is } 0.119 \$ / \mathrm{g} \text { for MP initial } \\
\text { concentration of } 2 \mathrm{mg} / \mathrm{L}, 0.024 \$ / \mathrm{g} \\
\text { for } 10 \mathrm{mg} / \mathrm{L} \text { and } 0.012 \$ / \mathrm{g} \text { for } \\
20 \mathrm{mg} / \mathrm{L} \text {. } \\
\text { Regarding } \mathrm{P}=20 \mathrm{~W}, \mathrm{t}=15 \mathrm{~min}, \\
\mathrm{~V}=200 \mathrm{~mL}, \mathrm{ZnO}-\mathrm{rGO} \\
\text { dose }=0.015 \mathrm{~g} / \mathrm{L} \text { and } \mathrm{pH}=7\end{array}$ & [117] \\
\hline Photocatalysis & MP & $84 € / g$ & $\begin{array}{l}\text { - } \mathrm{TiO}_{2} \text { dose }=2 \mathrm{~g} / \mathrm{L} \text {, initial } \\
\text { concentration }=10 \mathrm{mg} / \mathrm{L}, \mathrm{pH}=6, \\
\mathrm{~V}=25 \mathrm{~mL}, \text { and } \mathrm{P}=125 \mathrm{~W} \\
\text { Regarding } \mathrm{MP} \text { degradation, the price } \\
\text { is } 100 \$ \mathrm{~g} \text {. }\end{array}$ & [117] \\
\hline Photocatalysis & EP & $166.25-443.33 € / g$ & $\begin{array}{l}\text { Price is } 263.889,197.917, \text { and } 527.778 \\
\$ / \mathrm{g} \text { for initial concentration of } 0.3 \\
\mathrm{mg} / \mathrm{L}(\mathrm{t}=60 \mathrm{~min}), 0.6 \mathrm{mg} / \mathrm{L}(\mathrm{t}=90 \\
\mathrm{min}) \text { and } 0.15 \mathrm{mg} / \mathrm{L}(\mathrm{t}=60 \mathrm{~min}) \\
\text { respectively and } \mathrm{P}=100 \mathrm{~W} \text { and } \mathrm{V}= \\
120 \mathrm{~mL} \text {. }\end{array}$ & {$[97,117]$} \\
\hline Ultrasonic & MP & $570-1050 € / g$ & $\begin{array}{l}\text { - Initial concentration of } 1.52 \mathrm{mg} / \mathrm{L} \text { at } \\
\mathrm{pH}=4.6 \text {. } \\
\text { Price is } 678.571,1417.910 \text {, and } 1250 \\
\$ / \mathrm{g} \text { for } \mathrm{P}=7 \mathrm{~W} / \mathrm{mL}(\mathrm{t}=90 \mathrm{~min}), \\
\mathrm{P}=22.75 \mathrm{~W} / \mathrm{mL}(\mathrm{t}=60 \mathrm{~min}), \text { and } \\
\mathrm{P}=40.25 \mathrm{~W} / \mathrm{mL}(\mathrm{t}=30 \mathrm{~min}), \\
\text { respectively. }\end{array}$ & {$[117,118]$} \\
\hline $\begin{array}{c}\text { Ozonation } \mathrm{w} / \text { Vulcanic } \\
\text { rocks }\end{array}$ & $\mathrm{MP}, \mathrm{EP}, \mathrm{PP}, \mathrm{BeP}$, and $\mathrm{BuP}$ & $0.08 € / \mathrm{m}^{3}$ & $\begin{array}{l}\text { - } 10 \mathrm{mg} / \mathrm{L} \text { mixture of MP, EP, PP, BeP, } \\
\text { and BuP in ultrapure water } \\
\text { - } \quad \text { Associated treatment costs } \\
\text { - } \quad \text { Total contaminants removal } \\
\text { - } \quad \text { Value is } 0.66 \mathrm{kWh} / \mathrm{m}^{3}\end{array}$ & [125] \\
\hline
\end{tabular}


Table 11. Cont.

\begin{tabular}{|c|c|c|c|c|}
\hline Treatment & Contaminant & Associated Costs & Observations & Reference \\
\hline Ozonation & MP, EP, PP, BeP, and BuP & $0.26 € / \mathrm{m}^{3}$ & $\begin{array}{l}\text { - } \quad 10 \mathrm{mg} / \mathrm{L} \text { mixture of MP, EP, } \mathrm{PP}, \mathrm{BeP}, \\
\text { and BuP in ultrapure water } \\
\text { - } \quad \text { Associated treatment costs in } 120 \mathrm{~min} \\
\text { - } \quad \text { Value is } 2.04 \mathrm{kWh} / \mathrm{m}^{3}\end{array}$ & [125] \\
\hline $\mathrm{O}_{3}+\mathrm{UVA}$ & $\mathrm{MP}, \mathrm{EP}, \mathrm{PP}, \mathrm{BeP}$, and BuP & $1.91 € / \mathrm{m}^{3}$ & $\begin{array}{l}\text { - } 10 \mathrm{mg} / \mathrm{L} \text { mixture of MP, EP, } \mathrm{PP}, \mathrm{BeP}, \\
\text { and BuP in ultrapure water } \\
\text { - } \quad \text { Associated treatment costs in } 90 \mathrm{~min} \\
\text { - } \quad \text { Value is } 15 \mathrm{kWh} / \mathrm{m}^{3}\end{array}$ & [125] \\
\hline $\mathrm{O}_{3}+\mathrm{TiO}_{2}$ & $\mathrm{MP}, \mathrm{EP}, \mathrm{PP}, \mathrm{BeP}$, and BuP & $0.11 € / \mathrm{m}^{3}$ & $\begin{array}{l}\text { - } 10 \mathrm{mg} / \mathrm{L} \text { mixture of MP, EP, } \mathrm{PP}, \mathrm{BeP}, \\
\text { and BuP in ultrapure water } \\
\text { - } \quad \text { Associated treatment costs in } 120 \mathrm{~min} \\
\text { - } \quad \text { Value is } 0.84 \mathrm{kWh} / \mathrm{m}^{3}\end{array}$ & [125] \\
\hline $\mathrm{O}_{3}+\mathrm{TiO}_{2}+\mathrm{UVA}$ & MP, EP, PP, BeP, and BuP & $1.20 € / \mathrm{m}^{3}$ & $\begin{array}{l}\text { - } 10 \mathrm{mg} / \mathrm{L} \text { mixture of MP, EP, } \mathrm{PP}, \mathrm{BeP}, \\
\text { and BuP in ultrapure water } \\
\text { - } \quad \text { Associated treatment costs in } 60 \mathrm{~min} \\
\text { - } \quad \text { Value is } 9.4 \mathrm{kWh} / \mathrm{m}^{3}\end{array}$ & [125] \\
\hline
\end{tabular}

Gomes et al. [27] estimated the degradation costs of a mixture of MP, EP, PP, BeP, and $\mathrm{BuP}$ by photocatalytic ozonation with UVA, catalytic ozonation, photolytic ozonation with UVA, and single ozonation, estimating an expense of $2.04 \mathrm{kWh} / \mathrm{m}^{3}\left(0.26 € / \mathrm{m}^{3}\right)$, $15 \mathrm{kWh} / \mathrm{m}^{3}\left(1.91 € / \mathrm{m}^{3}\right), 0.84 \mathrm{kWh} / \mathrm{m}^{3}\left(0.11 € / \mathrm{m}^{3}\right)$, and $9.4 \mathrm{kWh} / \mathrm{m}^{3}\left(1.20 € / \mathrm{m}^{3}\right)$ for these techniques, respectively. In this study, the use of $\mathrm{TiO}_{2}$ catalyst seems to decrease the associated treatment costs. Dhaka et al. [73] used different reagents with UV radiation for EP abatement, achieving a value of $7.06 \$ / \mathrm{m}^{3}\left(5.93 € / \mathrm{m}^{3}\right), 6.26 \$ / \mathrm{m}^{3}\left(5.26 € / \mathrm{m}^{3}\right)$, and $14.62 \$ / \mathrm{m}^{3}\left(12.28 € / \mathrm{m}^{3}\right)$ for UV/ $\mathrm{H}_{2} \mathrm{O}_{2}$, UV/PS, and UV/PMS, respectively, and Dhaka et al. [74] removed MP by UV/PS, estimating costs of $54.2 \mathrm{kWh} / \mathrm{m}^{3}\left(6.92 € / \mathrm{m}^{3}\right)$. These technologies are more expensive than the ones studied by Gomes et al. [27], and this can be related to the costs related to the reagents and with radiation. Furthermore, in Gomes et al.'s [27] study, the presence of catalyst and radiation seems to decrease the technologies' costs, and the use of single UVA with ozone is cheaper than catalyst with ozone and then UVA with catalyst and ozone. Catalytic ozonation was the most expensive treatment process, but this was not verified when photocatalytic ozonation was used. Moreover, this study suggests that the use of UVA makes the treatment more expensive but reduces the time of treatment, which can lead to smaller equipment and cheaper investment costs. When volcanic rocks are considered as the catalyst, the technology price decreases to $0.08 € / \mathrm{m}^{3}$, which may indicate a significant decrease in operational costs when low-price catalysts are used and when UV radiation is not considered.

Furthermore, Nian et al. [117] calculated the costs of Lin et al. [7] photocatalysis with $\mathrm{TiO}_{2}$ for MP removal, achieving treatment costs of $100 \$ / \mathrm{g}(84 € / \mathrm{g})$, and Sasi et al. [118] used sonochemical oxidation for methylparaben abatement. The cost is dependent on the chosen power density, but the cost varied from $197.92 \$ / \mathrm{g}$ to $527.78 \$ / \mathrm{g}(570-1050 € / \mathrm{g})$. These studies report high expensive technologies, which present a huge disadvantage in using these treatments applied at industrial scale.

Steter et al. [112] achieved an MP removal comprised between $19.85 \%$ and $34.65 \%$, using electrocatalysis with a BDD anode. The cost is related to the energy consumption, which is dependent on current density and was estimated to be between about $1.49 \mathrm{kWh} / \mathrm{kg}$ and $36 \mathrm{kWh} / \mathrm{kg}(0.19-4.59 € / \mathrm{kg})$ and $0.26 \mathrm{kWh} / \mathrm{m}^{3}$ and $7.24 \mathrm{kWh} / \mathrm{m}^{3}\left(0.03-0.92 € / \mathrm{m}^{3}\right)$. In fact, the real price for this technology is more expensive, since the costs with the BDD, the other electrodes, the electrolyte solution, which needs to be replaced several times (the costs related to reagents), etc. are not considered. Furthermore, these energy costs are only 
related to single MP removal, and if more parabens (in mixture) are considered, the price will normally increase.

Table 11 shows some associated costs of different advanced oxidation processes in the abatement of parabens mixtures as a pollutant.

Considering the presented studies regarding the treatment costs, a solid comparison and analysis can only be completed if several parameters are considered. In this case, this is difficult to do, since these parameters are different from study and study and due to the fact that not the same parameters are considered by all the studies. However, the state of the art was analyzed based on several studies from literature, and this should motivate more investigation in this subject.

Moreover, from doing an ad hoc analysis, it seems that the technologies using different oxidizing agents are more expensive than others using catalysts or radiation, which can be expected since the use of reagents should enhance the operational costs because these agents cannot be recovered. The use of sonolysis and some photocatalytic degradation treatments seems to be also expensive, but other reported works using ozonation, catalytic ozonation, and photocatalytic ozonation with $\mathrm{TiO}_{2}$ show low values associated. In general, it seems that the use of catalysts reduces the operational costs, but the use of UV radiation and the catalyst increases the related costs as well. Therefore, a balance between the operational costs, toxicity abatement, and pollutants removal performance should be considered to choose the technology for wastewater treatment. Furthermore, the values reported by Vela et al. [3] exhibit values from a study at a pilot scale regarding a real treatment plant, and it already considers some important project variables, parameters, and costs that must be taken in economic analysis. Compared to the studies at the laboratory scale, higher values were reached, and these values should be closer to real values at the industrial scale.

To understand the real values related to these technologies, extensive in-depth studies at a real scale for the same effluent and the same operational conditions should be done using the different AOP technologies.

\section{Future Perspectives}

The elimination of parabens and other CECs has been studied using different AOP technologies over the years by different authors. However, much research must be done before these can be easily implemented with low costs and in an environmentally friendly manner.

In general, and regarding the treatment of parabens, it seems that the use of catalysts should be preferred to the use of radiation or reagents alone. Furthermore, to lower the catalyst cost, it is important to guarantee that these can be used several times and can be recovered, regenerated, and reused. The use of radiation and catalyst should be considered depending on the technique to be applied, since some technologies, such as photocatalysis, need radiation to work. If the catalyst can be activated by solar radiation, the costs related to these technologies should be lower and attractive for industrial implementation. The common catalyst that is reported $\left(\mathrm{TiO}_{2}\right)$ cannot be activated by this type of radiation or by visible radiation, but it is already known that this can be possible with catalyst doping. Furthermore, another thing to turn the industrial application closer is the use of immobilized catalysts, since the most used ones are present in powder form, and this can make industrial application difficult, since the powder will need more separation and recovery units, which can be traduced into more equipment, energy, labor, or resuming more operational and investment costs.

During the use of different AOPs, it is noticed that the poor mineralization and the increase in toxicity can occur due to the generation of more (toxic) by-products (or, in other words, the lack of complete oxidation into $\mathrm{CO}_{2}$ and $\mathrm{H}_{2} \mathrm{O}$ ). This parameter should always be considered since it is possible to remove the wanted target compounds while, on the other hand, generating more toxic compounds that, when released into the environment, could have a worse impact than the initial pollutant's solution. 
Moreover, in the AOP treatment designs, the associated costs (investment and operational costs) are another important evaluation parameter for the choice of the technology to be used. In fact, one major disadvantage of this group of advanced treatments is the associated high costs, especially related to energy and reagents consumption; this problem needs to be overcome in order to make these technologies feasible. Furthermore, in some of the countries already affected by water scarcity, the costs may be the biggest obstacle for advanced wastewater treatment technologies.

With this, there are many parameters that need to be considered and optimized for the implementation of these technologies on an industrial scale, but it is important that in the near future, the implementation of easily operational, efficient, low-cost, and environmentally friendly AOPs technologies be applied for real wastewater treatment.

So, for future perspectives, it is important to

- $\quad$ Produce high-performance catalysts with lower costs;

- Dope and support catalyst to allow their reuse and the use of other types of radiation, such as solar radiation;

- $\quad$ Produce cheaper and more eco-friendly radiation sources;

- $\quad$ Test different types of reactors and operational parameters;

- Test different AOP technologies for the same effluent on a real scale;

- Study in depth the toxicological effects in different species and impacts in the environment;

- Study in depth the operational economics for different technologies.

Based on the reviewed works, regarding parabens' treatment (which may not be applied to other CECs or real wastewater solutions due to the diversity of compounds presented in wastewaters from different places), authors appear to be focused on photocatalysis and ozone-based solutions. In fact, some disadvantages of other technologies such as the generation of iron sludge in Fenton's process, the high energy needed and low efficiency in sonochemical methods, the high costs and difficult reuse of specific materials (electrodes) that can be related to the use of electrochemical oxidation, the high amount of reagent needed in the use of oxidizing agents, or the needed severe conditions in wet air oxidation may be responsible for the lack of improvement in these technologies. Although photocatalysis and ozone-based technologies present disadvantages, the solution to overcome these problems can be easily explored, which, together with its operational simplicity and high efficiency, can be the reason why these technologies are the subject of several studies by different authors. For example, the poor mineralization of ozonolysis can be diminished by using catalysts. Furthermore, it is important to consider that the use of combined AOPs or the use of AOP technology followed by secondary treatment or other combination can have a synergetic effect. For example, if the wastewater solution is very blurred, the use of photocatalysis will require a pretreatment of coagulation and flocculation (for example) to make the wastewater less blurred and so the radiation can penetrate it. Furthermore, for the poor mineralization of ozonolysis, or even to complete the mineralization of catalytic ozonation or photocatalytic ozonation, a secondary treatment technology can probably be used after this treatment. These are only a few hypotheses of problems that can be related to the photocatalysis or ozone technologies use and their possible solutions.

However, none of these technologies should be removed from consideration until some research for the treatment of a specific wastewater is carried out. In fact, the choice of technology depends on several parameters already mentioned, and others, such as the volume/flow of wastewater to treat, wastewater composition, and wastewater properties ( $\mathrm{pH}, \mathrm{COD}, \mathrm{BOD}$, turbidity, etc.). It is also important to note that AOPs can/should be implemented considering other treatment technologies that are already common in WWTPs (as preliminary, primary, and secondary treatments) to take advantage of their synergetic effect, increasing the treatment station efficiency (as an entire treatment) and possibly reducing costs in project and operational treatments. 


\section{Conclusions}

Different AOP technologies are discussed in this work for parabens degradation from water. These compounds' detection in the environment is related to effluents discharge and weak parabens elimination in WWTPs. The correct parabens' removal is possible using advanced oxidation processes, so the parabens abatement by different AOP technologies (such as ozone-based technologies, photolysis and photocatalysis, oxidizing agents, Fenton' process, sonochemical technologies, and electrochemical technologies) is reviewed in this work. Literature does not have so many references for the use of some AOP, regarding parabens abatement, which can be related to the technology's characteristics. Furthermore, some of these technologies may be infeasible for industrial application due to some related disadvantages, for example, high operational costs or low efficiencies.

The impact of treated solutions was revealed with an overview of different ecotoxicity tests. This type of experiment is important to choose the technology to use in the treatment of wastewater, since the AOPs interfere with and change the solutions' toxicity, which can make it more dangerous to the environment than the initial solution. Among the technology performance and removal efficiency, the operational costs are another characteristic to consider in the choice of treatment technologies, so with this in mind, several costs presented in the literature were reviewed.

Finally, regarding the parabens removal from wastewater with different technologies, the results are encouraging for efficient use, but there are still opportunities improvement that must be investigated. However, it is important to remember that these results are only for a specific pollutants mixture solution (mainly parabens in most cases), so their behavior for treatment of other CEC compounds or other toxic pollutants must also be analyzed. On the other hand, since these compounds enter wastewater with a diverse composition including several compounds, it will interesting to study further steps before the real application can be achieved, such as the use and analysis of these technologies' efficiency and characteristics for the treatment of real wastewater stream.

Author Contributions: Conceptualization, J.G., R.C.M.; methodology, J.L.; investigation, J.L.; R.C.M. and J.G.; data curation, J.L.; writing—original draft preparation, J.L.; writing—review and editing, J.G., R.C.M.; supervision, J.G., R.C.M. All authors have read and agreed to the published version of the manuscript.

Funding: This research was funded by the European Union through the European Fund for Regional Development (FEDER) within the framework COMPETE2020 by the financial support of the project POCI-01-0247-FEDER-033193 (SERENA-Development of a sludge free Fenton-integrated treatment methodology for olive mill wastewaters: a water recovery). This work was also financially supported by Fundação para a Ciência e Tecnologia (FCT-MEC), Portugal, under contracts UIDB/00102/2020. The authors gratefully acknowledge Foundation for Science and Technology-FCT (Portugal) for its financial support (CEECIND/01207/2018).

Institutional Review Board Statement: Not applicable.

Informed Consent Statement: Not applicable.

Data Availability Statement: Not applicable.

Conflicts of Interest: The authors declare no conflict of interest.

\section{References}

1. WWF-World Wildlife. Water Scarcity. 2020. Available online: https:/ /www.worldwildlife.org/threats/water-scarcity (accessed on 1 December 2020).

2. Rizzo, L.; Gernjak, W.; Krzeminski, P.; Malato, S.; McArdell, C.S.; Perez, J.A.S.; Schaar, H.; Fatta-Kassinos, D. Best available technologies and treatment trains to address current challenges in urban wastewater reuse for irrigation of crops in EU countries. Sci. Total Environ. 2020, 710, 136312. [CrossRef]

3. Vela, N.; Calín, M.; Yáñez-Gascón, M.J.; Garrido, I.; Pérez-Lucas, G.; Fenoll, J.; Navarro, S. Solar reclamation of wastewater effluent polluted with bisphenols, phthalates and parabens by photocatalytic treatment with $\mathrm{TiO}_{2} / \mathrm{Na}_{2} \mathrm{~S}_{2} \mathrm{O}_{8}$ at pilot plant scale. Chemosphere 2018, 212, 95-104. [CrossRef] [PubMed] 
4. Frontistis, Z.; Antonopoulou, M.; Petala, A.; Venieri, D.; Konstantinou, I.; Kondarides, D.I.; Mantzavinos, D. Photodegradation of ethylparaben using simulated solar radiation and $\mathrm{Ag}_{3} \mathrm{PO}_{4}$ photocatalyst. J. Hazard. Mater. 2017, 323, 478-488. [CrossRef]

5. Esplugas, S.; Bila, D.M.; Krause, L.G.T.; Dezotti, M. Ozonation and advanced oxidation technologies to remove endocrine disrupting chemicals (EDCs) and pharmaceuticals and personal care products (PPCPs) in water effluents. J. Hazard. Mater. 2007, 149, 631-642. [CrossRef]

6. Fernandes, R.A.; Sampaio, M.J.; Dražić, G.; Faria, J.L.; Silva, C.G. Efficient removal of parabens from real water matrices by a metal-free carbon nitride photocatalyst. Sci. Total Environ. 2020, 716, 135346. [CrossRef] [PubMed]

7. Lin, Y.; Ferronato, C.; Deng, N.; Wu, F.; Chovelon, J.-M. Photocatalytic degradation of methylparaben by TiO2: Multivariable experimental design and mechanism. Appl. Catal. B Environ. 2009, 88, 32-41. [CrossRef]

8. Sousa, J.C.; Ribeiro, A.R.; Barbosa, M.O.; Ribeiro, C.; Tiritan, M.E.; Pereira, M.F.R.; Silva, A.M. Monitoring of the 17 EU Watch List contaminants of emerging concern in the Ave and the Sousa Rivers. Sci. Total Environ. 2019, 649, 1083-1095. [CrossRef]

9. Lincho, J.; Martins, R.C.; Gomes, J. Paraben compounds-Part I: An overview of their characteristics, detection, and impacts. Appl. Sci. 2021, 11, 2307. [CrossRef]

10. Jonkers, N.; Sousa, A.; Galante-Oliveira, S.; Barroso, C.M.; Kohler, H.-P.E.; Giger, W. Occurrence and sources of selected phenolic endocrine disruptors in Ria de Aveiro, Portugal. Environ. Sci. Pollut. Res. 2009, 17, 834-843. [CrossRef]

11. Carmona, E.; Andreu, V.; Picó, Y. Occurrence of acidic pharmaceuticals and personal care products in Turia River Basin: From waste to drinking water. Sci. Total Environ. 2014, 484, 53-63. [CrossRef] [PubMed]

12. Li, W.; Shi, Y.; Gao, L.; Liu, J.; Cai, Y. Occurrence and human exposure of parabens and their chlorinated derivatives in swimming pools. Environ. Sci. Pollut. Res. 2015, 22, 17987-17997. [CrossRef]

13. Gibs, J.; Stackelberg, P.E.; Furlong, E.T.; Meyer, M.; Zaugg, S.D.; Lippincott, R.L. Persistence of pharmaceuticals and other organic compounds in chlorinated drinking water as a function of time. Sci. Total Environ. 2007, 373, 240-249. [CrossRef] [PubMed]

14. Gorga, M.; Petrovic, M.; Barceló, D. Multi-residue analytical method for the determination of endocrine disruptors and related compounds in river and waste water using dual column liquid chromatography switching system coupled to mass spectrometry. J. Chromatogr. A 2013, 1295, 57-66. [CrossRef] [PubMed]

15. Li, W.; Gao, L.; Shi, Y.; Wang, Y.; Liu, J.; Cai, Y. Spatial distribution, temporal variation and risks of parabens and their chlorinated derivatives in urban surface water in Beijing, China. Sci. Total Environ. 2016, 539, 262-270. [CrossRef]

16. Ana, F.; Fonseca, A.P. Parabens paradoxes in cosmetic formulations: A review. Int. J. Med. Res. Pharm. Sci. 2016, 3, 1-11.

17. Tavares, R.S.; Martins, F.C.; Oliveira, P.J.; Ramalho-Santos, J.; Peixoto, F.P. Parabens in male infertility-Is there a mitochondrial connection? Reprod. Toxicol. 2009, 27, 1-7. [CrossRef]

18. Błędzka, D.; Gromadzińska, J.; Wąsowicz, W. Parabens. From environmental studies to human health. Environ. Int. 2014, 67, 27-42. [CrossRef]

19. Terasaka, S.; Inoue, A.; Tanji, M.; Kiyama, R. Expression profiling of estrogen-responsive genes in breast cancer cells treated with alkylphenols, chlorinated phenols, parabens, or bis- and benzoylphenols for evaluation of estrogenic activity. Toxicol. Lett. 2006, 163, 130-141. [CrossRef]

20. Chen, F.; Wang, F.; Li, Q.; Cao, C.; Zhang, X.; Ma, H.; Guo, Y. Effect of support (Degussa $\mathrm{P}_{25} \mathrm{TiO}_{2}$, anatase $\mathrm{TiO}_{2}, \gamma-\mathrm{Al}_{2} \mathrm{O}_{3}$, and $\mathrm{AlOOH})$ of Pt-based catalysts on the formaldehyde oxidation at room temperature. Catal. Commun. 2017, 99, 39-42. [CrossRef]

21. Darbre, P.D.; Aljarrah, A.; Miller, W.R.; Coldham, N.G.; Sauer, M.J.; Pope, G.S. Concentrations of parabens in human breast tumours. J. Appl. Toxicol. 2004, 24, 5-13. [CrossRef]

22. Peng, X.; Yu, Y.; Tang, C.; Tan, J.; Huang, Q.; Wang, Z. Occurrence of steroid estrogens, endocrine-disrupting phenols, and acid pharmaceutical residues in urban riverine water of the Pearl River Delta, South China. Sci. Total Environ. 2008, 397, 158-166. [CrossRef] [PubMed]

23. Cuerda-Correa, E.M.; Domínguez, J.R.; Muñoz-Peña, M.J.; González, T. Degradation of parabens in different aqueous matrices by several O3-derived advanced oxidation processes. Ind. Eng. Chem. Res. 2016, 55, 5161-5172. [CrossRef]

24. Tay, K.S.; Rahman, N.A.; Bin Abas, M.R. Ozonation of parabens in aqueous solution: Kinetics and mechanism of degradation. Chemosphere 2010, 81, 1446-1453. [CrossRef]

25. Tay, K.S.; Rahman, N.A.; Bin Abas, M.R. Kinetic studies of the degradation of parabens in aqueous solution by ozone oxidation. Environ. Chem. Lett. 2010, 8, 331-337. [CrossRef]

26. Gomes, J.F.; Bednarczyk, K.; Gmurek, M.; Stelmachowski, M.; Zaleska-Medynska, A.; Bastos, F.C.; Quinta-Ferreira, M.E.; Costa, R.; Quinta-Ferreira, R.M.; Martins, R.C. Noble metal-TiO ${ }_{2}$ supported catalysts for the catalytic ozonation of parabens mixtures. Process. Saf. Environ. Prot. 2017, 111, 148-159. [CrossRef]

27. Gomes, J.F.; Leal, I.; Bednarczyk, K.; Gmurek, M.; Stelmachowski, M.; Diak, M.; Quinta-Ferreira, M.E.; Costa, R.; Quinta-Ferreira, R.M.; Martins, R.C. Photocatalytic ozonation using doped $\mathrm{TiO}_{2}$ catalysts for the removal of parabens in water. Sci. Total Environ. 2017, 609, 329-340. [CrossRef]

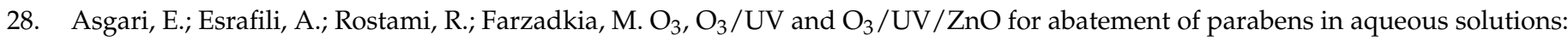
Effect of operational parameters and mineralization/biodegradability improvement. Process. Saf. Environ. Prot. 2019, 125, 238-250. [CrossRef]

29. Martins, R.C.; Gmurek, M.; Rossi, A.F.; Corceiro, V.; Costa, R.; Quinta-Ferreira, M.E.; Ledakowicz, S.; Quinta-Ferreira, R.M. Application of Fenton oxidation to reduce the toxicity of mixed parabens. Water Sci. Technol. 2016, 74, 1867-1875. [CrossRef] 
30. Gmurek, M.; Gomes, J.F.; Martins, R.C.; Quinta-Ferreira, R.M. Comparison of radical-driven technologies applied for paraben mixture degradation: Mechanism, biodegradability, toxicity and cost assessment. Environ. Sci. Pollut. Res. 2019, 26, 37174-37192 [CrossRef] [PubMed]

31. Orak, C.; Atalay, S.; Ersöz, G. Photocatalytic and photo-Fenton-like degradation of methylparaben on monolith-supported perovskite-type catalysts. Sep. Sci. Technol. 2017, 52, 1310-1320. [CrossRef]

32. Lin, Y.; Ferronato, C.; Deng, N.; Chovelon, J.-M. Study of benzylparaben photocatalytic degradation by TiO 2 . Appl. Catal. B Environ. 2011, 104, 353-360. [CrossRef]

33. Xiao, X.; Lu, M.; Nan, J.; Zuo, X.; Zhang, W.; Liu, S.; Wang, S. Rapid microwave synthesis of I-doped $\mathrm{Bi}_{4} \mathrm{O}_{5} \mathrm{Br}_{2}$ with significantly enhanced visible-light photocatalysis for degradation of multiple parabens. Appl. Catal. B Environ. 2017, 218, 398-408. [CrossRef]

34. Kotzamanidi, S.; Frontistis, Z.; Binas, V.; Kiriakidis, G.; Mantzavinos, D. Solar photocatalytic degradation of propyl paraben in Al-doped TiO2 suspensions. Catal. Today 2018, 313, 148-154. [CrossRef]

35. Gmurek, M.; Rossi, A.F.; Martins, R.C.; Quinta-Ferreira, R.M.; Ledakowicz, S. Photodegradation of single and mixture of parabens-Kinetic, by-products identification and cost-efficiency analysis. Chem. Eng. J. 2015, 276, 303-314. [CrossRef]

36. Martins, A.S.; Nuñez, L.; Lanza, M.R.D.V. Enhanced photoelectrocatalytic performance of $\mathrm{TiO}_{2}$ nanotube array modified with $\mathrm{WO}_{3}$ applied to the degradation of the endocrine disruptor propyl paraben. J. Electroanal. Chem. 2017, 802, 33-39. [CrossRef]

37. Daghrir, R.; Dimboukou-Mpira, A.; Seyhi, B.; Drogui, P. Photosonochemical degradation of butyl-paraben: Optimization, toxicity and kinetic studies. Sci. Total Environ. 2014, 490, 223-234. [CrossRef]

38. Nikolaou, S.; Vakros, J.; Diamadopoulos, E.; Mantzavinos, D. Sonochemical degradation of propylparaben in the presence of agro-industrial biochar. J. Environ. Chem. Eng. 2020, 8, 104010. [CrossRef]

39. Papadopoulos, C.; Frontistis, Z.; Antonopoulou, M.; Venieri, D.; Konstantinou, I.K.; Mantzavinos, D. Sonochemical degradation of ethyl paraben in environmental samples: Statistically important parameters determining kinetics, by-products and pathways. Ultrason. Sonochem. 2016, 31, 62-70. [CrossRef] [PubMed]

40. Kanakaraju, D.; Glass, B.D.; Oelgemöller, M. Advanced oxidation process-mediated removal of pharmaceuticals from water: A review. J. Environ. Manag. 2018, 219, 189-207. [CrossRef] [PubMed]

41. Paździor, K.; Bilińska, L.; Ledakowicz, S. A review of the existing and emerging technologies in the combination of AOPs and biological processes in industrial textile wastewater treatment. Chem. Eng. J. 2019, 376, 120597. [CrossRef]

42. Boczkaj, G.; Fernandes, A. Wastewater treatment by means of advanced oxidation processes at basic $\mathrm{pH}$ conditions: A review. Chem. Eng. J. 2017, 320, 608-633. [CrossRef]

43. Babu, D.S.; Srivastava, V.; Nidheesh, P.; Kumar, M.S. Detoxification of water and wastewater by advanced oxidation processes. Sci. Total Environ. 2019, 696, 133961. [CrossRef]

44. Ge, J.; Zhang, Y.; Heo, Y.-J.; Park, S.-J. Advanced design and synthesis of composite photocatalysts for the remediation of wastewater: A review. Catalysts 2019, 9, 122. [CrossRef]

45. Litter, M.I.; Quici, N. Photochemical advanced oxidation processes for water and wastewater treatment. Recent Pat. Eng. 2010, 4 , 217-241. [CrossRef]

46. M'Arimi, M.; Mecha, C.; Kiprop, A.; Ramkat, R. Recent trends in applications of advanced oxidation processes (AOPs) in bioenergy production: Review. Renew. Sustain. Energy Rev. 2020, 121, 109669. [CrossRef]

47. Gaya, U.I.; Abdullah, A.H. Heterogeneous photocatalytic degradation of organic contaminants over titanium dioxide: A review of fundamentals, progress and problems. J. Photochem. Photobiol. C Photochem. Rev. 2008, 9, 1-12. [CrossRef]

48. Tufail, A.; Price, W.E.; Mohseni, M.; Pramanik, B.K.; Hai, F.I. A critical review of advanced oxidation processes for emerging trace organic contaminant degradation: Mechanisms, factors, degradation products, and effluent toxicity. J. Water Process. Eng. 2021, 40, 101778. [CrossRef]

49. Miklos, D.B.; Remy, C.; Jekel, M.; Linden, K.G.; Drewes, J.E.; Hübner, U. Evaluation of advanced oxidation processes for water and wastewater treatment-A critical review. Water Res. 2018, 139, 118-131. [CrossRef]

50. Herrmann, J.-M. Heterogeneous photocatalysis: State of the art and present applications. Top. Catal. 2005, 34, 49-65. [CrossRef]

51. Rueda-Marquez, J.J.; Levchuk, I.; Ibañez, P.F.; Sillanpää, M. A critical review on application of photocatalysis for toxicity reduction of real wastewaters. J. Clean. Prod. 2020, 258, 120694. [CrossRef]

52. Vela, N.; Calín, M.; Yáñez-Gascón, M.J.; Garrido, I.; Pérez-Lucas, G.; Fenoll, J.; Navarro, S. Photocatalytic oxidation of six pesticides listed as endocrine disruptor chemicals from wastewater using two different $\mathrm{TiO}_{2}$ samples at pilot plant scale under sunlight irradiation. J. Photochem. Photobiol. A Chem. 2018, 353, 271-278. [CrossRef]

53. Byrne, C.; Subramanian, G.; Pillai, S.C. Recent advances in photocatalysis for environmental applications. J. Environ. Chem. Eng. 2018, 6, 3531-3555. [CrossRef]

54. Al-Mamun, M.R.; Kader, S.; Islam, M.S.; Khan, M.Z.H. Photocatalytic activity improvement and application of UV-TiO 2 photocatalysis in textile wastewater treatment: A review. J. Environ. Chem. Eng. 2019, 7, 103248. [CrossRef]

55. Zhang, J.; Zhou, P.; Liu, J.; Yu, J. New understanding of the difference of photocatalytic activity among anatase, rutile and brookite $\mathrm{TiO}_{2}$. Phys. Chem. Chem. Phys. 2014, 16, 20382-20386. [CrossRef]

56. Shan, A.Y.; Ghazi, T.I.M.; Rashid, S.A. Immobilisation of titanium dioxide onto supporting materials in heterogeneous photocatalysis: A review. Appl. Catal. A Gen. 2010, 389, 1-8. [CrossRef]

57. Canle, M.; Pérez, M.I.F.; Santaballa, J.A. Photocatalyzed degradation/abatement of endocrine disruptors. Curr. Opin. Green Sustain. Chem. 2017, 6, 101-138. [CrossRef] 
58. Gomes, J.; Lincho, J.; Domingues, E.; Gmurek, M.; Mazierski, P.; Zaleska-Medynska, A.; Klimczuk, T.; Quinta-Ferreira, R.M.; Martins, R.C. $\mathrm{TiO}_{2}$ nanotube arrays-based reactor for photocatalytic oxidation of parabens mixtures in ultrapure water: Effects of photocatalyst properties, operational parameters and light source. Sci. Total Environ. 2019, 689, 79-89. [CrossRef] [PubMed]

59. Kaur, T.; Sraw, A.; Wanchoo, R.; Toor, A.P. Solar assisted degradation of carbendazim in water using clay beads immobilized with $\mathrm{TiO}_{2}$ \& Fe doped $\mathrm{TiO}_{2}$. Sol. Energy 2018, 162, 45-56. [CrossRef]

60. Kaur, T.; Sraw, A.; Toor, A.P.; Wanchoo, R. Utilization of solar energy for the degradation of carbendazim and propiconazole by Fe doped $\mathrm{TiO}_{2}$. Sol. Energy 2016, 125, 65-76. [CrossRef]

61. Abramović, B.F.; Šojić, D.V.; Anderluh, V.B.; Abazović, N.D.; Čomor, M.I. Nitrogen-doped $\mathrm{TiO}_{2}$ suspensions in photocatalytic degradation of mecoprop and (4-chloro-2-methylphenoxy)acetic acid herbicides using various light sources. Desalination 2009, 244, 293-302. [CrossRef]

62. Gagol, M.; Przyjazny, A.; Boczkaj, G. Wastewater treatment by means of advanced oxidation processes based on cavitation-A review. Chem. Eng. J. 2018, 338, 599-627. [CrossRef]

63. Quiñones, D.H.; Álvarez, P.M.; Rey, A.; Beltrán, F.J. Removal of emerging contaminants from municipal WWTP secondary effluents by solar photocatalytic ozonation. A pilot-scale study. Sep. Purif. Technol. 2015, 149, 132-139. [CrossRef]

64. Quiñones, D.; Rey, A.; Álvarez, P.; Beltrán, F.; Puma, G.L. Boron doped $\mathrm{TiO}_{2}$ catalysts for photocatalytic ozonation of aqueous mixtures of common pesticides: Diuron, o-phenylphenol, MCPA and terbuthylazine. Appl. Catal. B Environ. 2015, 178, 74-81. [CrossRef]

65. Bertagna Silva, D.; Cruz-Alcalde, A.; Sans, C.; Giménez, J.; Esplugas, S. Performance and kinetic modelling of photolytic and photocatalytic ozonation for enhanced micropollutants removal in municipal wastewaters. Appl. Catal. B Environ. 2019, 249, 211-217. [CrossRef]

66. Mehrjouei, M.; Müller, S.; Möller, D. A review on photocatalytic ozonation used for the treatment of water and wastewater. Chem. Eng. J. 2015, 263, 209-219. [CrossRef]

67. Orge, C.; Faria, J.; Pereira, M. Photocatalytic ozonation of aniline with $\mathrm{TiO}_{2}$-carbon composite materials. J. Environ. Manag. 2017, 195, 208-215. [CrossRef] [PubMed]

68. Kim, E.-J.; Oh, D.; Lee, C.-S.; Gong, J.; Kim, J.; Chang, Y.-S. Manganese oxide nanorods as a robust Fenton-like catalyst at neutral pH: Crystal phase-dependent behavior. Catal. Today 2017, 282, 71-76. [CrossRef]

69. Lee, H.-J.; Lee, H.; Lee, C. Degradation of diclofenac and carbamazepine by copper(II)-catalyzed dark and photo-assisted Fenton-like systems. Chem. Eng. J. 2014, 245, 258-264. [CrossRef]

70. Prieto-Rodríguez, L.; Spasiano, D.; Oller, I.; Fernández-Calderero, I.; Agüera, A.; Malato, S. Solar photo-Fenton optimization for the treatment of MWTP effluents containing emerging contaminants. Catal. Today 2013, 209, 188-194. [CrossRef]

71. Ribeiro, A.R.; Nunes, O.C.; Pereira, M.F.R.; Silva, A.M.T. An overview on the advanced oxidation processes applied for the treatment of water pollutants defined in the recently launched Directive 2013/39/EU. Environ. Int. 2015, 75, 33-51. [CrossRef]

72. Nidheesh, P.V.; Couras, C.; Karim, A.V.; Nadais, H. A review of integrated advanced oxidation processes and biological processes for organic pollutant removal. Chem. Eng. Commun. 2021, 1-43. [CrossRef]

73. Dhaka, S.; Kumar, R.; Lee, S.-H.; Kurade, M.B.; Jeon, B.-H. Degradation of ethyl paraben in aqueous medium using advanced oxidation processes: Efficiency evaluation of UV-C supported oxidants. J. Clean. Prod. 2018, 180, 505-513. [CrossRef]

74. Dhaka, S.; Kumar, R.; Khan, M.A.; Paeng, K.-J.; Kurade, M.B.; Kim, S.-J.; Jeon, B.-H. Aqueous phase degradation of methyl paraben using UV-activated persulfate method. Chem. Eng. J. 2017, 321, 11-19. [CrossRef]

75. Velegraki, T.; Hapeshi, E.; Fatta-Kassinos, D.; Poulios, I. Solar-induced heterogeneous photocatalytic degradation of methylparaben. Appl. Catal. B Environ. 2015, 178, 2-11. [CrossRef]

76. Błędzka, D.; Gryglik, D.; Olak, M.; Gębicki, J.L.; Miller, J.S. Degradation of n-butylparaben and 4-tert-octylphenol in $\mathrm{H}_{2} \mathrm{O}_{2} / \mathrm{UV}$ system. Radiat. Phys. Chem. 2010, 79, 409-416. [CrossRef]

77. Popiel, S.; Nalepa, T.; Dzierżak, D.; Stankiewicz, R.; Witkiewicz, Z. Rate of dibutylsulfide decomposition by ozonation and the $\mathrm{O}_{3} / \mathrm{H}_{2} \mathrm{O}_{2}$ advanced oxidation process. J. Hazard. Mater. 2009, 164, 1364-1371. [CrossRef] [PubMed]

78. Saritha, P.; Aparna, C.; Himabindu, V.; Anjaneyulu, Y. Comparison of various advanced oxidation processes for the degradation of 4-chloro-2 nitrophenol. J. Hazard. Mater. 2007, 149, 609-614. [CrossRef] [PubMed]

79. Zangeneh, H.; Zinatizadeh, A.; Feizy, M. A comparative study on the performance of different advanced oxidation processes $\left(\mathrm{UV} / \mathrm{O}_{3} / \mathrm{H}_{2} \mathrm{O}_{2}\right)$ treating linear alkyl benzene (LAB) production plant's wastewater. J. Ind. Eng. Chem. 2014, 20, 1453-1461. [CrossRef]

80. Siciliano, A.; Stillitano, M.A.; Limonti, C. Energetic valorization of wet olive mill wastes through a suitable integrated treatment: $\mathrm{H}_{2} \mathrm{O}_{2}$ with lime and anaerobic digestion. Sustainability 2016, 8, 1150. [CrossRef]

81. Afify, A.S.; Mahmoud, M.A.; Emara, H.A.; Abdelkreem, K.I. Phenolic compounds and COD removal from olive mill wastewater by chemical and biological procedures. Aust. J. Basic. Appl. Sci. 2009, 3, 1087-1095.

82. Martínez-Huitle, C.A.; Brillas, E. Decontamination of wastewaters containing synthetic organic dyes by electrochemical methods: A general review. Appl. Catal. B Environ. 2009, 87, 105-145. [CrossRef]

83. Bosio, M.; Souza-Chaves, B.; Gomes, J.; Gmurek, M.; Martins, R.; Saggioro, E.; Dezotti, M.; Bassin, J.; Quinta-Ferreira, M. Electrochemical oxidation of paraben compounds and the effects of byproducts on neuronal activity. Energy Rep. 2020, 6, 903-908. [CrossRef] 
84. Feng, L.; Van Hullebusch, E.D.; Rodrigo, M.A.; Esposito, G.; Oturan, M.A. Removal of residual anti-inflammatory and analgesic pharmaceuticals from aqueous systems by electrochemical advanced oxidation processes. A review. Chem. Eng. J. 2013, 228, 944-964. [CrossRef]

85. Frontistis, Z.; Antonopoulou, M.; Yazirdagi, M.; Kilinc, Z.; Konstantinou, I.; Katsaounis, A.; Mantzavinos, D. Boron-doped diamond electrooxidation of ethyl paraben: The effect of electrolyte on by-products distribution and mechanisms. J. Environ. Manag. 2017, 195, 148-156. [CrossRef] [PubMed]

86. Steter, J.R.; Brillas, E.; Sirés, I. On the selection of the anode material for the electrochemical removal of methylparaben from different aqueous media. Electrochim. Acta 2016, 222, 1464-1474. [CrossRef]

87. Domínguez, J.R.; Muñoz-Peña, M.J.; González, T.; Palo, P.; Cuerda-Correa, E.M. Parabens abatement from surface waters by electrochemical advanced oxidation with boron doped diamond anodes. Environ. Sci. Pollut. Res. 2016, 23, 20315-20330. [CrossRef]

88. Steter, J.R.; Brillas, E.; Sirés, I. Solar photoelectro-Fenton treatment of a mixture of parabens spiked into secondary treated wastewater effluent at low input current. Appl. Catal. B Environ. 2018, 224, 410-418. [CrossRef]

89. Seibert, D.; Zorzo, C.F.; Borba, F.H.; de Souza, R.M.; Quesada, H.B.; Bergamasco, R.; Baptista, A.T.; Inticher, J.J. Occurrence, statutory guideline values and removal of contaminants of emerging concern by Electrochemical Advanced Oxidation Processes: A review. Sci. Total Environ. 2020, 748, 141527. [CrossRef]

90. Li, J.; Li, Y.; Xiong, Z.; Yao, G.; Lai, B. The electrochemical advanced oxidation processes coupling of oxidants for organic pollutants degradation: A mini-review. Chin. Chem. Lett. 2019, 30, 2139-2146. [CrossRef]

91. Gomes, J.F.; Leal, I.; Bednarczyk, K.; Gmurek, M.; Stelmachowski, M.; Zaleska-Medynska, A.; Quinta-Ferreira, M.E.; Costa, R.; Quinta-Ferreira, R.M.; Martins, R.C. Detoxification of parabens using UV-A enhanced by noble metals- $\mathrm{TiO}_{2}$ supported catalysts. J. Environ. Chem. Eng. 2017, 5, 3065-3074. [CrossRef]

92. Zúñiga-Benítez, H.; Peñuela, G.A. Solar lab and pilot scale photo-oxidation of ethylparaben using $\mathrm{H}_{2} \mathrm{O}_{2}$ and $\mathrm{TiO}_{2}$ in aqueous solutions. J. Photochem. Photobiol. A Chem. 2017, 337, 62-70. [CrossRef]

93. Gomes, F.E.; Bergo, P.L.; Trap, M.A.; Spadoto, M.; Galinaro, C.A.; Rodrigues-Filho, E.; Leitão, A.; Tremiliosi-Filho, G. Photolysis of parabens using medium-pressure mercury lamps: Toxicity effects in MCF7, Balb/c 3T3 cells and Ceriodaphnia dubia. Chemosphere 2018, 208, 325-334. [CrossRef] [PubMed]

94. Álvarez, M.A.; Ruidíaz-Martínez, M.; Cruz-Quesada, G.; López-Ramón, M.V.; Rivera-Utrilla, J.; Sánchez-Polo, M.; Mota, A.J. Removal of parabens from water by UV-driven advanced oxidation processes. Chem. Eng. J. 2020, 379, 122334. [CrossRef]

95. Chuang, L.C.; Luo, C.H. Photocatalytic degradation of parabens in aquatic environment: Kinetics and degradation pathway. Kinet. Catal. 2015, 56, 412-418. [CrossRef]

96. Frontistis, Z.; Antonopoulou, M.; Venieri, D.; Dailianis, S.; Konstantinou, I.; Mantzavinos, D. Solar photocatalytic decomposition of ethyl paraben in zinc oxide suspensions. Catal. Today 2017, 280, 139-148. [CrossRef]

97. Petala, A.; Frontistis, Z.; Antonopoulou, M.; Konstantinou, I.K.; Kondarides, D.I.; Mantzavinos, D. Kinetics of ethyl paraben degradation by simulated solar radiation in the presence of $\mathrm{N}$-doped $\mathrm{TiO}_{2}$ catalysts. Water Res. 2015, 81, 157-166. [CrossRef] [PubMed]

98. Petala, A.; Bontemps, R.; Spartatouille, A.; Frontistis, Z.; Antonopoulou, M.; Konstantinou, I.; Kondarides, D.I.; Mantzavinos, D. Solar light-induced degradation of ethyl paraben with $\mathrm{CuOx} / \mathrm{BiVO}_{4}$ : Statistical evaluation of operating factors and transformation by-products. Catal. Today 2017, 280, 122-131. [CrossRef]

99. Kumar, A.; Sharma, G.; Naushad, M.; Kumar, A.; Kalia, S.; Guo, C.; Mola, G.T. Facile hetero-assembly of superparamagnetic $\mathrm{Fe}_{3} \mathrm{O}_{4} / \mathrm{BiVO}_{4}$ stacked on biochar for solar photo-degradation of methyl paraben and pesticide removal from soil. J. Photochem. Photobiol. Chem. 2017, 337, 118-131. [CrossRef]

100. Sousa, S.C.; Cardoso, J.; Monteiro, O. Improved performance of titanate nanostructures for manganese adsorption and posterior pollutants photocatalytic degradation. J. Photochem. Photobiol. A Chem. 2019, 378, 9-16. [CrossRef]

101. Klementova, S.; Kahoun, D.; Doubkova, L.; Frejlachova, K.; Dusakova, M.; Zlamal, M. Catalytic photodegradation of pharmaceuticals-Homogeneous and heterogeneous photocatalysis. Photochem. Photobiol. Sci. 2017, 16, 67-71. [CrossRef]

102. Gomes, J.; Lincho, J.; Mazierski, P.; Miodyńska, M.; Zaleska-Medynska, A.; Martins, R.C. Unexpected effect of ozone on the paraben's mixture degradation using $\mathrm{TiO}_{2}$ supported nanotubes. Sci. Total Environ. 2020, 743, 140831. [CrossRef]

103. Fernandes, E.; Contreras, S.; Medina, F.; Martins, R.C.; Gomes, J. N-doped titanium dioxide for mixture of parabens degradation based on ozone action and toxicity evaluation: Percursor of nitrogen and titanium effect. Process. Saf. Environ. Prot. 2020, 138, 80-89. [CrossRef]

104. Fernandes, E.; Martins, R.C.; Gomes, J. Photocatalytic ozonation of parabens mixture using $10 \% \mathrm{~N}^{-\mathrm{TiO}_{2}}$ and the effect of water matrix. Sci. Total Environ. 2020, 718, 137321. [CrossRef] [PubMed]

105. Zúñiga-Benítez, H.; Aristizábal-Ciro, C.; Peñuela, G.A. Photodegradation of the endocrine-disrupting chemicals benzophenone-3 and methylparaben using Fenton reagent: Optimization of factors and mineralization/biodegradability studies. J. Taiwan Inst. Chem. Eng. 2016, 59, 380-388. [CrossRef]

106. Domínguez, J.R.; Muñoz, M.J.; Palo, P.; González, T.; Peres, J.A.; Cuerda-Correa, E.M. Fenton advanced oxidation of emerging pollutants: Parabens. Int. J. Energy Environ. Eng. 2014, 5, 1-10. [CrossRef]

107. Ioannidi, A.; Frontistis, Z.; Mantzavinos, D. Destruction of propyl paraben by persulfate activated with UV-A light emitting diodes. J. Environ. Chem. Eng. 2018, 6, 2992-2997. [CrossRef] 
108. Yang, J.-C.E.; Lin, Y.; Peng, H.-H.; Yuan, B.; Dionysiou, D.D.; Huang, X.-D.; Zhang, D.-D.; Fu, M.-L. Novel magnetic rod-like Mn-Fe oxycarbide toward peroxymonosulfate activation for efficient oxidation of butyl paraben: Radical oxidation versus singlet oxygenation. Appl. Catal. B Environ. 2020, 268, 118549. [CrossRef]

109. Bekris, L.; Frontistis, Z.; Trakakis, G.; Sygellou, L.; Galiotis, C.; Mantzavinos, D. Graphene: A new activator of sodium persulfate for the advanced oxidation of parabens in water. Water Res. 2017, 126, 111-121. [CrossRef]

110. Matthaiou, V.; Oulego, P.; Frontistis, Z.; Collado, S.; Hela, D.; Konstantinou, I.K.; Diaz, M.; Mantzavinos, D. Valorization of steel slag towards a Fenton-like catalyst for the degradation of paraben by activated persulfate. Chem. Eng. J. 2019, 360, 728-739. [CrossRef]

111. Dionisio, D.; Motheo, A.; Sáez, C.; Rodrigo, M. Effect of the electrolyte on the electrolysis and photoelectrolysis of synthetic methyl paraben polluted wastewater. Sep. Purif. Technol. 2019, 208, 201-207. [CrossRef]

112. Steter, J.R.; Rocha, R.S.; Dionísio, D.; Lanza, M.R.; Motheo, A.J. Electrochemical oxidation route of methyl paraben on a boron-doped diamond anode. Electrochim. Acta 2014, 117, 127-133. [CrossRef]

113. Dionisio, D.; Santos, L.H.; Rodrigo, M.A.; Motheo, A.J. Electro-oxidation of methyl paraben on DSA®-Cl2: UV irradiation, mechanistic aspects and energy consumption. Electrochim. Acta 2020, 338, 135901. [CrossRef]

114. Pueyo, N.; Ormad, M.P.; Miguel, N.; Kokkinos, P.; Ioannidi, A.; Mantzavinos, D.; Frontistis, Z. Electrochemical oxidation of butyl paraben on boron doped diamond in environmental matrices and comparison with sulfate radical-AOP. J. Environ. Manag. 2020, 269, 110783. [CrossRef] [PubMed]

115. Gomes, F.E.; de Souza, N.E.; Galinaro, C.A.; Arriveti, L.O.; de Assis, J.B.; Tremiliosi-Filho, G. Electrochemical degradation of butyl paraben on platinum and glassy carbon electrodes. J. Electroanal. Chem. 2016, 769, 124-130. [CrossRef]

116. Rosales, E.; Buftia, G.; Pazos, M.; Lazăr, G.; Sanromán, M. Ángeles Highly active based iron-carbonaceous cathodes for heterogeneous electro-Fenton process: Application to degradation of parabens. Process. Saf. Environ. Prot. 2018, 117, 363-371. [CrossRef]

117. Nian, P.; Peng, L.; Feng, J.; Han, X.; Cui, B.; Lu, S.; Zhang, J.; Liu, Q.; Zhang, A. Aqueous methylparaben degradation by dielectric barrier discharge induced non-thermal plasma combined with ZnO-rGO nanosheets. Sep. Purif. Technol. 2019, $211,832-842$. [CrossRef]

118. Sasi, S.; Rayaroth, M.P.; Devadasan, D.; Aravind, U.K.; Aravindakumar, C.T. Influence of inorganic ions and selected emerging contaminants on the degradation of Methylparaben: A sonochemical approach. J. Hazard. Mater. 2015, 300, 202-209. [CrossRef]

119. Zanias, A.; Frontistis, Z.; Vakros, J.; Arvaniti, O.S.; Ribeiro, R.S.; Silva, A.M.; Faria, J.L.; Gomes, H.T.; Mantzavinos, D. Degradation of methylparaben by sonocatalysis using a Co-Fe magnetic carbon xerogel. Ultrason. Sonochem. 2020, 64, 105045. [CrossRef]

120. Gomes, J.F.; Frasson, D.; Pereira, J.L.; Gonçalves, F.J.; Castro, L.M.; Quinta-Ferreira, R.M.; Martins, R.C. Ecotoxicity variation through parabens degradation by single and catalytic ozonation using volcanic rock. Chem. Eng. J. 2019, 360, 30-37. [CrossRef]

121. Gomes, J.F.; Lopes, A.; Bednarczyk, K.; Gmurek, M.; Stelmachowski, M.; Zaleska-Medynska, A.; Quinta-Ferreira, M.E.; Costa, R.; Quinta-Ferreira, R.M.; Martins, R.C. Effect of noble metals (Ag, Pd, Pt) loading over the efficiency of TiO2 during photocatalytic ozonation on the toxicity of parabens. ChemEngineering 2018, 2, 4. [CrossRef]

122. Molins-Delgado, D.; Díaz-Cruz, M.S.; Barceló, D. Ecological risk assessment associated to the removal of endocrine-disrupting parabens and benzophenone-4 in wastewater treatment. J. Hazard. Mater. 2016, 310, 143-151. [CrossRef] [PubMed]

123. Gomes, A.I.; Soares, T.F.; Silva, T.F.; Boaventura, R.A.; Vilar, V.J. Ozone-driven processes for mature urban landfill leachate treatment: Organic matter degradation, biodegradability enhancement and treatment costs for different reactors configuration. Sci. Total Environ. 2020, 724, 138083. [CrossRef] [PubMed]

124. Buthiyappan, A.; Raman, A.A.A. Energy intensified integrated advanced oxidation technology for the treatment of recalcitrant industrial wastewater. J. Clean. Prod. 2019, 206, 1025-1040. [CrossRef]

125. Gomes, J.F.; Quinta-Ferreira, M.E.; Costa, R.; Quinta-Ferreira, R.M.; Martins, R.C. Paraben degradation using catalytic ozonation over volcanic rocks. Environ. Sci. Pollut. Res. 2017, 25, 7346-7357. [CrossRef] [PubMed] 